\title{
Segmentation of Animations
}

Citation for published version (APA):

Spanjers, I. A. E. (2012). Segmentation of Animations: Explaining the Effects on the Learning Process and Learning Outcomes . [Doctoral Thesis, Maastricht University]. Maastricht University. https://doi.org/10.26481/dis.20120705is

Document status and date:

Published: 01/01/2012

DOI:

10.26481/dis.20120705is

Document Version:

Publisher's PDF, also known as Version of record

\section{Please check the document version of this publication:}

- A submitted manuscript is the version of the article upon submission and before peer-review. There can be important differences between the submitted version and the official published version of record.

People interested in the research are advised to contact the author for the final version of the publication, or visit the DOI to the publisher's website.

- The final author version and the galley proof are versions of the publication after peer review.

- The final published version features the final layout of the paper including the volume, issue and page numbers.

Link to publication

\footnotetext{
General rights rights.

- You may freely distribute the URL identifying the publication in the public portal. please follow below link for the End User Agreement:

www.umlib.nl/taverne-license

Take down policy

If you believe that this document breaches copyright please contact us at:

repository@maastrichtuniversity.nl

providing details and we will investigate your claim.
}

Copyright and moral rights for the publications made accessible in the public portal are retained by the authors and/or other copyright owners and it is a condition of accessing publications that users recognise and abide by the legal requirements associated with these

- Users may download and print one copy of any publication from the public portal for the purpose of private study or research.

- You may not further distribute the material or use it for any profit-making activity or commercial gain

If the publication is distributed under the terms of Article $25 \mathrm{fa}$ of the Dutch Copyright Act, indicated by the "Taverne" license above, 


\section{Segmentation of Animations: \\ Explaining the Effects \\ on the Learning Process and Learning \\ Outcomes}


The research reported here was carried out at the Open Universiteit Nederland, and at Maastricht University in the School of Health Professions Education (SHE), in the context of the research school ICO (Interuniversity Center for Educational Research), and was funded by NWO (the Netherlands Organisation for Scientific Research) under project number 400-07-017.

\section{Open Universiteit}

www.ou.nl

\section{Maastricht University in Leaming!}
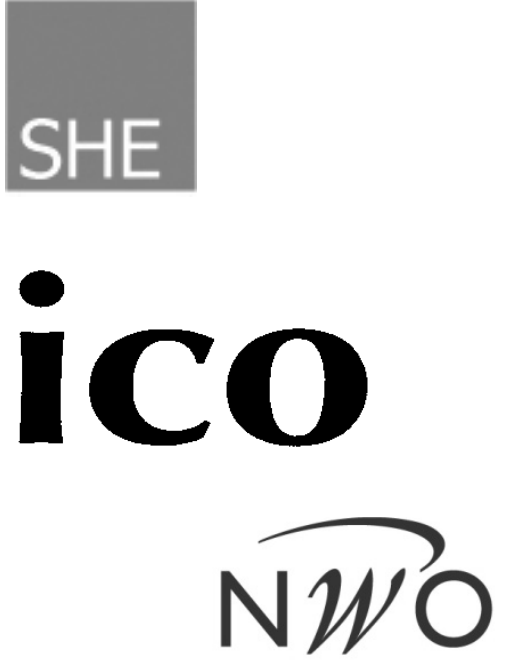

Nederlandse Organisatie voor Wetenschappelijk Onderzoek

ISBN: 978-90-5335-549-7

Copyright (C) Ingrid A. E. Spanjers, Eindhoven, The Netherlands, 2012

Cover design: Ingrid Spanjers \& Ridderprint

Printed by Ridderprint

All rights reserved 


\section{Segmentation of Animations: Explaining the Effects on the Learning Process and Learning Outcomes}

\section{PROEFSCHRIFT}

ter verkrijging van de graad van doctor

aan de Universiteit Maastricht,

op gezag van de Rector Magnificus,

Prof. mr. G.P.M.F. Mols

volgens het besluit van het College van Decanen,

in het openbaar te verdedigen

op donderdag 5 juli 2012 om 14:00 uur

door

Ingrid Antonia Elisabeth Spanjers 


\section{Promotores}

Prof. dr. J. J. G. van Merriënboer

Prof. dr. T. van Gog, Erasmus Universiteit Rotterdam

\section{Beoordelingscommissie}

Prof. dr. D. H. J. M. Dolmans (voorzitter)

Prof. dr. P. Ayres, University of New South Wales, Sydney, Australia

Dr. A. B. H. de Bruin

Dr. P. W. M. van Gerven

Prof. dr. F. G. W. C. Paas, Erasmus Universiteit Rotterdam 


\section{Contents}

Chapter 1

General introduction

Chapter 2

A theoretical analysis of how segmentation of dynamic visualizations optimizes students' learning

Chapter 3

An expertise reversal effect of segmentation in learning from animated worked-out examples

Chapter 4

Segmentation of worked example: Effects on cognitive load and learning

Chapter 5

Explaining the segmentation effect in learning from animations: The role of pausing and temporal cueing

Chapter 6

Effects of meaningful and random segmentation of animations on learning outcomes and mental effort invested

Chapter 7

General discussion

Summary

Samenvatting

Dankwoord

Curriculum vitae

SHE Dissertation Series

ICO Dissertation Series 



\section{Chapter 1}

\section{General introduction}

Animations are computer-created visual representations that show changes taking place over time. Instructional animations are animations created for educational purposes. They show and explain, for instance, biological processes such as chemical and electrical processes occurring in synapses between neurons (Amadieu, Mariné, \& Laimay, 2011) or blood circulation through the heart (De Koning, Tabbers, Rikers, \& Paas, 2007), natural processes such as the determinants of day and night (Hasler, Kersten \& Sweller, 2007) or lightning formation (Mayer \& Chandler, 2001), mechanical systems such as a piano (Boucheix \& Lowe, 2010) or an electric motor (Mayer, Dow, \& Mayer, 2003) or a fourstroke engine (Meyer, Rasch, \& Meyer, 2010), and different types of procedures such as first aid techniques (Arguel \& Jamet, 2009) or probability calculation methods (Wouters, Paas, \& Van Merriënboer, 2010).

In recent years, with the advance of ICT in the classroom, animations have become attractive to use for instruction, despite the fact that they are relatively expensive to produce (e.g., Chandler, 2004; 2009; Hegarty, Kriz, \& Cate, 2003; Ploetzner \& Lowe, 2004; Tversky, Morrison, \& Betrancourt, 2002). For instance, various websites within and outside the Netherlands provide instructional animations (e.g., www.bioplek.org; www.edumedia-sciences.com;www.manssen.nl-2011/06/10/animaties-voor-

aardrijkskunde/; www.medischonderwijs.nl). Besides being attractive for educators, animations are often expected to be more beneficial for learning than static pictures, because animations show changes taking place over time (Ploetzner \& Lowe, 2004). This means students do not have to mentally infer these changes as they would when viewing a series of static pictures (e.g., Betrancourt, 2005; Schnotz, Böckheler, \& Grzondziel, 1999; Schnotz \& Lowe, 2008). This inferring of changes is a process which likely imposes a high load on working memory (Hegarty, 1992).

In contrast to this notion, however, research has shown that instructional animations are not always more effective for learning than series of static pictures (e.g., Hegarty et al., 2003; Mayer, Hegarty, Mayer \& Campbell, 2005; Tversky et al., 2002). Seeing changes in processes or procedures taking place over time can actually be very cognitively demanding when transience is involved (e.g., Lowe, 1999; Schnotz \& Lowe, 2008). Transience means that information presented lasts only briefly, and is then replaced by new information. With additional instructional design manipulations though, negative effects of transience can be counteracted, reducing the ineffective cognitive load imposed by animations, and enhancing their effectiveness for learning. This dissertation focuses on one such manipulation: segmenting of animations, that is, presenting animations in pieces rather than as a continuous stream of information (e.g., Hasler et al., 2007; Mayer \& Chandler, 2001; Moreno, 2007). Possible explanations for the effects of segmentation on learning outcomes and cognitive load are examined. But before introducing the possible 
explanations, the next section will address the cognitive load imposed by transience of animations, and ways to counteract it.

\section{Cognitive load and learning from animations}

When learning from animations, students have to select relevant elements from the stream of information, maintain those in working memory in order to link them with information elements provided at other points in the animation, build relations between the information elements from different points, retrieve relevant prior knowledge, and integrate that prior knowledge with the new information elements (e.g., Mayer \& Moreno, 2003; Moreno \& Mayer, 2007). These processes can place high demands on working memory, which is limited in capacity and has time constraints (e.g., Baddeley, 2003; Barrouillet \& Camos, 2007; Cowan, 2001). Cognitive load theory (e.g., Sweller, 2010; Sweller, Van Merriënboer, \& Paas, 1998; Van Merriënboer \& Sweller, 2005) states that in order to optimize learning from animations it is important to take these limitations of working memory into account, and to ensure that the processes that impose ineffective load on working memory are reduced.

Cognitive load theory distinguishes between three different types of cognitive load. Intrinsic and extraneous cognitive load are imposed by cognitive activities needed to deal with the instructional material. The amount of intrinsic cognitive load imposed by an animation is dependent on the complexity of the content of the instructional material depicted in the animation. The more interrelations exist between the information elements presented in an animation, the more intrinsic load it imposes (Kalyuga, 2011; Sweller, 2010; Sweller et al., 1998; Van Merriënboer \& Sweller, 2005). The amount of extraneous cognitive load imposed by an animation is dependent on the number of cognitive activities needed for dealing with non-optimal aspects of the way the material is presented (Kalyuga, 2011; Sweller, 2010; Sweller et al., 1998). The additional processes which learners have to perform in order to deal with the transience of animations are examples of cognitive activities imposing extraneous cognitive load on the learner (e.g., Ayres \& Paas, 2007a). Germane cognitive load is constituted by the amount of working memory resources actually devoted to cognitive activities that are effective for learning (i.e., devoted to dealing with the intrinsic cognitive load imposed by the animation; Kalyuga, 2011; Sweller, 2010).

Because working memory resources are limited, fewer working memory resources are left for dealing with intrinsic cognitive load, when more working memory resources are needed for dealing with extraneous cognitive load, and learning could be hindered. Consequently, especially when an animation imposes a high intrinsic cognitive load, it is important to reduce the amount of extraneous cognitive load and to make it possible for learners to devote sufficient working memory resources to dealing with the content of the animation (Kalyuga, 2011; Sweller, 2010; Sweller et al, 1998; Van Merriënboer \& Sweller, 2005).

Based on cognitive load theory, a number of design guidelines for reducing extraneous cognitive load due to the transience of animations have been proposed (see for reviews: Mayer \& Moreno, 2003; Wouters, Paas, \& Van Merriënboer, 2008). Examples of 
those design guidelines are visuospatial cueing, that is manipulating visuospatial aspects of the animation to support learners in giving attention to the right information elements at the right moment (Boucheix \& Lowe, 2010; De Koning et al., 2007; Fischer \& Schwan, 2010), adjusting the presentation speed, which may enhance the salience of particular important aspects of the animation (Fischer, Lowe, \& Schwan, 2008; Fischer \& Schwan, 2010; Meyer et al., 2010) and segmentation, which is the topic of this dissertation.

\section{Possible explanations for the beneficial effects of segmentation}

A number of studies found positive effects of segmentation on learning, at least for novice students (e.g., Hasler et al., 2007; Mayer \& Chandler, 2001; Moreno, 2007). The aim of this dissertation is to examine why segmentation has positive effects on learning outcomes or mental effort invested (reflecting the actual cognitive load experienced by a learner) for novices. In this dissertation, two alternative, but not mutually exclusive explanations are provided and investigated. According to the 'time-to-process' (or 'pausing') explanation, the positive effects of segmentation are due to the pauses which are usually inserted between the segments. Those pauses provide the learners with time to process the previous segment without having to attend to new information (e.g., Mayer, 2005; Mayer \& Moreno, 2003), which may reduce the extraneous cognitive load imposed by the transience of the material and enhance learning (e.g., Ayres \& Paas, 2007a, b). According to the 'temporal cueing' explanation, the positive effects of segmentation are due to the division of the animation into meaningful pieces. During perception people usually mentally divide processes or procedures in pieces (e.g., Zacks, Speer, Swallow, Braver, \& Reynolds, 2007). Segmentation supports learners in this mentally segmenting of processes or procedures (Schnotz \& Lowe, 2008) and enhances the salience of the underlying structure (Boltz, 1992), which may also decrease cognitive load and enhance learning (Wouters et al., 2008; see also Schwan, Garsoffky, \& Hesse, 2000).

Segmentation can be expected to be effective mainly for novices, because students with more prior knowledge have already acquired more domain-specific schemas. Schemas incorporate a number of information elements, but can be handled in working memory as one element. Consequently, the same animation imposes less intrinsic cognitive load on working memory for students with more prior knowledge than for students with less prior knowledge (Kalyuga, 2011; Sweller et al, 1998; Van Merriënboer \& Sweller, 2005). Because of the support provided by these schemas, students with more prior knowledge might no longer need additional time to process and/or temporal cues provided by segmentation. This phenomenon that design guidelines with a positive effect on learning outcomes or cognitive load for students with no or little prior knowledge has no or a negative effect on learning outcomes or cognitive load for learners with more prior knowledge, and vice versa, is called the 'expertise reversal effect' (Kalyuga, 2007; 2008; Kalyuga, Ayres, Chandler, \& Sweller, 2003). In this dissertation, next to investigating the above-mentioned explanations for the segmentation effect, it will be established whether the expertise reversal effect applies to segmentation as well. 


\section{Overview of the dissertation}

This dissertation contains a literature study and four empirical studies, concluded with a general discussion. In Table 1.1 the research questions investigated in each chapter are presented. Each chapter was written as a separate article; hence, some overlap exists between the chapters. In Chapter 2, a review of the results from previous studies on segmentation is presented, and based on theories of perception and cognition, two alternative, but not mutually exclusive, processes are identified that may underlie the beneficial effects of segmentation of dynamic visualizations (i.e., the above-mentioned time-to-process and temporal cueing processes).

The study described in Chapter 3 examined whether an expertise reversal effect occurs with segmentation of animations. Secondary education students with different amounts of prior knowledge learned either from segmented or from non-segmented animations on probability calculation. We hypothesized that segmented animations would be more efficient (i.e., higher/equal learning outcomes with equal/less mental effort invested) than non-segmented ones for learners with lower prior knowledge, but that nonsegmented animations would be equally, or even more, efficient than segmented ones for learners with higher prior knowledge.

The studies in Chapter 4, 5 and 6 examined the plausibility of the two explanations for the beneficial effects of segmenting for novice students. The study presented in Chapter 4 explored the role that temporal cueing might play, by using static text-based materials. Third year secondary education students with low prior knowledge learned from text-based worked examples on probability calculation in one of three conditions: a) studying segmented worked examples (i.e., in pieces separated by blank lines), b) studying nonsegmented worked examples, or c) studying non-segmented worked examples and being instructed to actively segment them during study. Because written worked examples were used rather than transient animations, learners could pause at each moment, and hence, any effects of segmentation on learning gains or invested mental effort would be more likely to be due to a temporal cueing effect rather than pausing. Effects of instructing students to actively segment were explored, because such instructions increase students' interaction with the learning materials, which might encourage students to process the examples more deeply, and consequently might have a positive effect on learning. On the other hand, segmenting is an additional task which might impose additional load and distract attention, which might lead to negative effects on learning.

Chapter 5 presents an experiment designed to investigate the plausibility of the two explanations with animations. Third year secondary education students studied animations on probability calculation differing on two factors: insertion of pauses between events (yes, no) and temporarily darkening of the screen at event boundaries (yes, no). If the time-toprocess (or pausing) explanation applies, it would be expected that learners in the two conditions with pauses would learn more and/or would invest less mental effort while studying the animations. If, on the other hand, the positive effects of segmentation are due to temporal cueing, it would be expected that learners in the conditions in which the screen was temporarily darkened at segment boundaries would learn more and/or would invest less mental effort while studying the animations. 
Because it can be argued that pauses provide temporal cues as well (i.e., the start of a pause signals the end of a segment and as such pauses may highlight the structure of the material even without explicit visual cues), the study presented in Chapter 6 investigated the effects of animations segmented in meaningful pieces by pauses, animations segmented in random pieces by pauses, and non-segmented animations, on third year secondary education students' learning outcomes and mental effort invested during animation study. The time-to-process explanation would predict positive effects on learning outcomes and/or mental effort invested of both ways of segmenting the animations. When it is the combination of the time-to-process and temporal cueing explanation that explains the segmentation effect, however, segmentation would only be effective when segments are meaningful units, and segmentation in random units could potentially even hamper learning outcomes and/or increase mental effort.

The final chapter, Chapter 7, first provides a general discussion of the results. Subsequently, limitations are discussed, and theoretical and practical implications and directions for future research are presented.

Table 1.1

Research Question investigated in each Chapter of this Dissertation

\begin{tabular}{|c|c|}
\hline Chapter & Research question investigated \\
\hline Chapter 2 & How can the effects of segmentation found in previous studies be explained? \\
\hline Chapter 3 & Does an expertise reversal effect occur with segmentation of animations? \\
\hline Chapter 4 & $\begin{array}{l}\text { What are the effects on learning outcomes and mental effort invested of } \\
\text { presenting non-transient worked examples in a segmented format and of } \\
\text { instructing students to actively segment the worked examples? }\end{array}$ \\
\hline Chapter 5 & $\begin{array}{l}\text { What are the effects on learning outcomes and mental effort invested of } \\
\text { segmenting animations by pausing and/or by temporarily darkening the screen } \\
\text { slightly? }\end{array}$ \\
\hline Chapter 6 & $\begin{array}{l}\text { What are the effects on learning outcomes and mental effort invested of } \\
\text { segmenting animations in meaningful and random segments? }\end{array}$ \\
\hline
\end{tabular}

\section{References}

Amadieu, F., Mariné, C., \& Laimay, C. (2011). The attention-guiding effect and cognitive load in the comprehension of animations. Computers in Human Behavior, 27, 36-40.

Arguel, A., \& Jamet, E. (2009). Using video and static pictures to improve learning of procedural contents. Computers in Human Behavior, 25, 354-359.

Ayres, P., \& Paas, F. (2007a). Making instructional animations more effective: A cognitive load approach. Applied Cognitive Psychology, 21, 695-700.

Ayres, P., \& Paas, F. (2007b). Can the cognitive load approach make instructional animations more effective? Applied Cognitive Psychology, 21, 811-820.

Baddeley, A. (2003). Working memory: Looking back and looking forward. Nature Reviews Neuroscience, 4, 829-839.

Barrouillet, P., \& Camos, V. (2007). The time-based resource-sharing model of working memory. In N. Osaka, R. H. Logie, \& M. D'Esposito (Eds.), The cognitive neuroscience of working memory (pp. 59-80). Oxford, England: Oxford University Press.

Betrancourt, M. (2005). The animation and interactivity principles in multimedia learning. In R. E. Mayer (Ed.), The Cambridge handbook of multimedia learning (pp. 287-296). New York: Cambridge University Press. 
Boltz, M. (1992). Temporal accent structure and the remembering of filmed narratives. Journal of Experimental Psychology: Human Perception and Performance, 18, 90-105.

Boucheix, J.-M., \& Lowe, R. K. (2010). An eye tracking comparison of external pointing cues and internal continuous cues in learning with complex animations. Learning and Instruction, $20,123-135$.

Chandler, P (2004). The crucial role of cognitive processes in the design of dynamic visualizations. Learning and Instruction, 14, 353-357.

Chandler, P. (2009). Dynamic visualizations and hypermedia: Beyond the 'Wow' factor. Computers in Human Behavior, 25, 389-392.

Cowan, N. (2001). The magical number 4 in short-term memory: A reconsideration of mental storage capacity. Behavioral \& Brain Sciences, 24, 87-114.

De Koning, B. B., Tabbers, H. K., Rikers, R. M. J. P., \& Paas, F. (2007). Attention cueing as a means to enhance learning from an animation. Applied Cognitive Psychology, 21, 731-746.

Fischer, S., Lowe, R. K., \& Schwan, S. (2008). Effects of presentation speed of a dynamic visualization on the understanding of a mechanical system. Applied Cognitive Psychology, 22, 1126-1141.

Fischer, S., \& Schwan, S. (2010). Comprehending animations: Effects of spatial cueing versus temporal scaling. Learning and Instruction, 20, 465-475.

Hasler, B. S., Kersten, B., \& Sweller, J. (2007). Learner control, cognitive load and instructional animation. Applied Cognitive Psychology, 21, 713-729.

Hegarty, M. (1992). Mental animation: Inferring motion from static displays of mechanical systems. Journal of Experimental Psychology: Learning, Memory and Cognition, 18, 10841102.

Hegarty, M., Kriz, S., \& Cate, C. (2003). The roles of mental animations and external animations in understanding mechanical systems. Cognition and Instruction, 21, 209 - 249.

Kalyuga, S. (2007). Expertise reversal effect and its implications for learner-tailored instruction. Educational Psychology Review, 19, 509-539.

Kalyuga, S. (2008). Relative effectiveness of animated and static diagrams: An effect of learner prior knowledge. Computers in Human Behavior, 24, 852-861.

Kalyuga, S. (2011). Cognitive load theory: How many types of load does it really need? Educational Psychology Review, 23, 1-19.

Kalyuga, S., Ayres, P., Chandler, P., \& Sweller, J. (2003). The expertise reversal effect. Educational Psychologist, 38, 23-31.

Lowe, R. K. (1999). Extracting information from an animation during complex visual learning. European Journal of Psychology of Education, 14, 225-244.

Mayer, R. E. (2005). Principles for managing essential processing in multimedia learning: Segmenting, pretraining, and modality principles. In R. E. Mayer (Ed.), The Cambridge handbook of multimedia learning (pp. 169-182). New York: Cambridge University Press.

Mayer, R. E., \& Chandler, P. (2001). When learning is just a click away: Does simple user interaction foster deeper understanding of multimedia messages? Journal of Educational Psychology, 93, 390-397.

Mayer, R. E., Dow, G. T., \& Mayer, S. (2003). Multimedia learning in an interactive selfexplaining environment: What works in the design of agent-based microworlds? Journal of Educational Psychology, 95, 806-812.

Mayer, R. E., Hegarty, M., Mayer, S., \& Campbell, J. (2005). When static media promote active learning: Annotated illustrations versus narrated animations in multimedia instruction. Journal of Experimental Psychology: Applied, 11, 256-265.

Mayer, R. E., \& Moreno, R. (2003). Nine ways to reduce cognitive load in multimedia learning. Educational Psychologist, 38, 43 - 52.

Meyer, K., Rasch, T., \& Schnotz, W. (2010). Effects of animation's speed of presentation on perceptual processing and learning. Learning and Instruction, 20, 136-145.

Moreno, R. (2007). Optimising learning from animations by minimising cognitive load: Cognitive and affective consequences of signalling and segmentation methods. Applied Cognitive Psychology, 21, 765-781. 
Moreno, R., \& Mayer, R. (2007). Interactive multimodal learning environments. Educational Psychology Review, 19, 309-326.

Ploetzner, R. \& Lowe, R. (2004). Dynamic visualizations and learning. Learning and Instruction, $14,235-240$.

Schnotz, W., Böckheler, J., \& Grzondziel, H. (1999). Individual and co-operative learning with interactive animated pictures. European Journal of Psychology of Education, 14, 245-265.

Schnotz, W., \& Lowe, R. (2008). A unified view of learning from animated and static graphics. In R. Lowe \& W. Schnotz (Eds.), Learning with animations: Research implications for design (pp. 304-356). New York: Cambridge University Press.

Schwan, S., Garsoffky, B., \& Hesse, F. (2000). Do film cuts facilitate the perceptual and cognitive organization of activity sequences? Memory \& Cognition, 28, 214-223.

Sweller, J. (2010). Element interactivity and intrinsic, extraneous, and germane cognitive load. Educational Psychology Review, 22, 123-138.

Sweller, J., Van Merriënboer, J. J. G., \& Paas, F. (1998). Cognitive architecture and instructional design. Educational Psychology Review, 10, 251-296.

Tversky, B., Morrison, J. B., \& Betrancourt, M. (2002). Animation: Can it facilitate? International Journal of Human-Computer Studies, 57, 247-262.

Van Merriënboer, J. J. G., \& Sweller, J. (2005). Cognitive load theory and complex learning: Recent developments and future directions. Educational Psychology Review, 17, 147-177.

Wouters, P., Paas, F., \& Van Merriënboer, J. J. G. (2008). How to optimize learning from animated models: A review of guidelines based on cognitive load. Review of Educational Research, 78, 645-675.

Wouters, P., Paas, F., \& van Merriënboer, J. J. G. (2010). Observational learning from animated models: Effects of studying-practicing alternation and illusion of control on transfer. Instructional Science, 38, 89-104.

Zacks, J. M., Speer, N. K., Swallow, K. M., Braver, T. S., \& Reynolds, J. R. (2007). Event perception: A mind-brain perspective. Psychological Bulletin, 133, 273-293. 



\title{
Chapter 2
}

\section{A theoretical analysis of how segmentation of dynamic visualizations optimizes students' learning ${ }^{1}$}

\begin{abstract}
This chapter reviews studies investigating segmentation of dynamic visualizations (i.e., showing dynamic visualizations in pieces with pauses in between) and discusses two not mutually exclusive processes that might underlie the effectiveness of segmentation. First, cognitive activities needed for dealing with the transience of dynamic visualizations impose extraneous cognitive load which may hinder learning. Segmentation may reduce the negative effect of this load, by dividing animations into smaller units of information and providing pauses between segments that give students time for the necessary cognitive activities after each of those units of information. Second, event segmentation theory states that people mentally segment dynamic visualizations during perception (i.e., divide the information shown in pieces). Segmentation of dynamic visualisation could cue relevant segments to students, which may aid them in perceiving the structure underlying the process or procedure shown.
\end{abstract}

Dynamic visualizations such as videos and animations are increasingly used in instructional materials to visualize complex natural processes (e.g., the formation of lightning; Mayer \& Chandler, 2001), mechanical systems (e.g., an electric motor; Mayer, Dow, \& Mayer, 2003), and different kinds of procedures (e.g., solving probability calculation problems: Spanjers, Wouters, Van Gog, \& Van Merriënboer, 2011; or first aid: Arguel \& Jamet, 2009). Dynamic visualizations are seen as attractive for students (e.g., Chandler, 2009) and are usually expected to be more effective than static pictures because students can perceive changes over time rather than having to mentally infer them (e.g., Hegarty, Kriz, \& Cate, 2003; Lowe, 1999). The general idea is that compared to having to infer or imagine changes, perceiving changes frees up cognitive resources (Hegarty et al., 2003; Schnotz \& Rasch, 2005). However, research has shown that complex dynamic visualizations are not always more effective for learning than static pictures (e.g., Hegarty et al., 2003; Mayer, Hegarty, Mayer, \& Campbell, 2005; Tversky, Bauer-Morisson, \& Bétrancourt, 2002), although for certain types of tasks, dynamic visualizations seem to be more effective, especially demonstrations of procedures involving human movement (Höffler \& Leutner, 2007; see also Van Gog, Paas, Marcus, Ayres, \& Sweller, 2009).

To improve the effectiveness of complex dynamic visualizations, several design measures have been proposed (for reviews, see Wouters, Paas, \& Van Merriënboer, 2008; Wouters, Tabbers, \& Paas, 2007). Some of these measures involve the manipulation of characteristics of dynamic visualizations. De Koning, Tabbers, Rikers, and Paas (2009)

\footnotetext{
${ }^{1}$ This Chapter was published as

Spanjers, I. A. E., Van Gog, T., \& Van Merriënboer, J. J. G. (2010). A theoretical analysis of how segmentation of dynamic visualizations optimizes students' learning. Educational Psychology Review, 22, 411-423.
} 
reviewed ways to manipulate visuospatial characteristics, such as visually highlighting certain parts of the dynamic visualization to fix students' attention on those parts. Next to visuospatial characteristics, temporal characteristics can be manipulated. For example, by segmentation, that is, showing dynamic visualizations in segments. A segment is a piece of the dynamic visualization that has an identifiable begin and end point.

Several studies examined the effects of segmentation of complex dynamic visualizations on learning. In these studies, the segments were distinguished by inserting pauses between them (Boucheix \& Guignard, 2005; Hasler, Kersten, \& Sweller, 2007; Mayer \& Chandler, 2001; Mayer et al., 2003; Moreno, 2007; Spanjers et al., 2011). Boucheix and Guignard (2005) compared the effects on learning from different versions of a slideshow about gearing systems, consisting of two wheels and a motor: a version in which students were able to start the next slide or repeat the previous slide and a fast and slow version without learner control. They found larger gains from pretest to posttest for students who could start the next slide or repeat the previous one. In separate analyses for groups differing in prior knowledge, the effect was only significant in the low prior knowledge group (i.e., an expertise reversal effect; Kalyuga, 2007). In the multimedia learning environment of Mayer et al. (2003), an animated pedagogical agent explained the functioning of an electric motor with some animations. In one condition, students could decide at the end of each segment when to continue with the next segment as well as which segment to continue with or to repeat the animation (if there was one). In the other condition, the same material was shown in a continuous presentation. They found that students who studied the segmented learning environment performed better on a transfer test, in which they had to use what they learned to answer novel questions, than students in the other condition. Although these studies provide some evidence that segmentation might be beneficial, the effects may have been influenced by the learner control options that students were given in these studies (e.g., the possibility to repeat slides or animations and/or to select the next segment) and the design of the learning materials (e.g., a division in different slides).

In the studies of Moreno (2007), Mayer and Chandler (2001), and Hasler et al. (2007), some learner control was also present in combination with segmentation, although to a lesser extent: the dynamic visualisations stopped automatically at the end of each segment, and the participants could decide when they wanted to continue with the next segment. Moreno (2007) found that participants who studied a segmented version of an exemplary classroom video (experiment 1 ) or animation (experiment 2) in which teaching skills were modeled, remembered more of the modelled behaviour, reported to invest less mental effort, and experienced the learning materials as less difficult than participants who studied non-segmented versions of the material. Mayer and Chandler (2001) found that students who learned with a segmented animation on the formation of lightning performed better on a transfer test than students who learned with a non-segmented animation. Hasler et al. (2007) compared four versions of their learning material on the causes of day and night: a segmented animation, a non-segmented animation that students could pause at each moment (i.e., with learner control), a non-segmented animation without learner control, and a non-segmented audio-only version without learner control. Learning time was equalized for the conditions by having students study the learning material repeatedly 
until 10 min were over. Their results showed that learners who studied the segmented animation or the animation that they could pause performed better on difficult test questions than students who studied one of the two other versions of the material, even though most learners who could pause the animation did not use that option. Although learners in these studies by Moreno (2007), Mayer and Chandler (2001), and Hasler et al. (2007) had less control than the learners in the studies of Boucheix and Guignard (2005) and Mayer et al. (2003), learner control might still have influenced the effects of segmentation that were found.

In the study by Spanjers et al. (2011) segmentation was not combined with learner control. They investigated the effects of segmented and non-segmented animations on probability calculation procedures, and their segmented animations automatically paused after each segment and automatically continued after $2 \mathrm{~s}$. A significant interaction was found between the effects of segmentation and prior knowledge: Students with lower levels of prior knowledge learned more efficiently from segmented animations than from nonsegmented animations, while students with higher levels of prior knowledge learned equally efficiently from non-segmented and segmented ones (i.e., an expertise reversal effect; Kalyuga, 2007).

These studies show that, at least for novices, segmentation may have positive effects on learning from dynamic visualizations. But how can this effect be explained, or in other words, what cognitive processes underlie this effect? We propose that two possible though not mutually exclusive processes might be responsible: (1) segmentation reduces the high cognitive load associated with information transience due to the fact that the dynamic visualization is divided into smaller units of information and is paused several times that yields extra time for processing those units, and (2) segmentation breaks the dynamic visualization down into meaningful pieces, which may foster students' understanding of the underlying structure of the depicted process or procedure. These processes will be discussed in more detail in the next sections.

\section{Reducing information transience}

One main cause for why learning from dynamic visualizations is often not more effective than learning from static pictures is that information in dynamic visualizations is usually transient; that is, information is continuously replaced with new information, and what is visible now makes way for other information presented in the next moment (Ayres \& Paas, 2007). Learning involves the construction of cognitive schemas, which are stored in longterm memory. To construct those schemas, information from the dynamic visualizations needs to be maintained and processed in working memory (Sweller, Van Merriënboer, \& Paas, 1998). That is, information elements need to be selected from the stream of information, and then need to be mentally integrated with information that was presented earlier and with prior knowledge in order to form a representation from the shown information (Moreno \& Mayer, 2007). Therefore, the limitations of working memory pose a bottleneck for learning (Sweller, 2010; Sweller et al., 1998).

The time-based resource-sharing model of working memory (Barouillet \& Camos, 2007) states that the focus of attention in working memory is capacity limited, which 
implies that attention can be directed at only one cognitive activity at a time. Maintaining information (i.e., refreshing memory traces) and processing information both require attention, which has to be shared between these cognitive activities by rapidly and frequently switching attention from one activity to the other. Cognitive load therefore depends not only on the number of processes that are competing for attention but also on how fast processing needs to be done (e.g., in a continuous dynamic visualization, information keeps coming in at a very high pace) and how long the processing takes. Under conditions of high cognitive load, some cognitive activities require attention during such a large proportion of the available time that insufficient time remains for attending to other cognitive activities.

Cognitive load theory (Sweller, 2010; Sweller et al., 1998; Van Merriënboer \& Sweller, 2005) makes a distinction between cognitive activities imposing intrinsic cognitive load and cognitive activities imposing extraneous cognitive load. Maintaining and processing information elements inherent to the learning content and the relations between those elements imposes intrinsic cognitive load on working memory. The higher the number of information elements and relations between them, the higher the intrinsic cognitive load and the more difficult the material is to learn. For example, an animation in which the names of the different parts of an eye are sequentially presented is less complex than an animation in which the changes occurring during accommodation of the eyes to see approaching objects clearly are presented because in the former animation, the different parts can be learned sequentially and in a relatively isolated manner, while in the latter, the relations and interactions between different parts of the eye need to be learned as well. But the number of interrelated information elements is not the sole determinant of intrinsic cognitive load. Students' prior knowledge influences what constitutes a single information element. As mentioned before, learning involves the construction of cognitive schemas, and a schema can be handled in working memory as one single information element. Therefore, the same learning materials impose less intrinsic load for students with higher levels of prior knowledge than for students with lower levels of prior knowledge or no prior knowledge (Sweller et al., 1998). Under conditions of very high intrinsic cognitive load, the number of information elements and their relations that have to be maintained and processed in working memory can be so high that insufficient time is available for attending to maintenance and processing of all the elements and relations. Therefore, cognitive load theory recommends that intrinsic load of learning materials is optimized, that is, at a difficulty level that is challenging but not too high (Sweller, 2010; Schnotz \& Kürschner, 2007). Optimizing cognitive load implies that one decreases the complexity of the material if the amount of intrinsic load might overload the learner's limited working memory, for example, by requiring learners first to learn the information elements inherent to the learning material without learning their relations, and subsequently requiring them to learn the relations between the previously learned information elements. It also implies increasing the complexity of the material, if learners do not fully use their working memory resources, for example by requiring that learners not only learn a particular procedure but also under which conditions they have to use that particular procedure (Sweller, 2010). In other words, one has to use tasks that are in the learner's zone of proximal development (Vygotsky, 1978; see also Schnotz \& Kürschner, 2007). 
Extraneous cognitive load is imposed by maintaining and processing activities that result from a non-optimal design of learning materials (Sweller, 2010; Sweller et al., 1998). For example, to learn from dynamic visualizations, information from different points in time needs to be mentally integrated, and when information is transient, this requires that information from a certain point in time is maintained in working memory and then linked to information presented later (Lowe, 1999). Moreover, new incoming information needs to be processed while maintaining the previously presented information (e.g., Ayres \& Paas, 2007; Moreno \& Mayer, 2007). Such cognitive activities that impose extraneous load reduce the time available for maintaining and processing activities that impose intrinsic cognitive load, and as a consequence, learning may be hampered because insufficient time is left for attending to these intrinsic maintenance and processing activities. This will happen especially when animations are high in intrinsic load; when they are low in intrinsic load, there may be sufficient time to attend to both processes that impose intrinsic and processes that impose extraneous load. Therefore, on complex dynamic visualizations that are high in intrinsic load, the need to attend to processes imposing extraneous load needs to be decreased as much as possible so that learning will not be hampered (Sweller, 2010; Sweller et al., 1998).

In segmented dynamic visualizations, the stream of information is divided into smaller units, and pauses between segments provide students with sufficient time to attend to necessary cognitive activities on the bit of information presented in the previous segment, without having to simultaneously attend to new incoming information (e.g., Mayer \& Moreno, 2003; Moreno \& Mayer, 2007). Thus, segmentation reduces the harmful effects of information transience in dynamic visualizations by reducing the co-occurrence of processing activities, thereby reducing cognitive load at certain points in time (e.g., Ayres \& Paas, 2007; Mayer \& Moreno, 2003; Moreno \& Mayer, 2007; Schnotz \& Lowe, 2008). It should be noted that by providing pauses, segmentation does increase the total available learning time. Yet, this does not imply that increased learning time causes the positive effects on learning. It can be questioned, for example, whether providing additional time at the end of an entire, continuous dynamic visualization would enhance learning because this would do nothing to alleviate the high load at certain points in time. Support for the claim that the segmentation effect is not simply due to differences in learning time is provided by the study of Hasler et al. (2007), in which learning time was equal for all conditions but segmentation still affected learning outcomes.

Next to the assumption that giving students extra time for necessary cognitive processes may have positive effects on learning, segmentation may also support learning by highlighting the structure underlying the process or procedure shown in dynamic visualizations. 


\section{Enhancing perception of the underlying structure}

In many dynamic visualizations multiple subevents or substeps in a process or procedure are shown across time (Meyer, Rasch, \& Schnotz, 2010; Schnotz \& Lowe, 2008). For example, in the case of a four-stroke engine, one can divide its functioning in several substeps such as intake stroke, compression stroke, etc. (Meyer et al., 2010). People also tend to perceive events or procedures shown in dynamic visualizations as consisting of a series of discrete subevents or substeps (e.g., Kurby \& Zacks, 2008; Zacks, Speer, Swallow, Braver, \& Reynolds, 2007). This implies that they mentally segment the continuous stream of information presented. The event segmentation theory (Zacks et al., 2007) describes the processes underlying mental segmentation. It is assumed that people form event models in working memory on the basis of incoming sensory information and prior knowledge. Based on these models, they form predictions about what will happen in the next moment and compare these predictions with what actually happens according to the new incoming sensory information. When the predictions and the new incoming sensory information differ too much, a new event model for the next segment needs to be constructed. At this point, a so-called event boundary is distinguished (Zacks et al., 2007). Physical changes in the information shown, such as changes in movements, speed, or distance between objects as well as structural changes, such as subgoal completion and initiation, lead to a decrease in predictability of the new incoming sensory information and therefore to the distinction of event boundaries (Kurby \& Zacks, 2008; Zacks, 2004; Zacks et al., 2007).

For example, if a general physician in a video about putting on walking plaster starts winding a layer of cotton around the patient's leg, one can predict that he or she will continue with that action until the patient's leg is wrapped up in a layer of cotton (Robroek \& Van de Beek, 2005). If the patient's leg is wrapped up in a layer of cotton, the coherent movement pattern of the general physician changes and another subgoal will be initiated, with the consequence that it is more difficult to predict the new incoming sensory information and an event boundary is distinguished (Zacks et al., 2007). Because the occurrence of discontinuities in the incoming sensory information and the completion and the initiation of subgoals are related to each other (although for some subevents more tightly than for others), mental segmentation on the basis of discontinuities in the incoming sensory information supports interpretation and therefore comprehension of the information shown in terms of subgoals (Baldwin, Baird, Saylor, \& Clark, 2001; Hard, Tversky, \& Lang, 2006; Zacks, 2004). At event boundaries, the representations in working memory are updated. Because more extensive processing of information takes place at event boundaries than between event boundaries, more information about those boundaries is stored in long-term memory than about the parts between the boundaries (Zacks et al., 2007). Finally, segmentation aids in chunking information, which reduces the cognitive load imposed by maintaining the information (Kurby \& Zacks, 2008; Schnotz \& Lowe, 2008).

Since mental segmentation is in this way related to interpretation and storage in long-term memory, it can be expected that individual differences in mental segmentation lead to differences in learning outcomes (cf. Koopman \& Newtson, 1981). Differences in 
segmentation rates have been found between participants who were asked to segment videos about several human activities (e.g., a couple playing a party game, a person doing dishes, assembling a saxophone, and fertilizing house plants); that is, there were differences in the size of the substeps or subevents in which participants divided the videos (Hanson \& Hirst, 1989; Zacks, Speer, Vettel, \& Jacoby, 2006; Zacks, Tversky, \& Iyer, 2001). Those differences have been shown to influence the recall of details of videos and memory for the temporal order of subevents or substeps shown. Participants who divided videos about a couple playing a game, a person cleaning a pistol, or a person upgrading a computer in smaller subevents, recalled more subevents on a free recall test (Hanson \& Hirst, 1989; Schwan, Garsoffky, \& Hesse, 2000). Zacks et al. (2006) did not examine free recall but assessed performance on a test requiring participants to sort pictures taken from videos of planting flowers in a window box, setting up a tent, washing clothes, and washing a car in the correct order. Their second experiment showed that requiring participants to segment in smaller subevents was associated with worse performance on the test than requiring them to segment in larger subevents. They suggest that segmentation in smaller subevents might have led to a focus on temporal relations between small subevents, which may have negative effects on memory of the more global temporal relations. Zalla, Pradat-Diehl, and Sirigu (2003) found that individuals with frontal lobe damage had difficulties with segmenting videos, depicting a person performing actions in an office or a couple playing a party game, in larger subevents. Although they recalled the same number of events from the videos as controls without brain lesions on a free recall test, they tended to recall the subevents without links between them and in a wrong temporal order. Like the second experiment by Zacks et al. (2006), this study suggests that segmentation in smaller subevents may be associated with difficulties in remembering the temporal order of subevents. Although the dynamic visualizations used in these studies depicted everyday life activities, they might have some relevance for education: consider for example dynamic visualizations on learning to perform first aid procedures (Arguel \& Jamet, 2009). In addition, Zacks et al. (2006; experiment 2) had some participants perform the test without having seen the videos, and their scores suggest that the temporal order was not completely arbitrary or commonsense. The order of segments of a process or procedure is relevant in many instructional dynamic visualizations as well. For example, in the study by Moreno and Valdez (2005), the learning task consisted of putting segments of an animation about lightning formation in the correct temporal and causal order.

Concerning instructional dynamic visualizations, these findings might imply that differences in learning outcomes may occur between students, depending on how they mentally segmented the dynamic visualization (cf. Koopman \& Newtson, 1981). Further evidence for an effect of mental segmentation differences on learning is provided by studies about design measures that likely disturbed participants' perception of the structure underlying the information shown (Kurby \& Zacks, 2008; Zacks et al., 2007). Schwan and Garsoffky (2004) showed participants videos about cleaning a pistol or upgrading a computer, either unaltered, with event boundaries replaced by a 1-s black screen, or with parts between event boundaries replaced by a 1-s black screen. The event boundaries had been determined by studying which locations experts indicated as such (see also Schwan et al., 2000). It was hypothesized that deleting event boundaries disrupts the event structure 
people use for their mental segmentation. Indeed, participants viewing a video from which event boundaries were deleted indicated the ends of segments about equally often at event boundaries as at points between event boundaries, whereas participants viewing other versions of the video indicated ends of segments about twice as often at event boundaries than at points between event boundaries. Moreover, participants who viewed the video from which event boundaries had been deleted recalled a lower proportion of the subevents than the participants from the other groups, which might be due to disruption of the event structure, reduced coherence of the video and a lower proportion of relevant steps shown. Between the unaltered version of the video, and the version with replacements between event boundaries, only small differences were found in the proportion of recalled subevents, but different subevents were recalled. Schwan and Garsoffky (2004) proposed that these differences are due to changes in the temporal density of subevents that are the consequence of the deletion of parts. Since deletions and insertions of black screens always co-occurred, it is not clear whether the insertion of black screens alone would affect learning.

Boltz (1992) showed participants an episode of a mini-series without commercials, or with commercials inserted either at event boundaries or between event boundaries. The locations of event boundaries had also been determined based on a previous study. She hypothesized that insertion of commercials between event boundaries would hinder perceiving the underlying event structure of the episode. Her results were in line with this hypothesis: Participants who saw this version recalled less from the episode than participants who saw another version. In addition, a positive effect on recall was found of inserting twice as many commercials at event boundaries and a negative effect of inserting twice as many commercials between event boundaries.

If design measures can hinder participants to perceive the underlying structure of a depicted event, process, or procedure, it is likely that they can be applied to aid perceiving that structure as well. When design measures make event boundaries more salient, they have a temporal cueing effect (Boltz, 1992; Schwan et al., 2000; Zacks et al., 2007). Temporal cueing involves highlighting points in time rather than visuospatial parts. A number of studies provide evidence that temporal cueing of event boundaries enhances remembering of information shown. Schwan et al. (2000) highlighted either event boundaries or points between event boundaries through cuts in videos about cleaning a pistol or upgrading a computer. It was found that cueing event boundaries prevented the occurrence of a negative relation between segmentation in smaller subevents and completeness (although not detailedness) of recall. Additionally, it was found that time periods around event boundaries that were cued by a cut were recalled better than around event boundaries that were not cued. Arguel and Jamet (2009, experiment 1) compared three versions of learning materials on first aid: dynamic visualizations combined with key frames (i.e., static pictures from different substeps), dynamic visualizations without key frames, and key frames without dynamic visualizations. The addition of the key frames to the dynamic visualization may have served as a cue of the underlying structure of the shown procedures, and this condition had better posttest performance than the other conditions. In experiment 1 all key frames were revealed at once, right at the beginning of the dynamic visualizations. In their second experiment, Arguel and Jamet (2009) showed 
that revealing the key frames sequentially (after which they remained visible) led to better posttest performance than presenting them at once at the beginning of the dynamic visualization. When twice as many frames as in experiment 1 were presented, this had a negative effect on posttest performance. This negative effect tended to disappear if the frames were presented sequentially. In addition to cueing the underlying event structure, presentation of key frames may aid in maintaining and chunking the shown information as well. Well-chosen key frames provide external representations of previous substeps, so that students do not have to use a proportion of the available time to refresh memory traces to be able to mentally integrate them with information presented later (Bétrancourt, Dillenbourg, \& Clavien, 2008). They also provide students with a compact presentation of the substeps so that students are aided in chunking the information (Schnotz \& Lowe, 2008). In other words, they lead to a reduction in cognitive activities imposing extraneous cognitive load (Arguel \& Jamet, 2009; Schnotz \& Lowe, 2008) and an increase in cognitive activities associated with learning.

Segmentation of instructional dynamic visualizations is another design measure that may cue event boundaries. That is, rather than relying on students' ability to mentally segment the dynamic visualisations, this is done for them. Segmentation might enhance learning by aiding students in perceiving the underlying structure of the process or procedure and by aiding chunking. This function of segmentation is suggested by the work of Catrambone on learning to solve probability calculation problems from worked examples (1995, 1996, 1998). For example, Catrambone (1995) compared four groups, which differed on whether or not a label for a particular calculation substep was provided (i.e., providing meaning to the step) and on whether or not that calculation substep was placed on a separate line (i.e., cue of what constituted a step). Learning outcomes were higher, and students mentioned a substep more often in their description of the calculation procedure if a label was provided, the step was visually isolated, or both the label was provided and the step was isolated, compared with a control condition in which no cues were provided. Segmentation of dynamic visualizations might have a similar effect. That is, by temporally cueing event boundaries, segmentation indicates which substeps or subevents belong together and which steps need to be separated. This may also encourage students to self-explain why particular substeps or subevents belong together or need to be separated, which might lead to deeper understanding of the process or procedure (Catrambone, 1995, 1996, 1998; see also Wouters et al., 2008).

Students with higher levels of prior knowledge might not need these temporal cues or might even be hampered by them. The findings of Boucheix and Guignard (2005) and Spanjers et al. (2011) show that students with higher levels of prior knowledge do not need additional guidance through segmentation. For students with higher levels of prior knowledge, the amount of cognitive resources they can devote to cognitive activities with a positive effect on learning is reduced when they have to reconcile the instructional guidance with the guidance given by their available cognitive schemas (Kalyuga, 2007). 


\section{Discussion}

This chapter proposed that two processes may underlie the effectiveness of segmentation of dynamic visualizations. First of all, in the studies on segmentation that were conducted thus far, segmentation was always associated with pauses between segments. These pauses may have caused the beneficial effects on cognitive load and learning because they give students time to perform the cognitive activities needed for learning on a smaller unit of information, without having to simultaneously attend to the next unit of information (e.g., Mayer \& Moreno, 2003: Moreno \& Mayer, 2007). This first explanation is mainly based on cognitive load theory (Sweller et al., 1998), although we also introduced a perspective on cognitive load based on the work by Barouillet and Camos (2007) that is new to cognitive load theory. Second, segmentation may be effective because it cues students to perceive event boundaries, thereby aiding them in perceiving the structure underlying the process or procedure shown (cf. Catrambone, 1995, 1996, 1998; see also Wouters et al., 2008). This second explanation is mainly based on event segmentation theory (Zacks et al., 2007). The two explanations are thus based on two different theories about processes involved in learning from dynamic visualisations. As mentioned before, the explanations are not mutually exclusive, and there are also some connections between the theories. For example, mental segmentation, which is the process on which the event segmentation theory focuses, influences the representations held in working memory (e.g., Zacks et al., 2007) that influence cognitive load.

Which of the two mechanisms, that is, pauses or temporal cueing, plays the most important role in explaining the positive effects of segmentation on learning or whether their combination is crucial cannot be judged based on previous studies in which a pause also automatically cued the end of a segment. Therefore, this remains an important empirical question for future studies in which different versions of instructional dynamic visualizations with segmentation through pauses, cues, or both could be compared.

Next to this central question, there are some other interesting directions for future research on the effects of segmentation of dynamic visualizations on cognitive load and learning. The first is whether effects of segmentation (or more specifically, of pauses and temporal cueing) would differ between different types of dynamic visualizations. Studies based on the event segmentation theory often used dynamic visualizations depicting everyday life activities, and naturally, all participants have experience with observing such activities (Hard et al., 2006; Zacks et al., 2007). Moreover, in some studies, some or even all of the depicted events were familiar to the participants (Hanson \& Hirst, 1989; Zacks et al., 2006; Zacks et al., 2001). Consequently, participants would already have relevant cognitive schemas for those events that would influence the construction of event models (Zacks et al., 2007); one might hypothesize that, perhaps, less cognitive load is required for the construction of event models in such visualizations of everyday tasks than in visualizations on, for example, natural or biological processes or on the spatial arrangement of complex chemical molecules and other structures. Furthermore, depictions of familiar human movements seem to automatically trigger activation of the mirror neuron system with the consequence that an effortless process of embodied simulation occurs (Van Gog et al., 2009), and mirror neurons have been suggested to be involved in the 
process of mental segmentation as well (Sommerville \& Decety, 2006). Therefore, differences in ease of mental segmentation and in the amount of cognitive load imposed by mental segmentation may exist between dynamic visualizations depicting human movement activities and those depicting other kinds of processes, procedures, or structures, and although segmenting dynamic visualizations might be effective for both types of visualizations, it might be most crucial for non-human movement activities if these indeed impose higher load. Whether the cognitive load imposed by constructing event models is lower in human movement tasks than in non-human movement tasks could be investigated with online physiological measures of cognitive load, such as pupil dilation (Kahneman \& Beatty, 1966; Van Gerven, Paas, Van Merriënboer, \& Schmidt, 2004) or EEG (Antonenko, Paas, Grabner, \& Van Gog, 2010). For example, Swallow and Zacks (2006) found transient small increases in participants' pupil dilation after event boundaries in dynamic visualisations.

A second direction for future research concerns the role of learner characteristics, such as prior knowledge that may interact with the effects of segmentation. In this chapter, we described two studies (Boucheix \& Guignard, 2005; Spanjers et al., 2011) that found an expertise reversal effect of segmentation on cognitive load and/or learning. However, before concluding that segmentation per se is not helpful for students with higher levels of prior knowledge, we might need to investigate the effects of different grain sizes of segments. There are no clear guidelines on how to determine the length of a segment; some researchers base the length on theories with regard to cognitive functioning (Hasler et al., 2007; Mayer \& Chandler, 2001; Moreno, 2007), while others consult experts in order to determine what meaningful pieces are in which to divide the dynamic visualizations (Arguel \& Jamet, 2009; Schwan \& Garsoffky, 2004; Schwan et al., 2000; Spanjers et al., 2011). The study by Boltz (1992) suggested that segment length may influence learning: She found a positive effect on recall of dividing dynamic visualizations in shorter segments by inserting twice as many commercials at event boundaries. The question is, however, whether the effects on cognitive load and learning of different segment lengths would be the same for low and high prior knowledge learners. It might be that novices need smaller segments because all information is new to them, whereas learners with more prior knowledge might benefit from larger segments. In addition, it might be interesting to investigate whether students with different levels of prior knowledge would benefit from actively segmenting dynamic visualizations themselves. Interactivity with dynamic visualizations has been proposed as a way to encourage students to engage in activities contributing to learning (Wouters et al., 2007). If students must segment dynamic visualisations themselves, they are encouraged to focus on which subevents or substeps are depicted, which may have a positive effect on learning. However, this positive effect is probably found only when cognitive resources are available for attending to this additional task while learning the content of the visualization (i.e., if students devote all their attention to determining segments, they might learn very little). Therefore, actively segmenting dynamic visualisations may only be beneficial for students with higher levels of prior knowledge. This kind of research on the effects of having learners segment animations themselves could perhaps also shed light on the required grain size of segments for different types of learners by providing indications on whether students with lower and 
higher prior knowledge would distinguish smaller or larger segments. The empirical findings from previous studies on mental segmentation with regard to this question are mixed. Participants in the study of Hard et al. (2006) who had seen the dynamic visualizations a number of times before they had to segment them, divided them in larger units than participants who had not seen the dynamic visualizations before. However, other studies found no effect of expertise, training, or familiarity with the content on the length of segments made by participants (Schwan, Hesse, \& Garsoffky, 1998; Zacks et al., 2001). Finally, next to prior knowledge, there may be other learner characteristics that influence the effects of segmentation on learning, such as motivation, spatial ability, or age.

In conclusion, two processes may underlie the effectiveness of segmented dynamic visualizations: pausing and temporal cueing. Future empirical studies should further examine these cognitive processes and associated cognitive load as well as factors influencing these processes.

\section{References}

Antonenko, P., Paas, F., Grabner, R., \& Van Gog, T. (2010). Using electroencephalography to measure cognitive load. Educational Psychology Review, 22, 425-438.

Arguel, A., \& Jamet, E. (2009). Using video and static pictures to improve learning of procedural contents. Computers in Human Behavior, 25, 354-359.

Ayres, P., \& Paas, F. (2007). Making instructional animations more effective: A cognitive load approach. Applied Cognitive Psychology, 21, 695-700.

Baldwin, D. A., Baird, J. A., Saylor, M. M., \& Clark, M. A. (2001). Infants parse dynamic action. Child Development, 72, 708-717.

Barrouillet, P., \& Camos, V. (2007). The time-based resource-sharing model of working memory. In N. Osaka, R. H. Logie \& D. E. Mark (Eds.), The cognitive neuroscience of working memory (pp. 57-80). Oxford, England: Oxford University Press.

Bétrancourt, M., Dillenbourg, P., \& Clavien, L. (2008). Display of key pictures from animation: Effects on learning. In Rouet, J.-F., Lowe, R., \& Schnotz, W. (Eds.)., Understanding multimedia documents (pp. 61-78). New York: Springer.

Boltz, M. (1992). Temporal accent structure and the remembering of filmed narratives. Journal of Experimental Psychology: Human Perception and Performance, 18, 90-105.

Boucheix, J. M., \& Guignard, H. (2005). What animated illustrations conditions can improve technical document comprehension in young students? Format, signaling and control of the presentation. European Journal of Psychology of Education, 20, 369-388.

Catrambone, R. (1995). Aiding subgoal learning: Effects on transfer. Journal of Educational Psychology, 87, 5-17.

Catrambone, R. (1996). Generalizing solution procedures learned from examples. Journal of Experimental Psychology: Learning, Memory, and Cognition, 22, 1020-1031.

Catrambone, R. (1998). The subgoal learning model: Creating better examples so that students can solve novel problems. Journal of Experimental Psychology: General, 127, 335-376.

Chandler, P. (2009). Dynamic visualizations and hypermedia: Beyond the "Wow" factor. Computers in Human Behavior, 25, 389-392.

De Koning, B. B., Tabbers, H. K., Rikers, R. M. J. P., \& Paas, F. (2009). Towards a framework for attention cueing in instructional animations: Guidelines for research and design. Educational Psychology Review, 21, 113-140. 
Hanson, C., \& Hirst, W. (1989). On the representation of events: A study of orientation, recall, and recognition. Journal of Experimental Psychology: General, 118, 136-147.

Hard, B. M., Tversky, B., \& Lang, D. (2006). Making sense of abstract events: Building event schemas. Memory \& Cognition, 34, 1221-1235.

Hasler, B. S., Kersten, B., \& Sweller, J. (2007). Learner control, cognitive load and instructional animation. Applied Cognitive Psychology, 21, 713-729.

Hegarty, M., Kriz, S., \& Cate, C. (2003). The roles of mental animation and external animation in understanding mechanical systems. Cognition and Instruction, 21, 325-360.

Höffler, T. N., \& Leutner, D. (2007). Instructional animation versus static pictures: A metaanalysis. Learning and Instruction, 17, 722-738.

Kahneman, D., \& Beatty, J. (1966). Pupil diameter and load on memory. Science, 154, 1583-1585.

Kalyuga, S. (2007). Expertise reversal effect and its implications for learner-tailored instruction. Educational Psychology Review, 19, 509-539.

Koopman, C., \& Newtson, D. (1981). Level of analysis in the perception of ongoing instruction: An exploratory study. Journal of Educational Psychology, 73, 212-223.

Kurby, C. A., \& Zacks, J. M. (2008). Segmentation in the perception and memory of events. Trends in Cognitive Sciences, 12, 72-79.

Lowe, R. K. (1999). Extracting information from an animation during complex visual learning. European Journal of Psychology of Education, 14, 225-244.

Mayer, R. E., \& Chandler, P. (2001). When learning is just a click away: Does simple user interaction foster deeper understanding of multimedia messages? Journal of Educational Psychology, 93, 390-397.

Mayer, R. E., Dow, G. T., \& Mayer, S. (2003). Multimedia learning in an interactive selfexplaining environment: What works in the design of agent-based microworlds? Journal of Educational Psychology, 95, 806-812.

Mayer, R. E., Hegarty, M., Mayer, S., \& Campbell, J. (2005). When static media promotes active learning: Annotated illustrations versus narrated animations in multimedia instruction. Journal of Experimental Psychology: Applied, 11, 256-265.

Mayer, R. E., \& Moreno, R. (2003). Nine ways to reduce cognitive load in multimedia learning. Educational Psychologist, 38, 43-52.

Meyer, K., Rasch, T., \& Schnotz, W. (2010). Effects of animation's speed of presentation on perceptual processing and learning. Learning and Instruction, 20. 136-145.

Moreno, R. (2007). Optimising learning from animations by minimising cognitive load: Cognitive and affective consequences of signalling and segmentation methods. Applied Cognitive Psychology, 21, 765-781.

Moreno, R., \& Mayer, R. (2007). Interactive multimodal learning environments. Educational Psychology Review, 19, 309-326.

Moreno, R., \& Valdez, A. (2005). Cognitive load and learning effects of having students organize pictures and words in multimedia environments: The role of student interactivity and feedback. Educational Technology Research and Development, 53(3), 35-45.

Robroek, W. C. L., \& Van de Beek, G. (2005). Vaardigheden in de geneeskunde: Verbanden en verbinden [Skills in medicine: Bandages and bandaging techniques]. Maastricht, the Netherlands: Mediview.

Schnotz, W., \& Kürschner, C. (2007). A reconsideration of cognitive load theory. Educational Psychology Review, 19, 460-508.

Schnotz, W., \& Lowe, R. (2008). A unified view of learning from animated and static graphics. In R. Lowe \& W. Schnotz (Eds.), Learning with animations: Research implications for design (pp. 304-356). New York: Cambridge University Press. 
Schnotz, W., \& Rasch, T. (2005). Enabling, facilitating, and inhibiting effects of animations in multimedia learning: Why reduction of cognitive load can have negative results on learning. Educational Technology Research and Development, 53, 47-58.

Schwan, S., \& Garsoffky, B. (2004). The cognitive representation of filmic event summaries. Applied Cognitive Psychology, 18, 37-55.

Schwan, S., Garsoffky, B., \& Hesse, F. W. (2000). Do film cuts facilitate the perceptual and cognitive organization of activity sequences? Memory \& Cognition, 28, 214-223.

Schwan, S., Hesse, F. W., Garsoffky, B. (1998). The relationship between formal filmic means and the segmentation behavior of film viewers. Journal of Broadcasting \& Electronic Media, 42, 237-249.

Sommerville, J. A., \& Decety, J. (2006). Weaving the fabric of social interaction: Articulating developmental psychology and cognitive neuroscience in the domain of motor cognition. Psychonomic Bulletin \& Review, 13, 179-200.

Spanjers, I. A. E., Wouters, P., Van Gog, T., \& Van Merriënboer, J. J. G. (2011). An expertise reversal effect of segmentation in learning from animations. Computers in Human Behavior, 27, 46-52.

Swallow, K. M. \& Zacks, J. M. (2006). Hierarchical grouping of events revealed by eye movements. Poster presented at the Annual Meeting of the Psychonomic Society, Houston, TX.

Sweller, J. (2010). Element interactivity and intrinsic, extraneous and germane cognitive load. Educational Psychology Review, 22, 123-138.

Sweller, J., Van Merriënboer, J. J. G., \& Paas, F. (1998). Cognitive architecture and instructional design. Educational Psychology Review, 10, 251-296.

Tversky, B., Bauer-Morrison, J., \& Bétrancourt, M. (2002). Animation: Can it facilitate? International Journal of Human-Computer Studies, 57, 247-262.

Van Gerven, P. W. M., Paas, F., Van Merriënboer, J. J. G., \& Schmidt, H. G. (2004). Memory load and the cognitive pupillary response in aging. Psychophysiology, 41, 167-174.

Van Gog, T., Paas, F., Marcus, N., Ayres, P., \& Sweller, J. (2009). The mirror-neuron system and observational learning: Implications for the effectiveness of dynamic visualisations. Educational Psychology Review, 21, 21-30.

Vygotsky, L. S. (1978). Mind in society. Cambridge, MA: Harvard University Press.

Van Merriënboer, J. J. G., \& Sweller, J. (2005). Cognitive load theory and complex learning: Recent developments and future directions. Educational Psychology Review, 17, 147-177.

Wouters, P., Paas, F., \& Van Merriënboer, J. J. G. (2008). How to optimize learning from animated models: A review of guidelines based on cognitive load. Review of Educational Research, $78,645-675$.

Wouters, P., Tabbers, H. K., \& Paas, F. (2007). Interactivity in video-based models. Educational Psychology Review, 19, 327-342.

Zacks, J. M. (2004). Using movement and intentions to understand simple events. Cognitive Science, 28, 979-1008.

Zacks, J. M., Speer, N. K., Swallow, K. M., Braver, T. S., \& Reynolds, J. R. (2007). Event perception: A mind-brain perspective. Psychological Bulletin, 133, 273-293.

Zacks, J. M., Speer, N. K., Vettel, J. M., \& Jacoby, L. L. (2006). Event understanding and memory in healthy aging and dementia of the Alzheimer type. Psychology and Aging, 21, 466-482.

Zacks, J., Tversky, B., \& Iyer, G. (2001). Perceiving, remembering, and communicating structure in events. Journal of Experimental Psychology: General, 130, 29-58.

Zalla, T., Pradat-Diehl, P., \& Sirigu, A. (2003). Perception of action boundaries in patients with frontal lobe damage. Neuropsychologia, 41, 1619-1627. 


\title{
Chapter 3
}

\section{An expertise reversal effect of segmentation in learning from animated worked-out examples ${ }^{2} 3$}

\begin{abstract}
Many animations impose a high cognitive load due to the transience of information, which often hampers learning. Segmentation, that is presenting animations in pieces (i.e., segments), has been proposed as a means to reduce this high cognitive load. The expertise reversal effect shows, however, that design measures that have a positive effect on cognitive load and learning for students with lower levels of prior knowledge, might not be effective, or might even have a negative effect on cognitive load and learning for students with higher levels of prior knowledge. This experiment with animated worked-out examples showed an expertise reversal effect of segmentation: segmented animations were more efficient than continuous animations (i.e., equal test performance with lower investment of mental effort during learning) for students with lower levels of prior knowledge, but not for students with higher levels of prior knowledge.
\end{abstract}

Animations are increasingly used in instructional material to visualize natural processes (e.g., Long Term Potentiation occurring in synapses: Amadieu, Mariné, \& Laimay, 2011; the formation of lightning; Schmidt-Weigand \& Scheiter, 2011) or mechanical systems (e.g., a car's braking system; Mayer et al., 2005), or to demonstrate and explain problem solving methods (e.g., animated worked-out examples demonstrating how to solve probability calculation problems; Wouters, Paas, \& Van Merriënboer, 2009, 2010). This is probably done because animations are considered to be attractive for students (e.g., Chandler, 2009; Tversky, Heiser, Mackenzie, Lozano, \& Morrison, 2008). However, they are expensive to develop, and research has shown that they are not always more effective for learning than static pictures (e.g., Hegarty, Kriz, \& Cate, 2003; Mayer, Hegarty, Mayer, \& Campbell, 2005; Tversky, Morisson, \& Betrancourt, 2002), although there seem to be certain types of tasks for which animations are more effective, which often involve animated examples demonstrating (psycho)motor procedures (Höffler \& Leutner, 2007; see also Van Gog, Paas, Marcus, Ayres, \& Sweller, 2009).

It has been argued that the efficiency and effectiveness of animations can be improved by design measures that take cognitive load into account (Ayres \& Paas, 2007). A number of measures has been proposed to improve the efficiency and effectiveness of animations by reducing extraneous or ineffective cognitive load and increasing germane or effective cognitive load. These include visuospatial cueing, that is, visually highlighting

\footnotetext{
${ }^{2}$ The animated worked-out examples in this Chapter are called animations in the other Chapters (except for Chapter 4) of the dissertation.

${ }^{3}$ This Chapter was published as

Spanjers, I. A. E., Wouters, P., Van Gog, T., \& Van Merriënboer, J. J. G. (2011). An expertise reversal effect of segmentation in learning from animated worked-out examples. Computers in Human Behavior, 27, 46-52.
} 
one or more elements in animations (e.g., De Koning, Tabbers, Rikers, \& Paas, 2007), pretraining, that is, presenting components of the instructional material before the animations (e.g., Mayer, Mathias, \& Wetzell, 2002), or segmentation, that is, showing animations in pieces or segments (e.g., Mayer \& Chandler, 2001). However, research on the expertise reversal effect (e.g., Wetzels, Kester, \& Van Merriënboer, 2011; see for a review Kalyuga, Ayres, Chandler, \& Sweller, 2003) has shown that measures that have a positive effect on efficiency and effectiveness for students with lower levels of prior knowledge might have no, or even a negative, effect on efficiency and effectiveness for students with higher levels of prior knowledge. This study investigates whether an expertise reversal effect of segmentation occurs with animated worked-out examples on probability calculation (see Wouters et al., 2009, 2010).

\section{Effects of segmentation and learner expertise}

To learn from animations, information needs to be maintained and processed in working memory. Working memory has a limited capacity (Baddeley, 2003) and has time constraints (Barrouillet \& Camos, 2007), as a consequence of which only two or three information elements can be simultaneously processed. Cognitive Load Theory (Sweller, Van Merriënboer, \& Paas, 1998; Van Merriënboer \& Sweller, 2005) distinguishes between three additive types of cognitive load imposed on working memory by maintaining and processing information: Extraneous (i.e., ineffective) and germane (i.e., effective) cognitive load imposed by the design of instructional materials, and intrinsic cognitive load, imposed by the number of novel, interacting information elements in the material that have to be simultaneously processed. Intrinsic load is also influenced by students' level of expertise: When students gain knowledge in a domain, they construct cognitive schemas by combining information elements and those schemas can be handled in working memory as single information elements. Therefore, the same animations impose less intrinsic load for students with higher levels of prior knowledge than for students with lower levels of prior knowledge. Consequently, students with higher levels of prior knowledge have more resources left to deal with processes that impose extraneous load (e.g., linking related elements from physically separated parts of the display) and to be engaged in processes that induce germane load (e.g., studying different problem variants) than students with lower levels of prior knowledge (Sweller et al., 1998).

Due to the transience of information in animations (i.e., information presented at one moment makes place for new information presented the next moment), learners need to maintain and process information, while simultaneously attending to new information (Mayer \& Moreno, 2003). Consequently, transience induces high extraneous load (Ayres \& Paas, 2007). Students with higher levels of prior knowledge are probably able to deal with this extraneous load, because the intrinsic load of the material is lower for them than for students with lower levels of prior knowledge. The high load imposed by transience, therefore, can be expected to mainly hinder students with lower levels of prior knowledge (cf. Kalyuga, 2008).

Segmentation has been proposed as a means to reduce the high load occurring due to the transience of animations (e.g., Ayres \& Paas, 2007; Mayer \& Moreno, 2003; Schnotz \& Lowe, 2008). In most segmentation studies, pauses between the segments are 
made, which gives students time to process the information presented in the previous segment without having to attend to new incoming information (Mayer \& Chandler, 2001; Mayer \& Moreno, 2003). In this way, segmentation can support students in dealing with the complexity of the material presented in the animation.

In addition, segmentation breaks the animation down into meaningful pieces (Schnotz \& Lowe, 2008). Consequently, segmentation can be seen as a kind of cueing, but on a temporal rather than a visuospatial level. That is, whereas visuospatial cueing highlights one or more elements in the animation, segmentation can highlight the underlying structure of the depicted process/ procedure by demarcating points in time, which could aid students' learning by making them aware of particular sub-steps and possibly - stimulating them to self-explain the goals of those sub-steps (cf. Catrambone, 1998).

However, as mentioned above, these beneficial effects of segmentation might mainly be relevant for students with lower levels of prior knowledge. When the information contained in an animation is (partly) familiar to students, they are able to deal with its transience (cf. Kalyuga, 2008). Therefore, segmentation might not be necessary or might even harm learning for students with higher levels of prior knowledge. Research on the expertise reversal effect has shown that measures to improve the efficiency and effectiveness of instructional material by providing additional guidance are often useful for students with lower levels of prior knowledge, but not for students with higher levels of prior knowledge, who do not need additional instructional guidance, and might even be bothered by it, because they would have to reconcile the guidance provided by their own schemas with the instructional guidance, which might induce extraneous load (Kalyuga et al., 2003). A study by Schnotz (2002) on simulations, provides preliminary support for the assumption that an expertise reversal effect might also occur with segmentation of animations. He found a positive effect of segmentation of a simulation for students with lower levels of prior knowledge, but no effect for students with higher levels of prior knowledge on one of the tests.

In sum, this study investigates whether an expertise reversal effect of segmentation arises in learning from animated worked-out examples on probability calculation (see Wouters et al., 2009, 2010). It is hypothesized that segmented, animated worked-out examples will lead to more effective and/or efficient learning processes, that is, equal/higher transfer test scores with lower/equal investment of mental effort during learning (Van Gog \& Paas, 2008) for students with lower levels of prior knowledge, but that with higher levels of prior knowledge the beneficial effects of segmentation will disappear, so that continuous, animated examples will be equally or more efficient than segmented ones for students with higher levels of prior knowledge.

\section{Method}

\section{Participants and design}

Participants were 76 Dutch secondary education students $(53 \%$ females; mean age $=16.16$, $S D=0.80$ ) attending the fourth or fifth year of senior general secondary education (total duration: 5 years) or pre-university education (total duration: 6 years). They were 
randomly assigned to either the segmented or the continuous, animated worked-out examples condition. Data from one participant had to be excluded due to too many missing values, which resulted in 37 students in the segmented and 38 in the continuous condition.

\section{Materials}

Learning environment. A computer-based learning environment developed in Flash MX (Macromedia., 2002) administered all parts of the experiment (prior knowledge test, animated worked-out examples, transfer tests). With the exception of the animated examples, all parts were learner-paced.

Prior knowledge test. A prior knowledge test consisting of four multiple-choice and eight open items about probability calculation (see Wouters et al., 2009, 2010) was used to measure students' prior knowledge. An example of an open item is: 'You are playing a game with some friends and it is your turn to throw a dice. If you throw sixes you win. What is the probability that you throw sixes?'. An example of a multiple-choice item is: 'You have a deck of cards from which you select four cards. You want to get an ace, king, queen, and jack - in this specific order. Does it matter whether you put back the selected cards before each new selection or not?', with answer options being (a) Yes, your chances increase when you put back the selected cards, (b) Yes, your chances decrease when you put back the selected cards, (c) No, your chances remain the same whether you put back the selected cards or not, or (d) This depends on the number of jokers in the deck of cards.

Animated worked-out examples. The learning phase consisted of eight animated worked-out examples on probability calculation (see Figure 3.1), preceded by a short introduction in which information relevant for learning about probability calculation was given, like what randomisation is, what individual and complex events are, and how counting can be used in solving probability calculation problems. The introduction was the same for both groups, except for a part in which information about the animated examples was given.

The animated examples, which were computer-paced and had a duration of approximately $2 \mathrm{~min}$, demonstrated and explained how probability calculation problems dealing with complex events (i.e., involving more than one individual event) need to be solved. They included a pedagogical agent (a dolphin) and text spoken by a male voice with a neutral accent. The animated examples depicted four different types of problems, determined by the four combinations that can be made with two factors that are important for probability calculation: (1) relevance of order (relevant, irrelevant), and (2) replacement after drawing (yes, no). Two animated examples were shown for each problem type, and the first always had a cover story about helmets handed out on a mountain bike trip, whereas the cover story of the second varied per problem type. The order of the problem types was: order relevant/without replacement, order relevant/with replacement, order irrelevant/without replacement and order irrelevant/with replacement. An example of a problem presented is: 'Together with your friend, you go on a 2-day mountain bike trip. Each day the instructor takes with him five helmets, which each have a different color: blue, green, yellow, red and silver. The helmets are distributed randomly, and are given back to the instructor at the end of the day. On both days you get a helmet 
first, and your friend second. What is the probability that on the first day, you will get the blue helmet and your friend will get the green helmet?'.

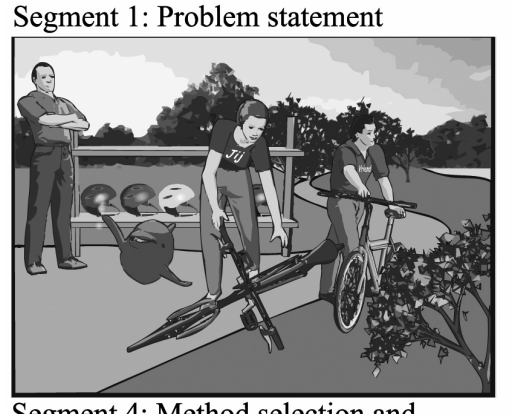

Segment 4: Method selection and probability for the $1^{\text {st }}$ individual event

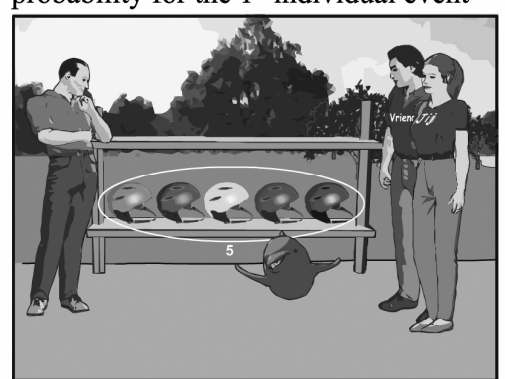

Segment 2: Order not relevant

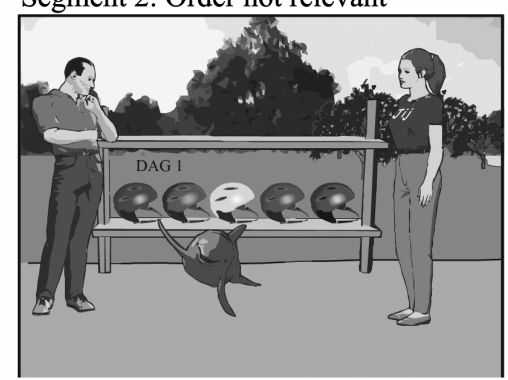

Segment 5: Probability for the $2^{\text {nd }}$

individual event

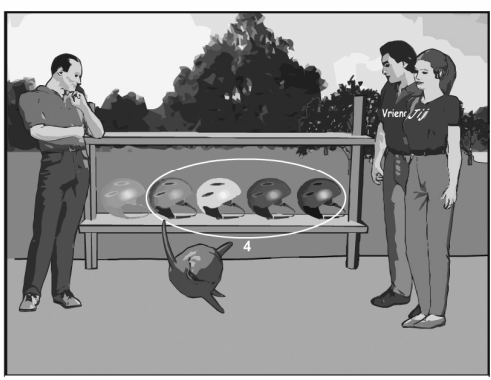

Segment 3: Drawing without replacment

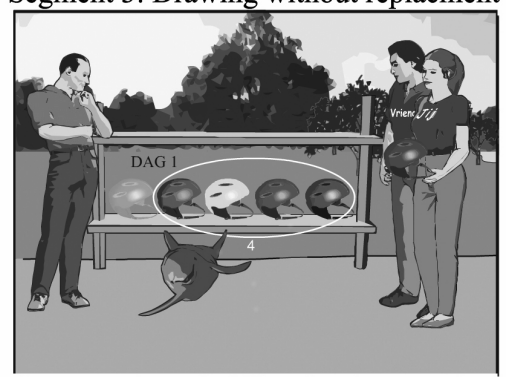

Segment 6: Probability for the complex event

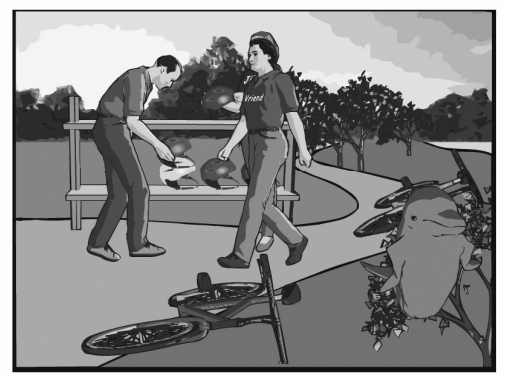

Figure 3.1 Series of screen shots from one of the animated worked-out examples (text was spoken).

Two methods for solving probability calculation problems were shown. The method of counting was shown if order was relevant in that problem and the method of individual events if order was irrelevant in that problem. The method of counting involves determining the number of possible outcomes and the number of correct outcomes. For example, if one wants to calculate the probability that one obtains a blue helmet out of five helmets on the first day of a mountain bike trip and a green one on the second day, one calculates that the number of possible outcomes is $5^{2}=25$ and determines that only one of those 25 outcomes is correct, so the probability is $1 / 25$. The method of individual events consists of determining the probability of individual events and multiplying those probabilities in order to calculate the probability of the complex event. In the example above, one could also have determined first that the probabilities for the individual events are $1 / 5$ and $1 / 5$ and subsequently calculate that the probability is $1 / 5 * 1 / 5=1 / 25$.

In the continuous condition each animated worked-out example was shown as one continuous stream of information. In the segmented condition each animated example was divided into segments with pauses of $2 \mathrm{~s}$ between them, during which the screen was slightly darkened. After the pauses, the animated examples continued automatically. The length of segments and the moment of the segment endings were determined together with three experts (one statistician and two math teachers) and were slightly adapted based on a pilot test. Depending on the problem type the number of segments varied between 5 and 7 . The first segment presented the problem statement. The second described whether order was relevant or not for this problem and the third whether the problem was about drawing with or without replacement. In the fourth and subsequent segments the method to solve the problem was chosen and the different steps of the method were demonstrated. 
Transfer tests. The transfer tests consisted of eight open near transfer and four open far transfer items. The near transfer items had a similar structure to the problems presented in the animated examples (i.e., students could use the problem solving methods they had studied), but different cover stories (e.g., about concert tickets instead of helmets). The far transfer items consisted of problems with a different structure than those in the animated examples, so students had to adapt the problem solving methods. For example, some items required the students to combine the problem solving methods shown in the animated examples to solve problems consisting of two complex events: 'You are about to take an exam in order to determine the final mark for a subject. First, you have to perform two tasks, then a test consisting of eight multiple-choice questions. Two out of five possible tasks (A, B, C, D, and E) will be randomly assigned to you. You have already practiced tasks $\mathrm{D}$ and $\mathrm{E}$ a month ago. Eight multiple-choice questions will be selected for you from a large pool of 100 different questions. You have made a test before with eight questions from this pool. What is the probability that you are assigned tasks D and E as well as the eight questions you have had before?'

Mental effort. Immediately after studying each animated example, students rated how much mental effort they invested in studying it on a 9-point subjective rating scale ranging from (1) very, very low mental effort to (9) very, very high mental effort (Paas, 1992).

\section{Procedure}

The experiment was conducted in computer rooms at the students' schools. It had a duration of approximately $1.5 \mathrm{~h}$. First, students could read what the purpose of the experiment was and of which parts it consisted. Subsequently, they indicated their gender and age. After that they completed the prior knowledge test. This test was followed by the introduction on probability calculation. At the end of this introduction information about the animated examples was given. With a continue button the students could proceed to the animated examples, using headsets to listen to the auditory information. After each animated example students rated their invested mental effort. Finally, students completed the transfer tests, after which they were debriefed and thanked for their participation.

\section{Scoring}

Test performance was scored by giving 1 point for a correct answer (i.e., max. score prior knowledge: 12, near transfer: 8, far transfer: 4). No partial credit was given and computational errors were ignored (for more details on the scoring procedure, see Wouters et al., 2009, 2010). Efficiency on both the near and the far transfer test was calculated using the formula developed by Paas and Van Merriënboer (1993), but with test performance and mental effort invested in studying the animated examples (i.e., efficiency in terms of learning process, where a high efficiency denotes equal/low investment of effort during learning combined with high/equal performance on the test; see Van Gog \& Paas, 2008). In case of missing mental effort scores, these were replaced with the grand mean (see Paas \& Van Merriënboer, 1993). 


\section{Results}

Table 3.1 shows the descriptive statistics for prior knowledge, near and far transfer test performance, mental effort, efficiency on the near and far transfer tests, and time on task for the prior knowledge, near, and far transfer tests. Regression analyses on near and far transfer test performance, mental effort, and efficiency were executed with prior knowledge, condition and the interaction term prior knowledge * condition entered simultaneously as predictors (significance level .05). To avoid problems with multicollinearity, prior knowledge was centered (Aiken, \& West, 1991). Condition was coded as 0 for the continuous condition and 1 for the segmented condition in the model used to examine the presence of an interaction between prior knowledge and condition. Follow-up tests on significant interactions were conducted by examining the specific impact of prior knowledge in each of the conditions separately. This was done through testing the regression coefficient for prior knowledge in the continuous condition with condition coded as continuous $=0$ and segmented $=1$, and in the segmented condition with condition coded as continuous $=1$ and segmented $=0$. In addition, the interactions were further tested by examining the significance of the difference between the regression lines for students with lower and higher prior knowledge by testing the regression coefficients for condition at one standard deviation below (lower prior knowledge) and above (higher prior knowledge) the mean in models with condition coded as 0 for continuous and 1 for segmented (Aiken \& West, 1991).

Table 3.1

Descriptive Statistics for Prior Knowledge and the Outcome Variables for Both Conditions

\begin{tabular}{lcccc}
\hline & Continuous & \multicolumn{3}{c}{ Segmented } \\
\cline { 2 - 5 } & $M$ & $S D$ & $M$ & $S D$ \\
\hline Prior knowledge (0-12) & 5.13 & 1.55 & 4.92 & 1.99 \\
$\quad$ Time on task (in sec) & 641 & 278 & 586 & 275 \\
Instruction & & & & \\
$\quad$ Mental effort (1-9) & 2.53 & 1.56 & 2.35 & 1.11 \\
Near transfer test & & & & \\
$\quad$ Performance (0-8) & 2.24 & 1.85 & 2.86 & 1.92 \\
Efficiency & -0.16 & 1.28 & 0.17 & 1.04 \\
Time on task (in sec) & 464 & 225 & 476 & 213 \\
Far transfer test & & & & \\
Performance (0-4) & 0.37 & 0.71 & 0.46 & 0.61 \\
Efficiency & -0.10 & 1.28 & 0.10 & 0.86 \\
Time on task (in sec) & 310 & 200 & 329 & 174 \\
\hline
\end{tabular}

The regression models for performance on near and far transfer were both significant, near: $F(3,71)=8.61, p=.00$, adjusted $R^{2}=.24$; far: $F(3,71)=6.01, p=.00$, adjusted $R^{2}=.17$. The regression coefficients for the interaction terms were not significant, however.

The regression model for mental effort during instruction was marginally significant, $F(3,71)=2.57, p=.06$, adjusted $R^{2}=.06$, and the regression coefficient for the interaction term was significant, $\beta=0.38, t(71)=2.06, p=.04$. Figure 3.2 depicts the 
interaction between prior knowledge and condition on mental effort during instruction. At one standard deviation below the mean the difference in mental effort invested in studying continuous, animated examples was marginally higher than in studying segmented ones, $\beta$ $=-0.32, t(71)=-1.98, p=.05$. With higher levels of prior knowledge, the mental effort invested in studying continuous, animated examples decreased, $\beta=-0.49, t(71)=-2.71, p=$ .01 , whereas for segmented examples this remained almost equal, $\beta=-0.02, t(71)=-0.11$, $p=.91$. Consequently, no significant difference was found in the mental effort invested in studying continuous and segmented animated examples at one standard deviation above the mean, $\beta=0.16, t(71)=0.98, p=.33$.

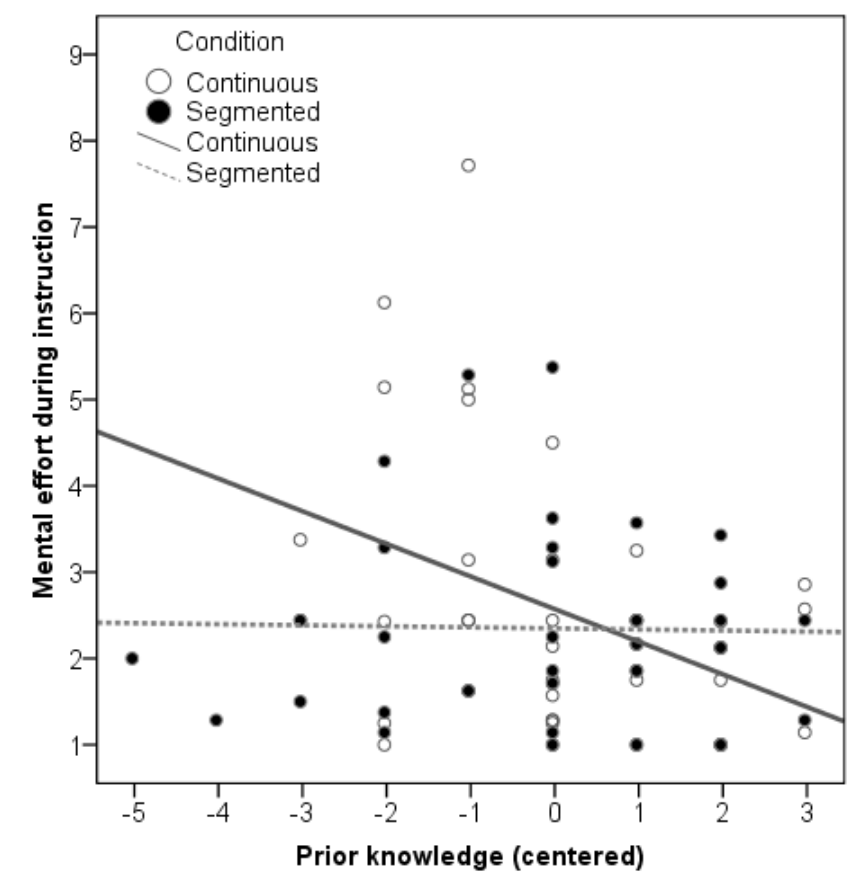

Figure 3.2 The interaction between prior knowledge (centered) and condition on mental effort during instruction.

The regression models for instructional efficiency on near and far transfer were both significant, near: $F(3,71)=7.13, p=.00$, adjusted $R^{2}=.20$; far: $F(3,71)=6.70, p=.00$, adjusted $R^{2}=.19$, and so were the regression coefficients for the interaction terms, near: $\beta$ $=-0.35, t(71)=-2.07, p=.04$; far: $\beta=-0.34, t(71)=-2.00, p=.05$. Figure 3.3 depicts the interactions between prior knowledge and condition on near and far transfer. It shows that at one standard deviation below the mean segmented, animated examples were more efficient than continuous ones, near $\beta=0.39, t(71)=2.60, p=.01$, far: $\beta=0.33, t(71)=$ $2.20, p=.03$. With higher levels of prior knowledge, the efficiency of continuous, animated examples increased significantly, near: $\beta=0.68, t(71)=4.04, p=.00$, far: $\beta=0.68, t(71)=$ $4.00, p=.00$, whereas the efficiency of segmented, animated examples increased more slowly and only marginally significant, near: $\beta=0.24, t(71)=1.79, p=.08$, far: $\beta=0.25$, $t(71)=1.85, p=.07$. As a consequence, the difference in efficiency between the two conditions had disappeared at one standard deviation above the mean, near: $\beta=-0.05, t(71)$ $=-0.36, p=.72$, far: $\beta=-0.10, t(71)=-0.67, p=.51$. 
A

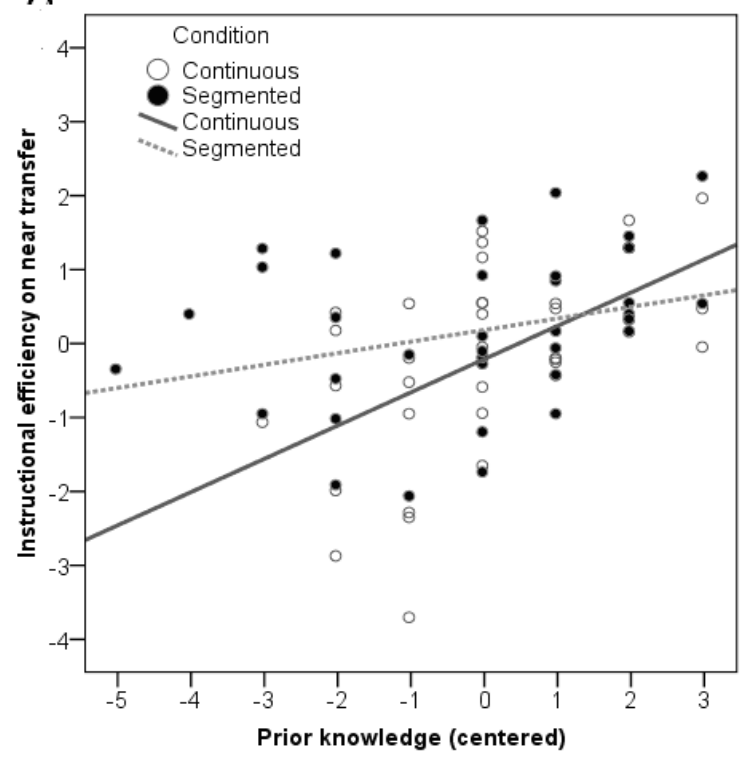

B

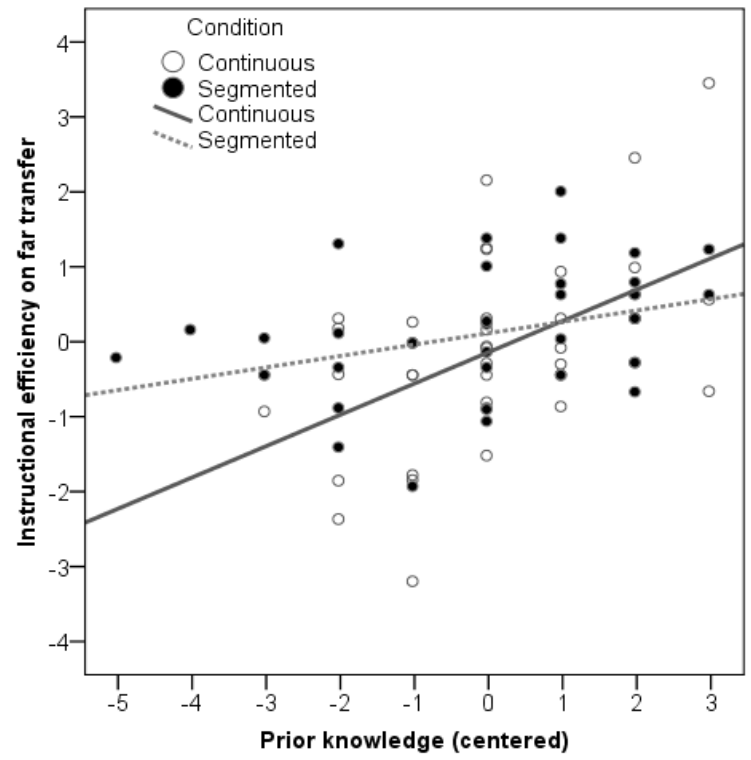

Figure 3.3 The interaction between prior knowledge (centered) and condition on instructional efficiency for near (A) and far transfer (B).

\section{Discussion}

In line with our hypothesis, the results showed an expertise reversal effect of segmentation in terms of efficiency: For students with lower levels of prior knowledge segmented, animated worked-out examples were more efficient than continuous, animated worked-out examples, that is, they attained equal performance with less investment of mental effort during learning. However, the superiority of segmented, animated worked-out examples disappeared at higher levels of prior knowledge. This suggests that only for students with lower levels of prior knowledge, segmentation successfully reduces the high cognitive load imposed by animations and leads to more efficient learning.

The positive effect of segmentation with lower levels of prior knowledge and its disappearance at higher levels of prior knowledge is mainly driven by differences in mental effort investment by students with different levels of prior knowledge. With regard to performance, no significant differences were found between the conditions in the increase of scores with higher levels of prior knowledge. Possibly, this is a consequence of the range of prior knowledge of participants in our study: most of them were not complete novices or full experts in the domain of probability calculation, so although there were differences in prior knowledge, these did not span the entire continuum. This may explain why we did not find an interaction of segmentation and prior knowledge on performance, but only on mental effort and efficiency, which constitute more subtle measures of differences in learning processes and outcomes between (groups of) participants (Van Gog \& Paas, 2008). Future studies might examine whether a broader range of prior knowledge would lead to an interaction effect on performance, and whether such a broader range might lead not only to a disappearance of benefits of segmentation, but to a complete 
reversal of effects, with continuous animations being more effective than segmented ones at high levels of prior knowledge.

As mentioned in the introduction, there are two possible (not mutually exclusive) explanations for the effectiveness of segmentation for students with lower levels of prior knowledge. First, segmentation as implemented in this and other studies may be effective, because there are pauses between segments, which gives students additional time to process the information presented (Mayer \& Moreno, 2003). Secondly, segmentation breaks the animation down into meaningful pieces (Schnotz \& Lowe, 2008), which may aid students by distinguishing the events or sub-steps in a process/ procedure and possibly - stimulating them to self-explain the structure of the process/procedure and the goals of those events or sub-steps (cf. Catrambone, 1998). However, which of these explanations is more plausible, or whether it is the combination of pausing and indicating the problem structure that makes segmenting effective for students with lower levels of prior knowledge, is an open question for future research to address.

A possible limitation of this study was that the pauses between segments led to a difference in learning time between the conditions: students in the segmented condition had more time for each animated example than students in the continuous condition. Note though, that during these pauses no additional information was provided (only the last frame of the previous segment was visible), and that $2 \mathrm{~s}$ is probably too short for processes such as reflection. In addition, it is questionable whether increasing learning time without temporarily suspending incoming information at meaningful intervals would be effective. In other words, pausing at meaningful intervals provides a more specific explanation for the effectiveness of segmentation for learners with low prior knowledge than increasing learning time in general, because it only predicts positive effects of inserting time periods without incoming information at particular places and not of other ways to increase learning time. Nevertheless, differences in time-on-task between conditions should be controlled in future studies in order to rule out this alternative explanation.

In addition, this study did not provide any clues as to what cognitive processes lead to the expertise reversal effect. Are advanced students hindered by the pauses? Or by the locations of the segments, which might interfere with the sub-steps indicated in their acquired problem solution schemas? Therefore, future studies should try to uncover the cognitive processes taking place during the studying of animations by students with lower and higher levels of prior knowledge. This can be done using verbal reports (Ericsson \& Simon, 1993), but given that animations often contain spoken text, thinking aloud during animation study is not a viable option. Cued retrospective reporting, that is, having students report retrospectively what they thought during studying the animations supported by a replay of the animations combined with a record of their eye movements (Van Gog, Paas \& Van Merriënboer, \& Witte, 2005) seems to be a good alternative and has been used in several studies on learning from animations and videos (De Koning, Tabbers, Rikers, \& Paas, 2010; Jarodzka, Scheiter, Gerjets, \& Van Gog, 2010).

Finally, an interesting question for future research is whether the expertise reversal effect of segmentation also applies to animations with different learning content. In this experiment, students acquired problem solving knowledge from the animated examples. It 
is unclear whether the results can be generalised to animations from which students have to acquire declarative knowledge about natural processes or mechanical systems.

In sum, this study provides some evidence that an expertise reversal effect of segmentation in animated worked-out examples occurs. Designers should, therefore, take prior knowledge of students into account when developing instructional animations, and implement measures such as segmentation to reduce the high cognitive load imposed by the transience of animations for students with lower levels of prior knowledge, but not for students with higher levels of prior knowledge.

\section{References}

Aiken, L. S., \& West, S. G. (1991). Multiple regression: Testing and interpreting interactions. Newbury Park, CA: Sage.

Amadieu, F., Mariné, C., \& Laimay, C. (2011). The attention-guiding effect and cognitive load in the comprehension of animations. Computers in Human Behavior, 27, 36-40.

Ayres, P., \& Paas, F. (2007). Can the cognitive load approach make instructional animations more effective? Applied Cognitive Psychology, 6, 811-820.

Baddeley, A. (2003). Working memory: Looking back and looking forward. Nature Reviews: Neuroscience, 4, 828-839.

Barrouillet, P., \& Camos, V. (2007). The time-based resource-sharing model of working memory. In N. Osaka, R. H. Logie \& D. E. Mark (Eds.), The cognitive neuroscience of working memory (pp. 57-80). Oxford, England: Oxford University Press.

Catrambone, R. (1998). The subgoal learning model: Creating better examples so that students can solve novel problems. Journal of Experimental Psychology: General, 127, 335-376.

Chandler, P. (2009). Dynamic visualizations and hypermedia: Beyond the 'Wow' factor. Computers in Human Behavior, 25, 389-392.

De Koning, B. B., Tabbers, H. K., Rikers, R. M. J. P., \& Paas, F. (2007). Attention cueing as a means to enhance learning from an animation. Applied Cognitive Psychology, 21, 731-746.

De Koning, B. B., Tabbers, H. K., Rikers, R. M. J. P., \& Paas, F. (2010). Attention guidance in learning from a complex animation: Seeing is understanding? Learning and Instruction, 20, 111-122.

Ericsson, K. A., \& Simon, H. A. (1993). Protocol analysis: Verbal reports as data (Rev. ed.). Cambridge, MA: MIT Press.

Hegarty, M., Kriz, S., \& Cate, C. (2003). The roles of mental animation and external animation in understanding mechanical systems. Cognition and Instruction, 21, 325-360.

Höffler, T. N., \& Leutner, D. (2007). Instructional animation versus static pictures: A metaanalysis. Learning and Instruction, 17, 722-738.

Jarodzka, H., Scheiter, K., Gerjets, P., \& Van Gog, T. (2010). In the eyes of the beholder: How experts and novices interpret dynamic stimuli. Learning and Instruction, 20, 146-154.

Kalyuga, S. (2008). Relative effectiveness of animated and static diagrams: An effect of learner prior knowledge. Computers in Human Behavior, 24, 852-861.

Kalyuga, S., Ayres, P., Chandler, P., \& Sweller, J. (2003). The expertise reversal effect. Educational Psychologist, 38, 23-31.

Macromedia. (2002). Flash $M X^{T M}$ [Computer software]. San Francisco, CA: Macromedia.

Mayer, R. E., \& Chandler, P. (2001). When learning is just a click away: Does simple user interaction foster deeper understanding of multimedia messages? Journal of Educational Psychology, 93, 390-397. 
Mayer, R. E., Hegarty, M., Mayer, S., \& Campbell, J. (2005). When static media promotes active learning: Annotated illustrations versus narrated animations in multimedia instruction. Journal of Experimental Psychology: Applied, 11, 256-265.

Mayer, R. E., Mathias, A., \& Wetzell, K. (2002). Fostering understanding of multimedia messages through pre-training: Evidence for a two-stage theory of mental model construction. Journal of Experimental Psychology: Applied, 8, 147-154.

Mayer, R. E., \& Moreno, R. (2003). Nine ways to reduce cognitive load in multimedia learning. Educational Psychologist, 38, 43-52.

Paas, F. (1992). Training strategies for attaining transfer of problem-solving skill in statistics: A cognitive-load approach. Journal of Educational Psychology, 84, 429-434.

Paas, F., \& Van Merriënboer, J. J. G. (1993). The efficiency of instructional conditions: An approach to combine mental effort and performance measures. Human Factors, 35, 737743.

Schmidt-Weigand, F., \& Scheiter, K. (2011). The role of spatial descriptions in learning from multimedia. Computers in Human Behavior, 27, 22-28.

Schnotz, W. (2002). Enabling, facilitating and inhibiting effects in learning from animated pictures. Paper presented at the International Workshop on Dynamic Visualizations and Learning, Tübingen, Germany. Downloaded on 31 July 2008 from http://www.iwmkmrc.de/workshops/visualization/schnotz.pdf

Schnotz, W., \& Lowe, R. (2008). A unified view of learning from animated and static graphics. In R. Lowe \& W. Schnotz (Eds.), Learning with animations: Research implications for design (pp. 304-356). New York: Cambridge University Press.

Sweller, J., Van Merriënboer, J. J. G., \& Paas, F. (1998). Cognitive architecture and instructional design. Educational Psychology Review, 10, 251-296.

Tversky, B., Heiser, J., Mackenzie, R., Lozano, S., \& Morrison, J. (2008). Enriching animations. In R. Lowe \& W. Schnotz (Eds.), Learning with animations: Research implications for design (pp. 263-285). New York: Cambridge University Press.

Tversky, B., Morrison, J. B., \& Betrancourt, M. (2002). Animation: Can it facilitate? International Journal of Human-Computer Studies, 57, 247-262.

Van Gog, T. \& Paas, F. (2008). Instructional efficiency: Revisiting the original construct in educational research. Educational Psychologist, 43, 16-26.

Van Gog, T., Paas, F., Marcus, N., Ayres, P., \& Sweller, J. (2009). The mirror neuron system and observational learning: Implications for the effectiveness of dynamic visualizations. Educational Psychology Review, 21, 21-30.

Van Gog, T. , Paas, F., Van Merriënboer, J. J. G., \& Witte, P. (2005). Uncovering the problemsolving process: Cued retrospective reporting versus concurrent and retrospective reporting. Journal of Experimental Psychology: Applied, 11, 237-244.

Van Merriënboer, J. J. G., \& Sweller, J. (2005). Cognitive load theory and complex learning: Recent developments and future directions. Educational Psychology Review, 17, 147-177.

Wetzels, S. A. J., Kester, L., \& Van Merriënboer, J. J. G. (2011). Adapting prior knowledge activation: Mobilisation, perspective taking, and learners' prior knowledge. Computers in Human Behavior, 27, 16-21.

Wouters, P., Paas, F., \& Van Merriënboer, J. J. G. (2009). Observational learning from animated models: Effects of modality and reflection on transfer. Contemporary Educational Psychology, 34, 1-8.

Wouters, P., Paas, F., \& Van Merriënboer, J. J. G. (2010). Observational learning from animated models: Effects of studying-practicing alternation and illusion of control on transfer. Instructional Science, 38, 89-104. 


\title{
Chapter 4
}

\section{Segmentation of worked examples: Effects on cognitive load and learning ${ }^{4}$}

\begin{abstract}
Two ways to improve worked examples are investigated: Presenting them in a segmented format (i.e., in pieces separated by blank lines), and instructing students to segment them actively (i.e., students must divide the examples in pieces). Segmented examples are expected to support learning because they show which information elements belong together. Learners might also be encouraged to think about which information elements belong together when they are instructed to actively segment, but, on the negative side, this is an additional task that might impose extra cognitive load without facilitating learning. Results showed that students in the actively segmenting condition invested more effort in learning than students in the other conditions without performing better. Furthermore, studying segmented examples required less effort to achieve equal learning outcomes than studying non-segmented. So, presenting learners with segmented examples improved the efficiency of the learning process, while instructing them to actively segment decreased this efficiency.
\end{abstract}

A large body of research has shown that for low prior knowledge learners, instruction consisting of studying worked examples is more effective (i.e., higher learning outcomes) and efficient (i.e., equal/higher learning outcomes reached with less/equal investment of time and/or mental effort) than instruction consisting of problem solving (for reviews, see Atkinson, Derry, Renkl, \& Wortham, 2000; Sweller, Van Merriënboer, \& Paas, 1998) or tutored problem solving (McLaren, Lim, \& Koedinger, 2008; Schwonke, Renkl, Krieg, Wittwer, Aleven, \& Salden, 2009). In addition to studying the benefits of worked examples compared to problem solving and tutored problem solving, research has also investigated means to further improve learning from worked examples, by improving the example design (for reviews, see Atkinson et al., 2000; Paas \& Van Gog, 2006; Van Gog \& Rummel, 2010) and/or adding interactivity (Atkinson \& Renkl, 2007). The present study investigates the effects of segmentation, both as an example design characteristic and as a form of interactivity, on learning outcomes and mental effort, and their combination.

\section{Learning from worked examples}

Instruction consisting of problem solving presents students only with a description of some "givens" (e.g., how much faster a car is driving than a truck and the time it takes the car to overtake a truck) and a goal statement (e.g., calculate how fast each vehicle is travelling; see Cooper \& Sweller, 1987). Because they lack knowledge of the procedures required to

\footnotetext{
${ }^{4}$ This Chapter will be published as Spanjers, I. A. E., Van Gog, T., Van Merriënboer, J. J. G. (in press). Segmentation of worked examples: Effect on cognitive load and learning. Applied Cognitive Psychology.
} 
solve such problems, instruction consisting of problem solving forces low prior knowledge learners to resort to so-called 'weak strategies', such as trial-and-error or means-ends analysis, to try to achieve the goal state. Through the use of weak strategies, a learner may eventually find the solution to the problem. However, such strategies impose a high cognitive load (i.e., they draw heavily on working memory resources) and do not facilitate the construction of a cognitive schema of how such problems should be solved. In other words, although such strategies may sometimes lead to acceptable performance, they do not lead to effective and efficient learning as shown by the ability to perform similar tasks in the future (Sweller, 1988; Sweller et al., 1998).

Worked examples provide the learner with the givens and a goal statement as well as with the solution moves that should be taken successively to solve the problem and achieve the goal state. Consequently, the high load imposed by weak problem-solving strategies that do not contribute to learning is prevented, and learners can devote the available working memory capacity to studying the given solution moves and constructing a cognitive schema that guides future problem solving (Sweller et al., 1998). Therefore, compared to instruction consisting of problem solving, instruction that relies more heavily on studying worked examples reduces extraneous (i.e., ineffective) cognitive load on working memory, and enhances learning as well as transfer performance. That is, students not only learn how to solve identical problems, but also novel problems for which they have to flexibly adapt the learned solution procedure (see Sweller et al., 1998). In addition to enhanced learning and transfer test performance, a heavier reliance on worked examples has also been shown to result in lower acquisition time (Sweller \& Cooper, 1985; Van Gog, Paas, \& Van Merriënboer, 2006; Zhu \& Simon, 1987), lower cognitive load experienced by students during instruction (Paas \& Van Merriënboer, 1994; Van Gog et al., 2006), and lower cognitive load experienced by students during the test (Paas, 1992; Paas \& Van Merriënboer, 1994).

This has become known as 'the worked example effect' (Sweller et al., 1998; Sweller, 2006). It should be noted though, that these beneficial effects of worked examples on learning outcomes, acquisition time, and cognitive load, compared to problem solving, seem to apply primarily to low prior knowledge learners: For advanced learners who have more prior knowledge of the problem-solving procedure, worked examples may no longer be effective or may even hamper learning (Kalyuga, Chandler, Tuovinen, \& Sweller, 2001; this is an example of the 'expertise reversal effect', see Kalyuga, 2007; Kalyuga, Ayres, Chandler, \& Sweller, 2003). Moreover, these beneficial effects apply only when the examples are well-designed. That is, following early studies on the effects of worked examples compared to problem solving by Sweller and Cooper (1985) and Cooper and Sweller (1987), it was soon discovered that studying worked examples was not always more effective for learning than problem solving. Rather, the design of the examples played a crucial role in their effectiveness (Tarmizi \& Sweller, 1988). If worked examples induced split attention, by presenting mutually referring information sources such as text and picture/diagram separately rather than integrated, a worked example effect was not obtained (Tarmizi \& Sweller, 1988). On the other hand, when information sources are not mutually referring and can be easily understood in isolation, extraneous cognitive load is imposed by the need to process redundant information. In this case, one of the information 
sources should be left out (see Chandler \& Sweller, 1991). The prevention of splitattention and redundancy are by now regarded as basic design guidelines for worked examples.

Next to these basic design guidelines, the effectiveness of examples can be enhanced even further by improving their design to cue important aspects of the procedure and/or stimulate more active processing of the examples (for reviews, see Atkinson et al., 2000; Paas \& Van Gog, 2006; Van Gog \& Rummel, 2010). Examples of guidelines aimed at the further improvement of worked examples are providing instructional explanations (e.g., Lovett, 1992), providing process information that helps students understand the principles behind the solution moves (e.g., Van Gog, Paas, \& Van Merriënboer, 2008), asking students to complete moves in partially worked-out examples (e.g., Paas, 1992; Van Merriënboer, 1990; Van Merriënboer \& De Croock, 1992), and asking students to selfexplain worked-out solution moves (e.g., Atkinson, Renkl, \& Merrill, 2003). The present study focuses on effects of segmentation.

\section{Effects of segmentation on cognitive load and learning outcomes}

Effects of segmentation have mainly been studied in research on dynamic visualizations, where segmentation refers to presenting an animation or video not as a continuous stream of information but divided into meaningful pieces. Segmentation has been proposed as a means to improve the effectiveness of dynamic visualizations (e.g., Ayres \& Paas, 2007b; Mayer \& Moreno, 2003; Moreno \& Mayer, 2007; Wouters, Paas \& Van Merriënboer, 2008). A number of studies indeed found positive effects of segmentation of dynamic visualisations (e.g., Hasler, Kersten, \& Sweller, 2007; Mayer \& Chandler, 2001; Moreno, 2007; Spanjers, Wouters, Van Gog, \& Van Merriënboer, 2011). For example, Mayer and Chandler (2001) found that students were better able to solve transfer questions (i.e., questions measuring understanding of the material rather than reproduction) after having seen a segmented animation than a non-segmented animation. And a recent study with animated worked examples (animations demonstrating and explaining how to solve a problem) on probability calculation has shown that for low prior knowledge learners, segmentation may reduce cognitive load (as measured by mental effort investment, see Paas, 1992), leading to higher efficiency of learning processes (for a discussion of efficiency, see Hoffman \& Schraw, 2010; Paas \& Van Merriënboer, 1993; Van Gog \& Paas, 2008): The same level of test performance was reached by low prior knowledge learners with less investment of mental effort in studying the animations (Spanjers et al., 2011).

Two explanations have been offered for the beneficial effects of segmentation of dynamic visualizations on cognitive load and learning outcomes (Spanjers, Van Gog, \& Van Merriënboer, 2010). First, in the studies on segmentation conducted so far, segmentation was associated with pauses between segments. The information in dynamic visualisations is often transient, that is, presented information quickly disappears and is continuously replaced by new information. To deal with this transience learners have to perform cognitive activities imposing extraneous cognitive load (Leahy \& Sweller, 2011), that is they have to maintain information in working memory to link it to later presented information while simultaneously processing new information (e.g., Ayres \& Paas, 2007a; 
Lowe, 1999; Mayer \& Moreno, 2003). When the dynamic visualisation has a complex content (i.e., causes a high intrinsic cognitive load), the consequence of this extraneous cognitive load may be that learners are not able to perform all the necessary cognitive processes, and information is lost before it can be integrated with other information and prior knowledge (Mayer \& Moreno, 2003). Consequently, the transience of dynamic visualizations may hinder learning, especially when the content of the dynamic visualizations is complex (Ayres \& Paas, 2007a; Leahy \& Sweller, 2011). Thus, the pauses between segments may have caused the beneficial effects on cognitive load and learning outcomes because they give students time to perform the cognitive activities needed for learning on smaller units of information, without having to simultaneously attend to the next unit of information (e.g., Mayer \& Moreno, 2003; Moreno, 2007; Moreno \& Mayer, 2007).

Secondly, segmentation breaks dynamic visualizations down into meaningful pieces. People mentally divide events or procedures described in text or shown in dynamic visualisations into pieces (e.g., Kurby \& Zacks, 2008; Zacks, Speer \& Reynolds, 2009; Zacks, Speer, Swallow, Braver \& Reynolds, 2007), and this influences the way in which they remember the information (see Kurby \& Zacks, 2008; Zacks et al., 2007). Providing learners with instructional material that is already divided into pieces may reduce cognitive load, since the segments provide a cue, so learners do not have to search for the boundaries between pieces themselves (cf., Schwan, Garsoffky, \& Hesse, 2000; see also Wouters et al., 2008). This reduction in cognitive load may lead to an increase in learning outcomes.

Although transience is a factor hindering learning from complex dynamic visualisations (Ayres \& Paas, 2007a; Leahy \& Sweller, 2011), transience does not play a role in 'traditional' written instructional material and worked examples. Yet, studies by Catrambone (1995) and Florax and Ploetzner (2010) suggest that segmentation can also be applied to written text and written worked examples. Florax and Ploetzner (2010) examined whether the split-attention effect in learning from text and pictures is a result of physical integration (i.e., reduction in spatial distance) or of the usually associated labelling of the picture and segmentation of the text to accomplish such physical integration. They found a significant effect on learning outcomes only of segmentation. Catrambone (1995) showed that making subgoals explicit in worked examples by visually isolating a move in the solution procedure (through placing it on a separate line) fostered learning. These findings support the 'cueing' explanation for the effectiveness of segmentation provided by Spanjers et al. (2010). According to Catrambone's subgoal learning model $(1996,1998)$, a cue as to which information elements belong together stimulates learners to group those elements and may induce learners to self-explain why they belong together, which fosters learning. Both of these studies did not measure effects of segmentation of worked examples or text on cognitive load, however.

\section{This study}

As discussed before, Spanjers et al. (2011) found that studying segmented animated worked examples led to equal learning outcomes with lower investment of effort. The current study will use written worked examples consisting of the same texts as used in the animations by Spanjers et al. (though in written rather than spoken form) to investigate 
whether cueing indeed contributed to this finding. Though it is plausible that learners pause shortly at the end of a segment, written worked examples are not transient and pauses can be made at any time during reading; hence, the 'pausing explanation' would be an unlikely explanation for finding positive results, and positive effects of segmentation in this study would provide evidence for the plausibility of the 'cueing explanation' of the segmentation effect.

In addition, it will be investigated whether instructing students to actively segment the written examples (i.e., dividing the examples in pieces themselves) while studying the material improves their learning outcomes. On the one hand, interactivity has been proposed as a means to stimulate learners to more actively process examples (Atkinson \& Renkl, 2007). Instructing learners to actively segment instructional material may focus their attention on subgoals, just like segmented examples do. It may also encourage learners to process the examples even more deeply because they have to decide for themselves which information elements belong together. This may increase cognitive load during learning but support learning as well if the additional load is associated with activities that directly contribute to learning (i.e., germane load; Sweller et al., 1998; Van Merriënboer \& Sweller, 2005). On the other hand, positive effects of interactivity are only found when the interactivity evokes the right kind of cognitive activities, that is activities which contribute to understanding (Moreno \& Mayer, 2007). Especially for low prior knowledge learners, the instruction to actively segment may be an additional task that requires cognitive capacity but distracts from learning (i.e., extraneous load; Sweller et al., 1998; cf. Schwan et al., 2000).

In sum, this study investigates whether the effects of segmentation on efficiency of learning found by Spanjers et al. (2011) can be replicated with written worked examples, and whether actively segmenting written examples will foster or hamper learning outcomes, invested mental effort, and their combination. The learning outcomes and mental effort were combined by calculating efficiency with the formula developed by Paas and Van Merriënboer (1993). However, in line with the analyses in Spanjers et al. (2011), we calculated efficiency with test performance and mental effort invested during studying the examples (i.e., efficiency in terms of learning process, where a high efficiency denotes equal/low investment of effort during learning combined with high/equal performance on the test) rather than with test performance and mental effort during solving the posttest items (i.e., efficiency in terms of learning outcomes, where a high efficiency denotes equal/low investment of effort during solving the posttest items combined with high/equal performance on the test; see Van Gog \& Paas, 2008).

\section{Method}

\section{Participants and design}

Fifty-two Dutch students in their third year of pre-university education (i.e., the highest level of secondary education in the Netherlands with a six year duration) participated in this study $(52 \%$ female; mean age 14.62 years, $S D=0.66)$. They were randomly assigned to one of three conditions: studying non-segmented worked examples $(n=18)$, studying 
segmented worked examples $(n=17)$, or actively segmenting worked examples while studying them $(n=17)$.

\section{Materials}

Worked examples. The four worked examples on probability calculation consisted of written text describing the solution moves to be taken in solving four different types of probability calculation problems. The four types of problems differed on two factors that are important for probability calculation: relevance of order and replacement after drawing. (cf. Opfermann, 2008; Spanjers et al., 2011; Wouters, Paas, \& Van Merriënboer, 2009; 2010). The text of the written examples was the same as the spoken text in the animated worked examples with mountain bike cover stories used by Spanjers et al. (2011; see also Wouters, Paas, \& Van Merriënboer, 2009; 2010). To encourage students to focus on relevant (instead of irrelevant) differences between the problem types, a similar cover story (i.e., about helmets distributed on a two-day mountain bike trip) was used in each worked example. An example of one of the problems presented in the worked examples is: 'Together with your friend, you go on a two-day mountain bike trip. Each day the instructor brings five helmets, which each have a different color: blue, green, yellow, red and silver. The helmets are distributed randomly and are given back to the instructor at the end of the day. On both days you get a helmet first and your friend second. What is the probability that on the first day, you will get the blue helmet and your friend will get the green helmet?'

Two methods for solving probability calculation problems are the method of counting and the method of individual events. The method of counting was demonstrated in the worked examples with a cover story implying that order was relevant. This method consists of determining both the number of possible outcomes and the number of correct outcomes. For example, if one wants to calculate the probability of getting a blue helmet out of five helmets on the first day of a mountain bike trip and a green helmet on the second day, one calculates that there are $5^{2}=25$ possible outcomes and determines that only one of those outcomes is correct. Therefore, the probability is $1 / 25$ that one gets a blue helmet out of five helmets on the first day of a mountain bike trip and a green one on the second day. The method of individual events was demonstrated in examples with cover stories implying that order was irrelevant. This method involves determining the probability of each of the individual events involved in the problem and multiplying those probabilities in order to calculate the probability for the complex event specified in the cover story. For example, if one wants to calculate the probability of obtaining the blue and the green helmet out of five helmets during a two day mountain bike trip (regardless of which helmet is obtained on which day), one determines that the probability for the first event is $2 / 5$ and for the second event $1 / 5$. Consequently, the probability of obtaining a blue and a green helmet during a two-day mountain bike trip is $2 / 5 * 1 / 5=2 / 25$.

In the segmented condition, blank lines were inserted to visually isolate the different segments in the examples. The segments were identical to the segments of four of the animated worked examples used in the study by Spanjers et al. (2011). The first segment presented the cover story including the problem statement; the second segment was about relevance of order, and the third segment about drawing with or without 
replacement. When the method of counting was demonstrated, the number of possible outcomes was calculated in the fourth segment. In the fifth segment the probability was determined based on this number of possible outcomes and the number of correct outcomes. When the method of individual events was demonstrated, the probability of the first individual event was determined in the fourth segment and the probability of the second individual event was determined in the fifth segment. In the sixth segment, the probabilities were multiplied to determine the probability for the complex event.

Pretest and posttest. The pretest and posttest were isomorphic, that is, they contained items with the same structural features, but different cover stories. They consisted of four multiple choice items and four open questions on probability calculation (cf. Gerjets, Scheiter, Opfermann, Hesse \& Eysink, 2009; Opfermann, 2008). An example of a multiple choice item is: 'You have an opaque bag with rummikub stones from which you select 3 stones. You want to get a red seven, orange eight, and black nine in this specific order. Does it matter whether you put back the selected stone before selecting a new stone or not?' The open questions consisted of problems with the same structural features, but cover stories that were different from the problems solved in the worked examples. An example of an open question is: 'If you shop for 10 euro at the supermarket, you obtain a key ring for free. It is decided randomly which key ring you will get. You like two of the six key rings. You shop two times for 10 euro. What is the probability that you get both key rings you like?'

Mental effort rating scale. To measure mental effort invested in studying the examples and in solving the posttest items, the nine-point rating scale developed by Paas (1992) was used, which ranges from (1) very, very low mental effort to (9) very, very high mental effort.

\section{Procedure}

This study was run at the students' school in classroom sessions, with students in each classroom being randomly assigned to one of the three conditions. Students first completed the pretest. Subsequently, they read a one-page introduction containing some information they needed for understanding the examples as well as the instructions concerning their specific condition. Students in the non-segmented and segmented condition were instructed to study the worked examples, and students in the actively segmenting condition were instructed to divide the non-segmented worked examples in minimally three and maximally nine non-overlapping and consecutive segments by placing markers at the boundaries during studying. After reading the introduction, participants studied the four worked examples and then completed the posttest. During the pretest and the posttest students were allowed to use a calculator and received a page of A4 paper that had the equations needed for solving the problems printed on it (this did not provide students with any clues as to when to use which equation). They were instructed to write out their problem solution for the open questions. Immediately after each example and after each posttest item, students rated the mental effort they invested in studying that example or solving that item. After the posttest they were debriefed and thanked for their participation. 


\section{Scoring}

Students' answers to the multiple choice items were scored by assigning one point for a correct answer, and their answers to the open questions were scored by assigning one point for use of the correct formula and one point for providing the correct answer. In scoring the formula both determining the number of possible and correct outcomes and multiplying the probabilities for the individual events involved were considered correct for each open question regardless of the type of problem involved. The maximum score on both the pretest and posttest was 12 points.

\section{Results}

Means and standard deviations of performance, mental effort and efficiency data are provided in Table 4.1. To report the effect sizes of the analyses $\eta_{\mathrm{p}}{ }^{2}$ is used. Values of .01, .06 , en.14 are respectively a small, moderate and large effect size.

Table 4.1

Descriptive Statistics for Pretest and Posttest Performance and Mental Effort During Example Study and Posttest per Condition

\begin{tabular}{lllllll}
\hline & \multicolumn{2}{c}{$\begin{array}{c}\text { Non- } \\
\text { segmented }\end{array}$} & & Segmented & \multicolumn{2}{c}{$\begin{array}{c}\text { Actively } \\
\text { segmenting }\end{array}$} \\
\cline { 2 - 8 } & $M$ & $S D$ & $M$ & $S D$ & $M$ & $S D$ \\
\hline Pretest performance (0-12) & 4.11 & 1.41 & 5.06 & 1.64 & 4.18 & 1.51 \\
Posttest performance (0-12) & 5.50 & 2.31 & 6.18 & 2.88 & 5.29 & 2.66 \\
Mental effort during example study (1-9) & 4.33 & 1.85 & 3.22 & 1.59 & 5.67 & 1.69 \\
Mental effort during the posttest (1-9) & 4.08 & 1.71 & 3.62 & 1.81 & 4.93 & 1.42 \\
Efficiency & -0.02 & 0.96 & 0.57 & 1.15 & -0.55 & 0.98 \\
\hline
\end{tabular}

\section{Performance increase}

A repeated measures ANOVA with scores on the pretest and the posttest as within-subjects variables and condition as a between-subjects variable showed a significant increase in scores from the pretest to the posttest, $F(1,49)=12.56, p=.001, \eta_{p}{ }^{2}=.204$, so on average students in all conditions learned from the examples. However, no significant differences were found between the three conditions, $F(2,49)<1$.

\section{Mental effort}

With regard to mental effort invested during example study, an ANOVA showed significant differences between conditions, $F(2,49)=8.68, p=.001, \eta_{p}{ }^{2}=.262$. Post-hoc analyses showed that in line with our hypothesis, the students in the actively segmenting condition invested significantly more mental effort in studying the examples than the students in the non-segmented condition $(p=.03)$ and the segmented condition $(p=.00)$. Also in line with our expectation, students in the segmented condition invested less mental effort in studying the examples than the students in the non-segmented condition, although this effect was only marginally significant $(p=.06)$.

Additionally, marginally significant differences were found with regard to mental effort invested in the posttest, $F(2,49)=2.73, p=.08, \eta_{p}{ }^{2}=.100$. Post-hoc analyses 
showed that the students in the actively segmenting condition invested more mental effort in solving the posttest items than the students in the segmented condition $(p=.03)$.

\section{Efficiency}

Furthermore, the conditions differed significantly with regard to efficiency, $F(2,49)=5.05$, $p=.01, \eta_{p}{ }^{2}=.171$. In line with the previous findings, learning was found to be more efficient for the students in the segmented worked examples condition than in the actively segmenting condition $(p=.003)$. Additionally, a marginally significant difference in favor of the segmented condition was found when compared to the non-segmented condition ( $p$ $=.10)$.

\section{Discussion}

This study had two aims. First, it was investigated whether the cueing explanation for the effectiveness of segmentation (see Spanjers et al., 2010) may explain why studying segmented animated worked examples leads to equal learning outcomes with less mental effort investment than studying continuous examples, as found by Spanjers et al. (2011). To study this, we used segmented and non-segmented written examples with the same text as the animated examples of Spanjers et al. The previous findings were replicated: studying worked examples in a segmented format decreased the mental effort required during learning without lowering performance on the test administered after study. This suggests that learning from segmented worked examples is more efficient than learning from nonsegmented examples, and indeed a marginally significant difference was found on the measure of efficiency. It provides further evidence that segmenting is not only effective for animated materials but also for static written learning materials (Catrambone, 1995; Florax \& Ploetzner, 2010). Though it is possible that learners paused shortly at the end of each segment, the examples were not transient and they could have paused at any time, making it unlikely that the pausing explanation (i.e., giving the learners additional time to perform necessary cognitive processes) can completely explain the findings. The positive effects of segmentation on mental effort seem to lend support to the cueing explanation, that is, the segments help learners to group information elements that belong together.

However, it should be noted that this does not necessarily imply that the pauses typically used in segmenting dynamic visualisations play no role at all in explaining the beneficial effects of segmentation. First of all, the two explanations for the effectiveness of segmentation in dynamic visualizations are not mutually exclusive (Spanjers et al., 2010), and - as mentioned above - we cannot rule out that the learners paused shortly when they came across the blank lines in the segmented examples in this study. The current study only found evidence for the cueing explanation of the segmentation effect, but future research should further disentangle the cognitive processes involved in cueing and pausing. To test their plausibility, the effects of inserting pauses in dynamic visualizations could be compared with the effects of inserting other cues which segment the dynamic visualisations without providing learners with additional time for processing. Alternatively, the plausibility of the two processes can be investigated by comparing the effects of pauses 
segmenting dynamic visualisations in meaningful segments with the effects of pauses segmenting them in random segments.

The second aim of this study was to investigate whether increased interactivity by instructing students to actively segment examples during study would hamper or enhance efficiency of learning. The results showed that active segmenting increased the mental effort invested in example study without positively influencing performance. Furthermore, students studying worked examples in a segmented format had to invest less mental effort during the posttest to achieve the same level of test performance than students who were instructed to actively segment the examples while studying them. Students studying worked examples in a segmented format, therefore, had a more efficient learning process than the students who were instructed to actively segment the examples while studying them. Thus, the results of this study suggest that actively segmenting as a form of interactivity is not efficient, at least for low prior knowledge learners like the students in this study. In a way, this is not surprising: students in the actively segmenting condition not only had to study the worked examples, just as the students in the other conditions, but they also had to indicate the end of segments. These two processes may have competed for cognitive resources, which may have had a negative effect on the process of learning from the worked examples (cf. Schwan et al., 2000). So, it appeared that actively segmenting was an additional task hindering learning by imposing extraneous cognitive load rather than a form of interactivity imposing germane cognitive load.

The finding that actively interacting with the instructional material does not improve learning compared to being provided with manipulated material is in agreement with the findings of Schwamborn, Thillmann, Opfermann, and Leutner (2011). They found that presenting text and pictures was associated with the investment of less mental effort and the need to generate pictures with the investment of more mental effort. Additionally, they found more positive effects on learning outcomes from providing pictures than from having them generated by the learners.

Based on these studies it can be concluded that interacting with learning material does not always positively affect learning, at least for low prior knowledge learners. Some factors influencing the effects of interactivity are mentioned in the literature. As shown by this study and also the study of Schwamborn et al. (2011), interacting with learning materials may increase the cognitive load imposed on the learner. To find positive effects on learning outcomes, the learner should not be cognitively overloaded in interactive learning environments (Moreno \& Mayer, 2007). Additionally, to find positive effects of interactivity, it should not only lead to behavioural activity, but should also stimulate learners to process the instructional materials more deeply (Moreno \& Mayer, 2007; Wouters, Tabbers, \& Paas, 2007). Moreover, this deep processing should be focused on the core of the learning material, and not on other parts of the learning material (Atkinson \& Renkl, 2007). Based on a review of studies investigating the effects of generating pictures during studying text, Schwamborn et al. (2011) argued that students need to be supported to profit from generation activities. A similar idea is proposed by Moreno and Mayer (2007), who state that guided interactivity in which students interact with a pedagogical agent who prompts them to actively engage in processing the material is better than unguided discovery learning. The given support or guidance should optimize the cognitive 
load provided by the interactivity, or in other words should decrease extraneous cognitive load to avoid cognitive overload and should increase germane cognitive load imposed by deeper processing of the core of the learning material (Moreno \& Mayer, 2007; Schwamborn et al., 2011; Van Merriënboer \& Kirschner, 2007). Future research should examine for other types of interactivity whether they are effective, and which types of support are needed with those types of interactivity to be effective.

Another interesting topic for future research is the influence of prior knowledge on the effects of segmentation. Spanjers et al. (2011) found that segmented animated worked examples were more efficient than continuous ones for students with lower levels of prior knowledge but not for students with higher levels of prior knowledge. This suggests that once students have sufficient prior knowledge, segmentation does no longer have a positive effect on efficiency. Research on the expertise reversal effect has indeed shown that once students have acquired some knowledge of a task, they become less dependent on instructional guidance and such guidance might sometimes even hamper learning (Kalyuga, 2007; Kalyuga, et al., 2003). However, it may be that once learners have acquired more knowledge, active segmenting becomes more effective. Because the load imposed by the learning task is lower for advanced learners (see Sweller et al., 1998), they may have the cognitive capacity available to engage in actively segmenting and to learn from interacting in this way with the instructional materials. Future research could examine whether an expertise reversal effect also occurs with actively segmenting instructional material.

In conclusion, this study contributes to our knowledge of effects of different example design and delivery techniques, by showing that presenting learners with worked examples in a segmented format increases the efficiency of the process of learning, while instructing them to actively segment examples decreases the efficiency of their learning process. Designers of instructional material for low prior knowledge learners could take these findings into account by presenting worked examples in a segmented format. Furthermore, they should not include interactivity consisting of asking students to actively segment worked examples themselves.

\section{References}

Atkinson, R. K., Derry, S. J., Renkl, A., \& Wortham, D. (2000). Learning from examples: Instructional principles from the worked examples research. Review of Educational Research, 70, 181-214.

Atkinson, R. K., \& Renkl, A. (2007). Using interactive example-based learning environments: Using interactive elements to encourage effective processing of worked examples. Educational Psychology Review, 19, 375-386.

Atkinson, R. K., Renkl, A., \& Merrill, M. M. (2003). Transitioning from studying examples to solving problems: Effects of self-explanation prompts and fading worked-out steps. Journal of Educational Psychology, 95, 774-783.

Ayres, P., \& Paas, F. (2007a). Making instructional animations more effective: A cognitive load approach. Applied Cognitive Psychology, 21, 695-700.

Ayres, P., \& Paas, F. (2007b). Can the cognitive load approach make instructional animations more effective? Applied Cognitive Psychology, 21, 811-820. 
Catrambone, R. (1995). Aiding subgoal learning: Effects on transfer. Journal of Educational Psychology, 87, 5-17.

Catrambone, R. (1996). Generalizing solution procedures learned from examples. Journal of Experimental Psychology: Learning, Memory, and Cognition, 22, 1020-1031.

Catrambone, R. (1998). The subgoal learning model: Creating better examples so that students can solve novel problems. Journal of Experimental Psychology: General, 127, 335-376.

Chandler, P., \& Sweller, J. (1991). Cognitive load theory and the format of instruction. Cognition and Instruction, 8, 293-332.

Cooper, \& Sweller, J. (1987). Effects of schema acquisition and rule automation on mathematical problem-solving transfer. Journal of Educational Psychology, 79, 347-362.

Florax, M., \& Ploetzner, R. (2010). What contributes to the split-attention effect? The role of text segmentation, picture labeling, and spatial proximity. Learning and Instruction, 20, 216224.

Gerjets, P., Scheiter, K., Opfermann, M., Hesse, F. W., \& Eysink, T. H. S. (2009). Learning with hypermedia: The influence of representational formats and different levels of learner control on performance and learning behavior. Computers in Human Behavior, 25, 360370 .

Hasler, B. S., Kersten, B., \& Sweller, J. (2007). Learner control, cognitive load and instructional animation. Applied Cognitive Psychology, 21, 713-729.

Hoffman, B., \& Schraw, G. (2010). Conceptions of efficiency: Applications in learning and problem solving. Educational Psychologist, 45, 1-14

Kalyuga, S. (2007). Expertise reversal effect and its implications for learner-tailored instruction. Educational Psychology Review, 19, 509-539.

Kalyuga, S., Ayres, P., Chandler, P., \& Sweller, J. (2003). The expertise reversal effect. Educational Psychologist, 38, 23-31.

Kaluyga, S., Chandler, P., Tuovinen, \& Sweller, J. (2001). When problem solving is superior to studying worked examples. Journal of Educational Psychology, 93, 579-588.

Kurby, C. A., \& Zacks, J. M. (2008). Segmentation in the perception and memory of events. Trends in Cognitive Sciences, 12, 72-79.

Leahy, W., \& Sweller, J. (2011). Cognitive load theory, modality of presentation and the transient information effect. Applied Cognitive Psychology, 25, 943-951.

Lovett, M. C. (1992). Learning by problem solving versus by examples: The benefits of generating and receiving information. In Proceedings of the $14^{\text {th }}$ Annual Conference of the Cognitive Science Society (pp. 956-961). Hillsdale, NJ: Erlbaum.

Lowe, R. K. (1999). Extracting information from an animation during complex visual learning. European Journal of Psychology of Education, 14, 225-244.

Mayer, R. E., \& Chandler, P. (2001). When learning is just a click away: Does simple user interaction foster deeper understanding of multimedia messages? Journal of Educational Psychology, 93, 390-397.

Mayer, R. E., \& Moreno, R. (2003). Nine ways to reduce cognitive load in multimedia learning. Educational Psychologist, 38, 43-52.

McLaren, B. M., Lim, S., \& Koedinger, K. R. (2008). When and how often should worked examples be given to students? New results and a summary of the current state of research. In B. C. Love, K. McRae, \& V. M. Sloutsky (Eds.), Proceedings of the 30th Annual Conference of the Cognitive Science Society (pp. 2176-2181). Austin, TX: Cognitive Science Society. 
Moreno, R. (2007). Optimising learning from animations by minimising cognitive load: Cognitive and affective consequences of signalling and segmentation methods. Applied Cognitive Psychology, 21, 765-781.

Moreno, R., \& Mayer, R. (2007). Interactive multimodal learning environments. Educational Psychology Review, 19, 309-326.

Opfermann, M. (2008). There's more to it than instructional design: The role of individual learner characteristics for hypermedia learning. Berlin: Logos.

Paas, F. (1992). Training strategies for attaining transfer of problem-solving skill in statistics: A cognitive-load approach. Journal of Educational Psychology, 84, 429-434.

Paas, F., \& Van Gog, T. (2006). Optimising worked example instruction: Different ways to increase germane cognitive load. Learning and Instruction, 16, 87-91.

Paas, F., \& Van Merriënboer, J. J. G. (1993). The efficiency of instructional conditions: An approach to combine mental effort and performance measures. Human Factors, 35, 737743.

Paas, F., \& Van Merriënboer, J. J. G. (1994). Variability of worked examples and transfer of geometrical problem-solving skills: A cognitive-load approach. Journal of Educational Psychology, 86, 122-133.

Schwamborn, A., Thillman, H., Opfermann, M., \& Leutner, D. (2011). Cognitive load and instructionally supported learning with provided and learner-generated visualizations. Computers in Human Behavior, 27, 89-93.

Schwan, S., Garsoffky, B., \& Hesse, F. W. (2000). Do film cuts facilitate the perceptual and cognitive organization of activity sequences? Memory \& Cognition, 28, 214-223.

Schwonke, R., Renkl, A., Krieg, C., Wittwer, J., Aleven, V., \& Salden, R. (2009). The workedexample effect: Not an artefact of lousy control conditions. Computers in Human Behavior, $25,258-266$.

Spanjers, I. A. E., Van Gog, T., \& Van Merriënboer, J. J. G. (2010). A theoretical analysis of how segmentation of dynamic visualizations optimizes students' learning. Educational Psychology Review.

Spanjers, I. A. E., Wouters, P., Van Gog, T., \& Van Merriënboer, J. J. G. (2011). An expertise reversal effect of segmentation in learning from animations. Computers in Human Behavior, 27, 46-52.

Sweller, J. (1988). Cognitive load during problem solving: Effects on learning. Cognitive Science, $12,2567-285$.

Sweller, J. (2006). The worked example effect and human cognition. Learning and Instruction, 16, 165-169.

Sweller, J., \& Cooper, G. A. (1985). The use of worked examples as a substitute for problem solving in learning algebra. Cognition and Instruction, 2, 59-89.

Sweller, J., Van Merriënboer, J. J. G., \& Paas, F. (1998). Cognitive architecture and instructional design. Educational Psychology Review, 10, 251-296.

Tarmizi, R., \& Sweller, J. (1988). Guidance during mathematical problem solving. Journal of Educational Psychology, 80, 424-436.

Van Gog, T. \& Paas, F. (2008). Instructional efficiency: Revisiting the original construct in educational research. Educational Psychologist, 43, 16-26.

Van Gog, T., Paas, F., \& Van Merriënboer, J. J. G. (2006). Effects of process-oriented worked examples on troubleshooting transfer performance. Learning and Instruction, 16, 154-164.

Van Gog, T., Paas, F., \& Van Merriënboer, J. J. G. (2008). Effects of studying sequences of process-oriented and product-oriented worked examples on troubleshooting transfer efficiency. Learning and Instruction, 18, 211-222. 
Van Gog, T., \& Rummel, N. (2010). Example-based learning: Integrating cognitive and socialcognitive research perspectives. Educational Psychology Review, 22, 155-174.

Van Merriënboer, J. J. G. (1990). Strategies for programming instruction in high school: Program completion vs. program generation. Journal of Educational Computing Research, 6, 265285.

Van Merriënboer, J. J. G., \& De Croock, M. B. M. (1992). Strategies for computer-based programming instruction: Program completion vs. program generation. Journal of Educational Computing Research, 8, 365-394.

Van Merriënboer, J. J. G., \& Kirschner, P. A. (2007). Ten steps to complex learning: A systematic approach to four-component instructional design. Mahwah, NJ: Erlbaum / Taylor and Francis.

Van Merriënboer, J. J. G., \& Sweller, J. (2005). Cognitive load theory and complex learning: Recent developments and future directions. Educational Psychology Review, 17, 147-177.

Wouters, P., Paas, F., \& Van Merriënboer, J. J. G. (2008). How to optimize learning from animated models: A review of guidelines based on cognitive load. Review of Educational Research, $78,645-675$.

Wouters, P., Paas, F., \& Van Merriënboer, J. J. G. (2009). Observational learning from animated models: Effects of modality and reflection on transfer. Contemporary Educational Psychology, 34, 1-8.

Wouters, P., Paas, F., \& Van Merriënboer, J. J. G. (2010). Observational learning from animated models: Effects of studying-practicing alternation and illusion of control on transfer. Instructional Science, 38, 89-104.

Wouters, P., Tabbers, H. K., \& Paas, F. (2007). Interactivity in video-based models. Educational Psychology Review, 19, 327-342.

Zacks, J. M., Speer, N. K., Reynolds, J. R. (2009). Segmentation in reading and film comprehension. Journal of Experimental Psychology: General, 13, 307-327.

Zacks, J. M., Speer, N. K., Swallow, K. M., Braver, T. S., \& Reynolds, J. R. (2007). Event perception: A mind-brain perspective. Psychological Bulletin, 133, 273-293.

Zhu, X. \& Simon, H. A. (1987). Learning mathematics from examples and by doing. Cognition and Instruction, 4, 137-166. 


\title{
Chapter 5
}

\section{Explaining the segmentation effect in learning from animations: The role of pausing and temporal cueing ${ }^{5}$}

\begin{abstract}
Segmentation of animations, that is presenting them in pieces rather than as a continuous stream of information, has been shown to have a beneficial effect on cognitive load and learning for novices. Two different explanations of this segmentation effect have been proposed. Firstly, pauses are usually inserted between the segments, which may give learners extra time to perform necessary cognitive processes. Secondly, because segmentation divides animations into meaningful pieces, it provides a form of temporal cueing which may support learners in perceiving the underlying structure of the process or procedure depicted in the animation. This study investigates which of these explanations is the most plausible. Secondary education students $(N=161)$ studied animations on probability calculation, after having been randomly assigned to one of four conditions: non-segmented animations, animations segmented by pauses only, animations segmented by temporarily darkening the screen only, and animations segmented by both pauses and temporarily darkening the screen. The results suggest that both pauses and cues play a role in the segmentation effect, but in a different way.
\end{abstract}

Dynamic visualizations, such as animations, are increasingly used in instructional materials, for example to illustrate natural processes (e.g., Lin \& Atkinson, 2011), biological processes (e.g., De Koning, Tabbers, Rikers, \& Paas, 2010), mechanical processes (e.g., Boucheix \& Lowe, 2010), and problem-solving procedures (e.g., Van Gog, 2011). However, research has shown that students do not always learn more from animations than from series of static pictures (e.g., Mayer, Hegarty, Mayer, \& Campbell, 2005; Tversky, Morisson, \& Betrancourt, 2002) - with the exception of animations showing human movement procedures (Höffler \& Leutner, 2007; Van Gog, Paas, Marcus, Ayres, \& Sweller, 2009).

It has been proposed that this is a consequence of the cognitive activities required for effectively learning from animations. Learners' working memory is limited in capacity and duration (Baddeley, 2003; Barrouillet \& Camos, 2007). According to cognitive load theory (Sweller, Van Merriënboer, \& Paas, 1998), the limitations of working memory should be taken into account in the design of instructional material in order for this material to be effective for learning. Animations are often transient, which imposes high cognitive load on working memory, because the transience of the information presented in animations requires learners to perform cognitive activities which they would not have to perform with static instructional material (cf., Leahy \& Sweller, 2011). As a consequence

\footnotetext{
${ }^{5}$ This Chapter was published as

Spanjers, I. A. E., Van Gog, T., Wouters, P., \& Van Merriënboer, J. J. G. (2012). Explaining the segmentation effect in learning from animations: The role of pausing and temporal cueing. Computers \& Education, 59, 274-280.
} 
of transience, information presented at one moment needs to be maintained in working memory for the learner to be able to integrate it with information presented later (Lowe, 1999). Moreover, while maintaining previously presented information, new information keeps streaming which needs to be processed simultaneously (e.g., Ayres \& Paas, 2007). As a result, the total cognitive load imposed by complex animations may be so high that maintaining and processing information needed for learning cannot be adequately coped with in working memory, and learning is hindered.

Several design measures have been proposed to reduce cognitive load and enhance learning from complex animations. One of them is segmentation, which involves showing animations in pieces rather than as a continuous stream of information (for a review see Spanjers, Van Gog, \& Van Merriënboer, 2010). Two alternative, though perhaps not mutually exclusive, processes have been proposed to underlie the beneficial effects of segmentation (Spanjers et al., 2010): pauses between segments give learners extra time to perform necessary cognitive processes (e.g., Mayer \& Moreno, 2003) and by dividing the animation into meaningful pieces, segmentation supports learners in perceiving the underlying structure of the presented information (Boltz, 1992). The present study experimentally investigates which of these two processes provides the most likely explanation of the segmentation effect.

\section{The effects of segmentation on learning outcomes and cognitive load}

A number of studies have found positive results of segmentation of animations on learning outcomes and cognitive load for novice learners (e.g., Hasler, Kersten \& Sweller, 2007; Mayer \& Chandler, 2001; Moreno, 2007; Spanjers, Wouters, Van Gog, \& Van Merriënboer, 2011). For example, Mayer and Chandler (2001; Experiment 2) found that college students who studied a segmented animation on lightning formation twice, achieved higher scores on a problem-solving transfer test than learners who saw the same animation twice in a non-segmented format. Hasler et al. (2007) had primary school children study instructional material on the determinants of night and day for ten minutes in one of four conditions: (a) a narrated non-segmented animation, (b) a narrated segmented animation, (c) a narrated animation which could be paused by the learner, or (d) the narration of the animation without visual information, segmentation, or a pausing option. They found that children who studied the segmented animation or the animation with the pausing option performed better on the more difficult posttest items than learners in the other two conditions.

In the segmented animations used in the studies by Mayer and Chandler (2001) and Hasler et al. (2007), learners had to click a button after each segment to start the next one. Including learner-control gives learners the possibility to decide when they want to start with the next segment. Furthermore, it may involve learners more actively in the learning process (Wouters, Tabbers, \& Paas, 2007). So, the learner-control implemented in combination with segmentation in these studies might have contributed to the positive effects of segmentation found. Spanjers et al. (2011) studied effects of segmentation on cognitive load and learning without giving participants any control over the animations and still found beneficial effects of segmentation. Secondary education students studied either non-segmented animations on probability calculation or animations that were segmented 
through pauses of 2 seconds, after which the animations continued automatically. During the pauses the screen was slightly darkened. A beneficial effect of segmentation on cognitive load was found for students with low prior knowledge: those studying segmented animations had to invest less mental effort than those studying non-segmented animations in order to reach the same level of posttest performance. So, positive effects of segmentation can be found without learner-control as well.

\section{Possible explanations for the effects of segmentation}

Note that the abovementioned studies reporting positive effects of segmentation differed in whether or not learner-control was present, but all of them involved pausing between the segments. The question is then, whether pausing is critical for a segmentation effect to arise. Spanjers et al. (2010) proposed that there may be two different, though perhaps not mutually exclusive, processes underlying the segmentation effect. Firstly, pausing may be crucial as it reduces the negative effects of transience by giving learners additional time to perform necessary cognitive processing and maintaining activities on the information (e.g., Mayer \& Moreno, 2003), which could enhance learning and reduce cognitive load. According to Barrouillet and Camos (2007) learners execute different cognitive processing and maintaining activities in working memory by sharing attention between these processes in a time-based way. Attention can be given to only one of these processes at a time. To be able to maintain information, learners have to give attention to that information. Similarly, learners need to give attention to processing new information. They do so by quickly and repeatedly switching their attention back and forth between these different cognitive activities. How much of the time learners can give attention to maintaining information, depends on the amount of time they need to give attention to processing. Inserting pauses between segments essentially eliminates the need to attend to new incoming information during that time, allowing learners to devote their attention to maintaining the information shown in the segment for a sufficient amount of time to consolidate it. Without pauses, both maintaining and processing receive less attention, and important information may not be processed or consolidated, which negatively affects learning. Note that this pausing explanation for the segmentation effect is more specific than simply giving learners additional time for the task. According to this explanation, the additional time should be given before learners have forgotten the information. So simply giving learners additional time at the end would not facilitate learning according to this explanation.

Secondly, the beneficial effects of segmentation might not be due so much to pausing as to the fact that segmentation divides animations into meaningful units (cf. Arguel \& Jamet, 2009), which can be seen as a form of temporal cueing. Temporal cueing makes natural boundaries between events in a process or procedure more salient (e.g., Schwan, Garsoffky, \& Hesse, 2000). People naturally tend to identify boundaries between events during perception (Zacks, Speer, Swallow, Braver, \& Reynolds, 2007), and temporal cueing may support learners in this process by reducing the need to identify those boundaries themselves, which may lead to a reduction in cognitive load (cf. Schwan et al., 2000; see also Wouters, Paas \& Van Merriënboer, 2008), which may in turn enhance learning. Temporal cueing may also enhance learning by making learners more aware of 
the structure of the process or procedure in terms of meaningful events or units (Boltz, 1992; Catrambone, 1998; Florax \& Ploetzner, 2010).

In sum, the positive effects of segmentation on learning outcomes and cognitive load may either be due to pausing, temporal cueing, or a combination of both. Which of those explanations is most plausible, or whether it is their combined effect, cannot be determined based on previous research, as all previous studies involved pauses between segments.

\section{Present study}

The present study aimed to address the question which of the two proposed explanations for the effects of segmentation is the most plausible, using animations on probability calculation (cf. Spanjers et al., 2011). We examined this by investigating the effects of inserting pauses, temporarily darkening the screen slightly at the boundaries of segments, and both, on measures of learning outcomes and cognitive load. Cognitive load was investigated by measuring invested mental effort. Although in the end it are learning outcomes which matter in educational situations, indications that a particular design measure reduces invested mental effort without lowering performance provides some evidence that this design measure supports learning. Design measures that free up working memory resources, allow more resources to be devoted to cognitive processes facilitating learning.

It is hypothesized that when the beneficial effect of segmentation is due to pauses, learning outcomes would be higher, or mental effort invested in learning would be lower in the two conditions with pauses than in the two conditions without pauses. On the other hand, when the beneficial effect of segmentation is due to a temporal cueing effect, learning outcomes would be higher, or mental effort invested in learning would be lower in the two conditions with temporarily darkening of the screen than in the two conditions without temporarily darkening the screen.

\section{Method}

\section{Participants and design}

One hundred and seventy one Dutch students in their third year of secondary education volunteered to participate in this study. They were either in general secondary education (which has a total duration of 5 years and gives access to universities of applied sciences) or pre-university education (which has a total duration of 6 years and gives access to universities of applied sciences as well as academic universities). The students were novices as this study took place prior to probability calculation being taught, which was also indicated by their pretest scores. The pre-university education students can be assumed to have higher general abilities than the general secondary education students, and this was indeed reflected in their posttest scores and mental effort ratings. However, given that they were randomly assigned to conditions and the distribution of different school types over conditions did not differ, this is unlikely to have affected the results. Data from ten students ( 1 to 4 from each condition) who presumably did not pay attention to the 
animations given that they showed no learning at all or even negative difference scores were removed.

This left 161 participants, distributed as follows across one of the four conditions resulting from a 2 x 2 design with factors Pausing (Yes vs. No) and Temporal Cueing (Yes vs. No): studying non-segmented animations $(n=42)$, animations segmented by temporarily darkening the screen only $(n=41)$, animations segmented by pauses only $(n=$ 40 ), or animations segmented by a combination of pauses and temporarily darkening the screen $(n=38)$. In Table 5.1 demographic descriptive statistics for age, gender and school type are presented for each of the conditions.

Table 5.1

Descriptive Statistics for Age, Gender and School Type per Condition

\begin{tabular}{|c|c|c|c|c|c|c|c|c|c|c|c|c|}
\hline & \multicolumn{3}{|c|}{ Non-segmented } & \multicolumn{3}{|c|}{$\begin{array}{l}\text { Segmented } \\
\text { by temporarily } \\
\text { darkening only }\end{array}$} & \multicolumn{3}{|c|}{$\begin{array}{l}\text { Segmented } \\
\text { by pauses only }\end{array}$} & \multicolumn{3}{|c|}{$\begin{array}{l}\text { Segmented } \\
\text { by pauses and } \\
\text { temporarily } \\
\text { darkening }\end{array}$} \\
\hline & $n$ & $M$ & $S D$ & $n$ & $M$ & $S D$ & $n$ & $M$ & $S D$ & $n$ & $M$ & $S D$ \\
\hline Age & 42 & 14.81 & 0.55 & 41 & 14.73 & 0.45 & 40 & 14.77 & 0.42 & 38 & 14.84 & 0.55 \\
\hline Female & 22 & & & 24 & & & 19 & & & 17 & & \\
\hline Male & 20 & & & 17 & & & 21 & & & 21 & & \\
\hline $\begin{array}{l}\text { Pre-university } \\
\text { education }\end{array}$ & 28 & & & 33 & & & 31 & & & 29 & & \\
\hline $\begin{array}{l}\text { General secondary } \\
\text { education }\end{array}$ & 14 & & & 8 & & & 9 & & & 9 & & \\
\hline
\end{tabular}

\section{Materials}

Animations. A computer-based learning environment developed in Flash CS4 (Adobe, 2008) presented the four animations on probability calculation (see Figure 5.1) during the learning phase, preceded by a written introduction. This introduction contained basic information required for learning from the animations about probability calculation, and for students in the three segmented conditions, the introduction also contained condition-specific information. It was stated that the animations were divided into pieces, divided by very short pauses (pauses only condition), divided by very short pauses during which the screen was darkened (pauses + darkening), or divided by temporarily darkening of the screen (darkening only). The darkening only and control condition received additional time corresponding to the duration of the pauses at the end of each animation. They were informed that at the end the screen would be darkened for a short time. The experimental conditions are explained in more detail below. The text in the animations was narrated by a male voice. The four animations were part of a larger set originally developed and used by Wouters, Paas, and Van Merriënboer. (2009) and were adapted for this study. The animations demonstrated and explained how to solve probability calculation problems dealing with complex events (i.e., involving more than one individual event). First, two animations on problems involving drawing without replacement were shown, followed by two animations on problems involving drawing with replacement. The animations clarify the meaning of abstract concepts from the problems, such as "drawing 
with/without replacement" by visualizing them. The first animation for each problem type had a cover story about helmets distributed during a two-day mountain bike trip. The second animation of a problem without replacement was about a mobile phone factory, and the second animation of a problem with replacement was about toys in cereal packs. The duration of each of the animations was a little over two minutes. An example of a cover story of a problem without replacement is: 'Together with your friend, you go on a twoday mountain bike trip. Each day the instructor brings five helmets, which each have a different color: blue, green, yellow, red and silver. The helmets are distributed randomly and are given back to the instructor at the end of the day. On both days you get a helmet first and your friend second. What is the probability that on the first day, you and your friend will get the blue and green helmet?'. In the remainder of the animation it was demonstrated and explained how this particular probability can be calculated.
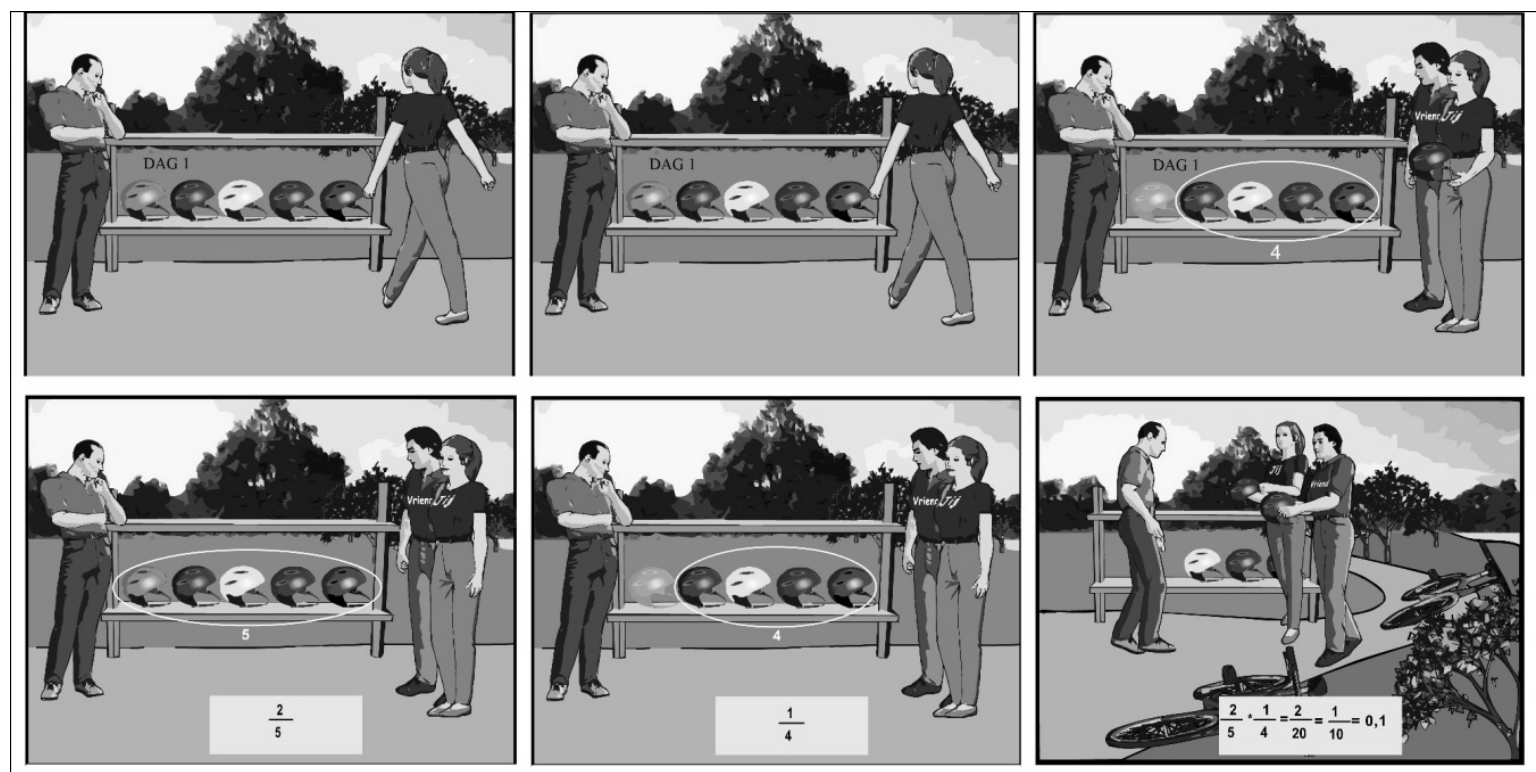

Figure 5.1 Series of screen shots from one of the animations (text was spoken).

The learners were not provided with any control over the animations. In the non-segmented condition, the animations were continuous. In the three segmented conditions the animations were divided into six or seven segments by means of pausing, slightly darkening the screen temporarily, or both. The first segment presented the problem statement (see the example above). The second described that order was not relevant in the problem shown. The third segment discussed whether it was a problem involving drawing with replacement or drawing without replacement. In the fourth and fifth or fourth, fifth, and sixth segments the probabilities of the two or three individual events involved in the problem were determined. In the example above, the probabilities of the individual events are $2 / 5$ and $1 / 4$. In the last segment (i.e., the sixth or seventh segment) the probabilities of the individual events were multiplied in order to calculate the probability of the complex event. For instance, in the example above, the probability of the complex event is $2 / 5^{*} 1 / 4$ $=2 / 20=1 / 10=0.1$. 
The animations segmented by pauses only contained pauses of 2 seconds between segments, after which the animation continued automatically. In the animations segmented by pauses and temporarily darkening, the screen was slightly darkened during the entire 2second pause. The slight darkening of the screen was done by overlaying a grey, transparent frame with the same size as the animation on the frame on which the animations paused. Although the screen was slightly darkened, it was still possible to see the frames on which the animations paused. In the animations segmented by temporarily darkening only, the segments were indicated by slightly darkening the screen at the boundaries of segments for half a second (in the same manner as mentioned above), and the animations did not pause while the screen was slightly darkened. To ensure an equal total duration, the animations in the two conditions without pauses contained a slightly darkened screen at the end of the animations for $10 \mathrm{~s}$. (in case of 5 pauses in the other conditions; i.e., animations with 6 segments) or $12 \mathrm{~s}$. (in case of 6 pauses in the other conditions; i.e., animations with 7 segments).

Pretest and posttest. The paper-and-pencil pretest and posttest consisted of different, but isomorphic items. The four items were all probability calculation problems with the same structural features, but different cover stories than the problems solved in the animations. The order of problems in terms of drawing with and without replacement was different for the two tests. An example of a problem is 'You and your friend work at the supermarket. Today eight persons are working. Two of them will need to clean the canteen, and you will draw lots to determine who that will be. You predict that you and your friend will have to do this task. What is the probability that your prediction comes true?'

Two points could be obtained for each test problem when the correct outcome was calculated using the correct formula (i.e., belonging to that problem type). One point was given if the correct formula was used, but the wrong answer was given. No points were assigned when the wrong formula was used, even when a correct outcome was reported (which sometimes happened due to calculation errors). The maximum score on both the pretest and the posttest was eight points.

Mental effort rating scales. Students were asked to rate how much mental effort they invested in studying each animation on a nine-point rating scale ranging from (1) very, very low mental effort to (9) very, very high mental effort (Paas, 1992). These rating scales were presented on paper. A mean score was calculated across the four animations.

\section{Procedure}

The experiment took place in computer rooms at participants' schools in group sessions with a duration of approximately one hour, with all conditions being present in each session. First, participants completed the pretest. Then they read the introduction to the experiment on the computer screen (4 minutes). Subsequently, they studied the four animations, using head phones to listen to the narration. After each animation, they rated the mental effort invested in studying the animation. Finally, they completed the posttest. After completing the posttest students were thanked for their participation. 


\section{Results}

Descriptive statistics for pretest and posttest scores and mental effort invested in learning from the animations are shown in Table 5.2. On the tests, missing answers were scored as errors. The significance level for the comparisons was set at .05, and eta-squared is reported as a measure of effect size, with .01 indicating a small, .06 a moderate and .14 a large effect. The conditions did not differ in pretest scores, $F(3,157)=1.21, \mathrm{MSE}=1.02, p$ $=.31, \eta_{\mathrm{p}}^{2}=.02$.

Table 5.2

Descriptive Statistics for Pretest and Posttest Performance and Mental Effort During Pretest, Posttest and Animations Study per Condition

\begin{tabular}{|c|c|c|c|c|c|c|c|c|c|c|c|c|}
\hline & \multicolumn{3}{|c|}{ Non-segmented } & \multicolumn{3}{|c|}{$\begin{array}{l}\text { Segmented } \\
\text { by temporarily } \\
\text { darkening only }\end{array}$} & \multicolumn{3}{|c|}{$\begin{array}{l}\text { Segmented } \\
\text { by pauses only }\end{array}$} & \multicolumn{3}{|c|}{$\begin{array}{l}\text { Segmented } \\
\text { by pauses and } \\
\text { temporarily } \\
\text { darkening }\end{array}$} \\
\hline & $n$ & $M$ & $S D$ & $n$ & $M$ & $S D$ & $n$ & $M$ & $S D$ & $n$ & $M$ & $S D$ \\
\hline \multicolumn{13}{|l|}{ Pretest $(0-8)$} \\
\hline Scores & 42 & 0.29 & 0.71 & 41 & 0.51 & 0.87 & 40 & 0.70 & 1.24 & 38 & 0.42 & 1.15 \\
\hline \multicolumn{13}{|l|}{ Learning } \\
\hline $\begin{array}{l}\text { Mental effort } \\
(1-9)\end{array}$ & 42 & 2.63 & 1.39 & 41 & 1.96 & 0.96 & 40 & 2.84 & 1.99 & 38 & 2.43 & 1.10 \\
\hline \multicolumn{13}{|l|}{ Posttest $(0-8)$} \\
\hline Scores & 42 & 5.64 & 2.27 & 41 & 5.95 & 2.05 & 40 & 6.82 & 1.38 & 38 & 6.08 & 2.10 \\
\hline
\end{tabular}

A 2-by-2 ANOVA revealed a main effect of Pausing on posttest scores: participants studying animations with pauses $(M=6.46, s d=1.79)$ performed significantly better on the posttest than participants studying animations without pauses $(M=5.80, s d=2.16)$, $F(1,157)=4.39, p=.04, M S E=3.92, \eta_{p}{ }^{2}=.03$. There was no significant main effect of Cueing, $F(1,157)=0.49, p=.48,, \eta_{p}{ }^{2}=.003$, nor an interaction effect between Cueing and Pausing, $F(1,157)=2.85, p=.09, \eta_{p}^{2}=.02$.

A 2-by-2 ANOVA on mental effort invested during animation study showed a significant main effect of Cueing: learning from animations with cues $(M=2.19$, $s d=$ $1.05)$ required significantly less investment of mental effort than learning from animations without cues $(M=2.73, s d=1.70), F(1,157)=5.67, p=.02, M S E=2.01, \eta_{p}{ }^{2}=.03$. There was no significant main effect of Pausing $F(1,157)=2.33, p=.13, \eta_{p}{ }^{2}=.01$, nor a significant interaction effect $F(1,157)=0.33, p=0.56, \eta_{p}{ }^{2}=.002$.

\section{Discussion}

Previous studies that showed benefits of segmentation of dynamic visualizations on learning outcomes and cognitive load all included pauses between segments (e.g., Hasler et al., 2007; Mayer \& Chandler, 2001; Moreno, 2007; Spanjers et al., 2011).Therefore, our study aimed to investigate whether pauses play a crucial role in the segmentation effect, as they provide learners with additional time for necessary cognitive activities (e.g., Mayer \& 
Moreno, 2003) or whether the effect is caused by temporal cues that make the underlying structure of the information shown clearer (Boltz, 1992). The results seem to suggest that both pausing and temporal cueing contribute to the effect, though in a different manner.

First of all, results showed that the insertion of pauses between segments had a positive effect on posttest achievement without affecting mental effort invested in studying the animations. These results provide evidence for the pausing explanation of the segmentation effect, which states that segmentation facilitates learning, because pauses give learners additional time during animation study to perform cognitive processes necessary for learning. It should be noted that learners studying animations without pauses were given additional time for information processing at the end of each animation, although we cannot be sure whether they actually used this time for on-task behaviour. However, the positive effect of the segmentation by pauses is not likely to be due to simply being given additional time to process each animation. Rather, some time needs to be provided after each segment (i.e., a small unit of information), to enable learners to maintain the information without having to attend to new incoming information.

Secondly, it was found that the insertion of cues in the form of slightly darkening the screen had a positive effect on mental effort investment during animation study: less effort was required for learning from the animations when cues were present, without affecting posttest achievement. These results provide evidence for the temporal cueing explanation, which states that segmentation influences learning outcomes or mental effort invested in learning positively, because it makes natural event boundaries more salient, reducing the need to search for those boundaries, and thereby reducing cognitive load.

Note that we cannot completely disentangle the two explanations, because the pauses also inherently provide cues regarding the structure of the material. We may conclude, however, that both segmentation by cueing in the form of temporarily darkening the screen and by pausing have a positive effect on learning outcomes or cognitive load. Although this suggest that both processes are underlying the segmentation effect, future research could attempt to further distinguish between the two explanations by comparing the effects of segmenting animations by means of pauses in meaningful and random segments. If temporal cueing plays a role, negative effects would arise in the randomly segmented condition. If it is only pausing that is important because it gives learners additional time to perform cognitive processes, than it should not make a difference whether segments are meaningful or random.

Although it would be interesting to replicate this study with animations on other topics than math, we feel our results might generalize to other animation content because the segmentation effect has also been demonstrated with dynamic visualizations on natural processes (Hasler et al. 2007; Mayer \& Chandler, 2001) and teaching skills (Moreno, 2007) in which pauses were included between segments.

A potential limitation of this study is that the posttest only contained one type of questions. Consequently, we did not assess whether students differed in, for example, the amount of conceptual knowledge they gained from the animations; however, conceptual knowledge is needed to be able to identify which solution procedure would be required in the items we used. The measure used to assess mental effort invested was a one item subjective rating scale. Although this measure is used often in educational research (Paas, 
Tuovinen, Tabbers, \& Van Gerven, 2003), and is sensitive to variations in cognitive load, especially when repeatedly applied as in this study (see Ayres, 2006; Paas et al., 2003), it is a measure of overall load that does not allow one to investigate fluctuations in cognitive load during animation study. Using objective and online measures in future research, such as secondary tasks (Brünken, Plass, \& Leutner, 2003) or psychophysiological measures such as eye tracking (Van Gerven, Paas, Van Merriënboer, \& Schmidt, 2004) or EEG (Antonenko, Paas, Grabner, \& Van Gog, 2010) could provide more insight into for example the processing activities that occur around segment boundaries during animation study. It might also be interesting to obtain more subjective process data, for example using verbal reports to uncover cognitive processes in response to animations with different types of segmentation. The most widely used verbal reporting method, thinking aloud (Ericsson \& Simon, 1993), may not be usable though, as thinking aloud when studying the animation would interfere with listening to the narrations. Cued retrospective reporting (Van Gog, Paas, Van Merriënboer, \& Witte, 2005) might provide an alternative. This method would request participants to retrospectively verbalize their thoughts during animation study supported by a replay of the animations with their own eye movements superimposed on them. Previous studies on learning from animations and videos have already used this method (De Koning et al., 2010; Jarodzka, Scheiter, Gerjets, \& Van Gog, 2010).

In sum, although further research is needed to further disentangle the two explanations, this study suggests that they both play a role in attaining a segmentation effect with transient dynamic visualizations, which is a useful finding for designers of instructional animations.

\section{References}

Adobe (2008). Flash CS4 ${ }^{\mathrm{TM}}$ [Computer software]. San Jose, CA: Adobe.

Antonenko, P., Paas, F., Grabner, R., \& Van Gog, T. (2010). Using electroencephalography to measure cognitive load. Educational Psychology Review, 22, 425-438.

Arguel, A., \& Jamet, E. (2009). Using video and static pictures to improve learning of procedural contents. Computers in Human Behavior, 25, 354-359.

Ayres, P. (2006). Using subjective measures to detect variations of intrinsic cognitive load within problems. Learning and Instruction, 16, 389-400.

Ayres, P., \& Paas, F. (2007). Making instructional animations more effective: A cognitive load approach. Applied Cognitive Psychology, 21, 695-700.

Baddeley, A. (2003). Working memory: Looking back and looking forward. Nature Reviews Neuroscience, 4, 829-839.

Barrouillet, P., \& Camos, V. (2007). The time-based resource-sharing model of working memory. In N. Osaka, R. H. Logie, \& M. D'Esposito (Eds.), The cognitive neuroscience of working memory (pp. 59-80). Oxford, England: Oxford University Press.

Boltz, M. (1992). Temporal accent structure and the remembering of filmed narratives. Journal of Experimental Psychology: Human Perception and Performance, 18, 90-105.

Boucheix, J.-M., \& Lowe, R. K. (2010). An eye tracking comparison of external pointing cues and internal continuous cues in learning with complex animations. Learning and Instruction, $20,123-135$. 
Brünken, R., Plass, J. L., \& Leutner, D. (2003). Direct measurement of cognitive load in multimedia learning. Educational Psychologist, 38, 53-61.

Catrambone, R. (1998). The subgoal learning model: Creating better examples so that students can solve novel problems. Journal of Experimental Psychology: General, 127, 355-376.

De Koning, B. B., Tabbers, H. K., Rikers, R. M. J. P., \& Paas, F. (2010). Attention guidance in learning from a complex animation: Seeing is understanding? Learning and Instruction, 20, 111-122.

Ericsson, K. A., \& Simon, H. A. (1993). Protocol analysis: Verbal reports as data (Rev. ed.). Cambridge, MA: MIT Press.

Florax, M., \& Ploetzner, R. (2010). What contributes to the split-attention effect? The role of text segmentation, picture labelling, and spatial proximity. Learning and Instruction, 20, 216224.

Hasler, B. S., Kersten, B., \& Sweller, J. (2007). Learner control, cognitive load and instructional animation. Applied Cognitive Psychology, 21, 713-729.

Höffler, T. N., \& Leutner, D. (2007). Instructional animation versus static pictures: A metaanalysis. Learning and Instruction, 17, 722-738.

Jarodzka, H., Scheiter, K., Gerjets, P., \& van Gog, T. (2010). In the eyes of the beholder: How experts and novices interpret dynamic stimuli. Learning and Instruction, 20, 146-154.

Leahy, W., \& Sweller, J. (2011). Cognitive load theory, modality of presentation and the transient information effect. Applied Cognitive Psychology, 25, 943-951.

Lin, L., \& Atkinson, R. K. (2011). Using animations and visual cueing to support learning of scientific concepts and processes. Computers \& Education, 56, 650-658.

Lowe, R. K. (1999). Extracting information from an animation during complex visual learning. European Journal of Psychology of Education, 14, 225-244.

Mayer, R. E., \& Chandler, P. (2001). When learning is just a click away: Does simple user interaction foster deeper understanding of multimedia messages? Journal of Educational Psychology, 93, 390-397.

Mayer, R. E., Hegarty, M., Mayer, S., \& Campbell, J. (2005). When static media promote active learning: Annotated illustrations versus narrated animations in multimedia instruction. Journal of Experimental Psychology: Applied, 11, 256-265.

Mayer, R. E., \& Moreno, R. (2003). Nine ways to reduce cognitive load in multimedia learning. Educational Psychologist, 38, 43 - 52.

Moreno, R. (2007). Optimising learning from animations by minimising cognitive load: Cognitive and affective consequences of signalling and segmentation methods. Applied Cognitive Psychology, 21, 765-781.

Paas, F. (1992). Training strategies for attaining transfer of problem-solving skill in statistics: A cognitive-load approach. Journal of Educational Psychology, 84, 429-434.

Paas, F., Tuovinen, J. E., Tabbers, H., \& Van Gerven, P. W. M. (2003). Cognitive load measurement as a means to advance cognitive load theory. Educational Psychologist, 38, $63-71$.

Schwan, S., Garsoffky, B., \& Hesse, F. (2000). Do film cuts facilitate the perceptual and cognitive organization of activity sequences? Memory \& Cognition, 28, 214-223.

Spanjers, I. A. E., Van Gog, T., \& Van Merriënboer, J. J. G. (2010). A theoretical analysis of how segmentation of dynamic visualizations optimizes students' learning. Educational Psychology Review, 22, 411-423.

Spanjers, I. A. E., Wouters, P., van Gog, T., \& van Merriënboer, J. J. G. (2011). An expertise reversal effect of segmentation in learning from animated worked-out examples. Computers in Human Behavior, 27, 46-52. 


\section{Chapter 5}

Sweller, J., Van Merriënboer, J. J. G., \& Paas, F. (1998). Cognitive architecture and instructional design. Educational Psychology Review, 10, 251-296.

Tversky, B., Morrison, J. B., \& Betrancourt, M. (2002). Animation: Can it facilitate? International Journal of Human-Computer Studies, 57, 247-262.

Van Gerven, P. W. M., Paas, F., Van Merriënboer, J. J. G., \& Schmidt, H. G. (2004). Memory load and the cognitive pupillary response in aging. Psychophysiology, 41, 167-174.

Van Gog, T. (2011). Effects of identical example-problem and problem-example pairs on learning. Computers \& Education, 57, 1775-1779.

Van Gog, T., Paas, F., Marcus, N., Ayres, P., \& Sweller, J. (2009). The mirror neuron system and observational learning: Implications for the effectiveness of dynamic visualizations. Educational Psychology Review, 21, 21-30.

Van Gog, T., Paas, F., Van Merriënboer, J. J. G., \& Witte, P. (2005). Uncovering the problemsolving process: Cued retrospective reporting versus concurrent and retrospective reporting. Journal of Experimental Psychology: Applied, 11, 237-244.

Wouters, P., Tabbers, H. K., \& Paas, F. (2007). Interactivity in video-based models. Educational Psychology Review, 19, 327-342.

Wouters, P., Paas, F., \& Van Merriënboer, J. J. G. (2008). How to optimize learning from animated models: A review of guidelines based on cognitive load. Review of Educational Research, 78, 645-675.

Wouters, P., Paas, F., \& van Merriënboer, J. J. G. (2009). Observational learning from animated models: Effects of modality and reflection on transfer. Contemporary Educational Psychology, 34, 1-8.

Zacks, J. M., Speer, N. K., Swallow, K. M., Braver, T. S., \& Reynolds, J. R. (2007). Event perception: A mind-brain perspective. Psychological Bulletin, 133, 273-293. 


\title{
Chapter 6
}

\section{Effects of meaningful and random segmentation of animations on learning outcomes and mental effort invested ${ }^{6}$}

\begin{abstract}
This study examined whether the positive effects of segmentation of animations are only due to the additional time that pauses between segments provide for necessary cognitive activities, or to a combination of additional time and cues regarding the structure of the materials provided by segments. Third-year secondary education students $(N=65)$ studied animations on probability calculation, which were: a) segmented by pauses in meaningful segments, b) segmented by pauses in random segments, or c) non-segmented. Studying animations segmented in meaningful segments required less mental effort than studying non-segmented animations. Additionally, students who studied animations segmented in random segments had to invest less mental effort in studying and in completing the posttest than students who studied non-segmented animations. These findings suggest that the positive effects of segmentation are due to additional time provided for necessary cognitive activities, rather than a combination of additional time and cues about the structure of materials, because random segments do not provide meaningful cues.
\end{abstract}

Instructional animations are widely used in education, but are not always as effective as they are assumed to be (e.g., Hegarty, Kriz, \& Cate, 2003; Mayer, Hegarty, Mayer, \& Campbell, 2005; Tversky, Morrison, \& Betrancourt, 2002). Only for particular tasks, especially tasks demonstrating human motor procedures, animations seem to be more effective than a series of static pictures (Höffler \& Leutner, 2007; see also Van Gog, Paas, Marcus, Ayres, \& Sweller, 2009). A problem of instructional animations is that they are transient, that is, information continuously disappears from the screen to make place for new information presented in the next moment (e.g., Ayres \& Paas, 2007a, b). This means students have to attend to incoming information elements while trying to maintain previously seen information elements in working memory in order to link them to later presented information elements, which imposes high cognitive load and hampers learning from complex animations (Ayres \& Paas, 2007a; Lowe, 1999; Mayer et al., 2005). According to the time-based resource-sharing model of working memory (Barouillet \& Camos, 2007) the focus of our attention is limited to one cognitive activity at a time. During learning from animations, students have to switch their attention rapidly back and forth between maintaining and processing activities, dividing their working memory resources across time between those activities. Information which has to be maintained in working memory decays over time unless the memory traces are refreshed by focusing attention on those traces. But when attention needs to be given to processing new incoming information during a large amount of the time available, too little time may be left to give

\footnotetext{
${ }^{6}$ This Chapter is submitted as

Spanjers, I. A. E., Van Gog, T., \& Van Merriënboer, J. J. G. (2012). Effects of meaningful and random segmentation of animations on learning outcomes and mental effort invested. Manuscript submitted for publication.
} 
attention to maintaining the information. As a consequence, information may be forgotten, and therefore, unavailable for linking it with other information, which hinders learning.

Transience seems to be less of a problem for animations demonstrating human movement tasks, because human movement can be processed almost effortlessly through activation of the motor system (Ayres, Marcus, Chan, \& Qian, 2009; Van Gog et al., 2009; Wong et al., 2009), which explains why animations are often found more effective than static pictures for such tasks. This does not mean, however, that instructional animations cannot be effectively used for teaching other types of content. Specific design measures can be taken to reduce the ineffective cognitive load caused by transience, and improve learning.

One such measure is segmentation, that is, showing animations in pieces rather than as a continuous stream of information (for a review, see Spanjers, Van Gog, \& Van Merriënboer, 2010). A number of studies (e.g., Hasler, Kersten, \& Sweller, 2007; Mayer \& Chandler, 2001; Moreno, 2007; Spanjers, Wouters, Van Gog, \& Van Merriënboer, 2011) found positive effects of segmentation on learning efficiency (i.e., either the learning outcomes were higher or the invested mental effort was lower, or both). Mayer and Chandler (2001), for example, compared a non-segmented animation with an animation in which the learner has to click on a button after each segment to continue with the next segment. They found that learners who studied the segmented animation about lightning formation twice performed better on a transfer test than learners who studied the nonsegmented version of the animation twice. Moreno (2007) required prospective teachers to study either only a text on teaching skills or the text combined with a video (experiment 1) or with an animation (experiment 2) in which the teaching skills were demonstrated. The video and animation were either with or without segmentation and with or without highlighting of labels on a ladder besides the video. In the segmented versions the learners had to click on a button after each segment to continue with the next segment. Positive effects were found of this segmentation on recalling the modelled teaching skills. Additionally, both groups studying animations with segmentation had lower cognitive load ratings than both groups studying non-segmented animations. In these two studies the duration of the pauses after each segment was learner-controlled. The duration of those pauses in the study by Spanjers, Wouters et al. (2011) was computer-controlled. In this study secondary education students learned either from non-segmented animations or from animations segmented by pauses of 2 seconds, after which the animations continued automatically. During the pauses the screen was slightly darkened. The animations demonstrated and explained how probability calculation problems can be solved. Learners with lower prior knowledge were found to learn more efficiently from segmented animations than from non-segmented ones (i.e., they achieved equal learning outcomes but tended to invest less mental effort). So it appears that segmentation can support students, at least students with lower prior knowledge, in learning from animations, even when the segmentation is not combined with learner control.

Two alternative, but not mutually exclusive, explanations for these positive effects of segmentation were proposed by Spanjers et al. (2010). First, there are pauses between the segments which give learners additional time for performing necessary cognitive activities on smaller units of information without the interruption of new incoming 
information (e.g., Mayer, 2005, 2009: Moreno \& Mayer, 2007); we will refer to this as the 'time-to-process explanation'. According to the time-based resource-sharing model of working memory (Barouillet \& Camos, 2007) pauses should reduce cognitive load and foster learning (for a detailed discussion, see Spanjers et al., 2010). Secondly, animations are -seemingly sensibly- divided in meaningful segments which gives learners cues regarding the structure underlying the information presented; we refer to this as the 'temporal cueing explanation'. This might help them distinguish sub steps or sub events, which might aid recall of the process or procedure shown (cf., Boltz, 1992; Catrambone, 1995). This latter process also seems to underlie positive effects of segmentation of textbased instructional material (Catrambone, 1995; Florax \& Ploetzner, 2010; Spanjers, Van Gog, \& Van Merriënboer, in press).

In a prior study investigating which of these two explanations would be the most plausible one, effects on learning outcomes and cognitive load (as measured by mental effort) of four types of animations were investigated: non-segmented, segmented by pauses only, segmented by slightly darkening the screen temporarily, or segmented by pauses plus slightly darkening temporarily (Spanjers, Van Gog, Wouters, \& Van Merriënboer, 2012). It appeared that inserting pauses had a positive effect on learning outcomes, and cueing segment boundaries by temporarily darkening the screen reduced the mental effort invested in studying the animations. So, these results suggest a role for both the time-to-process explanation and the temporal cueing explanation for the beneficial effects of segmentation. However, because a pause in itself also provides an indication regarding the boundaries of a segment, and segmentation was done in meaningful places, the pauses would also have emphasized the structure of the procedure. Thus, it cannot be ruled out that the positive effect of the pauses was also partly due to a temporal cueing effect.

Therefore, the present study investigates segmentation by pauses in both meaningful and random segments. If the explanation for the segmentation effect lies purely in time to process, both types of segmented animations should be effective (i.e., reduce cognitive load and/or enhance learning) compared to a non-segmented version. If it lies in the combination of the time-to-process and temporal cueing explanation, only the meaningfully segmented animations should be effective (i.e., reduce cognitive load and/or enhance learning), and random segments might even hamper learning. There is some evidence for the latter hypothesis, from a study using a very different kind of task and context though: Boltz (1992) showed participants episodes of a miniseries that were interrupted by commercials at natural event boundaries (boundaries between component actions), interrupted between natural event boundaries, or not interrupted. Insertion of commercials at natural event boundaries supported recall of what happened in the episode and in which order, while the insertion of commercials at points between event boundaries hindered recall of this information. These findings suggest that the insertion of additional formal means in the form of commercial breaks segmenting dynamic visualizations in pieces can support or hinder recalling the material, dependent on whether they are inserted in line with the underlying structure of the material or not. Carroll and Bever (1976) showed participants very short film clips which were divided in two segments by a change in the action, by a cut (i.e., changes in camera distance or angle) or by a combination of a cut and a change in the action. Participants took significantly longer to recognise stimuli 
when they were taken from before a change in the action, regardless whether the change in action was accompanied by a cut or not. Recognizing stimuli from before a cut which was not accompanied by a change in action did not take significantly longer than recognizing stimuli taken from a point in time after a cut, however. This finding suggests that participants are able to neglect segmentation by some additional formal means or under some circumstances. So, the question is whether segmentation of instructional animations by additional formal means in the form of pauses would hinder learning, when they are at random places rather than at meaningful ones.

\section{Method}

\section{Participants and design}

Participants were 65 Dutch secondary education students (mean age $=14.02, s d=$ $0.54,46 \%$ females) in the third year of the two highest levels of secondary education in The Netherlands (general secondary education and pre-university education). They were randomly assigned to one of the three conditions: a) studying non-segmented animations ( $n$ $=21)$, b) studying animations segmented in meaningful pieces by pauses $(n=22)$ or c) studying animations segmented in random segments by pauses $(n=22)$.

\section{Materials}

Animations. Four animations on probability calculation (see also Spanjers, Van Gog, Wouters, \& Van Merriënboer, 2012; Spanjers, Wouters, et al., 2011) were presented in a computer-based learning environment developed in Flash CS4 (Adobe, 2008). The animations were preceded by a written introduction with basic information relevant for learning about probability calculation.

The text in the animations was spoken by a male voice without an accent. The animations lasted a little over two minutes and did not contain learner control options. In the first two animations it was explained and demonstrated how probability calculation problems involving drawing without replacement can be solved. In the next two animations, it was demonstrated and explained how problems involving drawing with replacement can be solved. The order of drawing was unimportant for all four problems. An example of a problem without replacement is: 'Together with your friend, you go on a two-day mountain bike trip. Each day the instructor brings five helmets, which each have a different color: blue, green, yellow, red and silver. The helmets are distributed randomly and are given back to the instructor at the end of the day. On both days you get a helmet first and your friend second. What is the probability that on the first day, you and your friend will get the blue and green helmet?'

In the non-segmented condition the animations were not divided into pieces. In the segmented conditions the animations were divided into six or seven pieces by pauses of two seconds. The animations continued automatically after the two seconds. To equal the total duration for the segmented and non-segmented conditions students in the nonsegmented condition were given a pause of 10 or 12 seconds at the end of each animation (dependent on the number of segments and pauses in the animation). 
The segmentation in meaningful segments was the same as the segmentation used in Spanjers, Van Gog, Wouters, Van Merriënboer (2012). The moments to segment were determined together with one statistician and two math teachers, and slightly adjusted based on a pilot test. In the first segment a cover story to introduce the problem solved in that animation was presented. In the second segment it was explained that the order of drawing was not important. In the third segment drawing with or without replacement was discussed. In the fourth and fifth or fourth, fifth and sixth segment the probabilities for the two or three individual events involved in the problem were determined. In the example above these probabilities were $2 / 5$ and $1 / 4$. The last segment (sixth or seventh) was used to multiply the probabilities for the individual events involved in order to calculate the probability asked for. The segments had a duration of 13 to 35 seconds.

The number of segments distinguished in the randomly segmented animations was equal to the number of segments distinguished in the meaningfully segmented animations. Randomly, five different numbers in the range from 0 to the maximum duration of the shortest animation in seconds were generated on the website www.random.org (for the animation with six pauses one additional number was drawn). At the number of seconds resulting from the random generator, the pauses were inserted in the four animations. The segments had a duration of 7 to 35 seconds.

Tests. The pretest and posttest consisted of four isomorphic probability calculation problems. The structural features of the test problems were similar to the structural features of the problems solved in the animations. The cover stories from the test problems differed, however, from the cover stories presented in the animations. The cover stories in the pretest were also different from those in the posttest. An example of a test problem is: 'You and your friend work at the supermarket. Today eight persons are working. Two of them will need to clean the canteen, and you draw lots to determine who that will be. You predict that you and your friend will have to do this task. What is the probability that your prediction comes true?'

Two points were assigned for giving the correct formula and correct answer. One point was assigned if the correct formula was used, but the correct answer was not obtained. No points were assigned, if the correct answer was given, but an incorrect or no formula was given. Also no points were assigned for giving an incorrect formula and an incorrect answer.

Mental effort scales. Nine-point subjective rating scales (Paas, 1992) ranging from (1) very, very low mental effort to (9) very, very much mental effort were used to assess the mental effort invested in completing the pretest and the posttest and in studying the animations. Participants filled these rating scales out on paper.

\section{Procedure}

The study was run in group sessions of about one hour at participants' school. The sessions started with the pretest. Directly after each problem on the pretest, participants rated the amount of mental effort they invested in solving the problem. After completing the pretest, participants entered the computer-based learning environment. They first read the introduction (three minutes), and then studied the four animations. The students used head phones to listen to the audio of the animations. Directly after each animation participants 
were prompted to rate how much mental effort they invested in studying that animation. After having studied all four animations, they completed the posttest, and rated the amount of mental effort invested for each problem directly after having completed the problem. Finally, the students were debriefed and thanked for their participation.

\section{Results}

The descriptive statistics for scores on the pretest and posttest and for mean mental effort invested in studying the animations and completing the pretest and posttest are presented in Table 6.1. On the tests, missing answers were scored as errors. When a mental effort rating was missing $(1.4 \%)$, the mean mental effort for that phase of the experiment was calculated based on the remaining scores.

Table 6.1

Descriptive Statistics for Pretest and Posttest Performance and Mental Effort during Animation Study and Posttest per Condition

\begin{tabular}{lllllll}
\hline & \multicolumn{2}{l}{$\begin{array}{l}\text { Non-segmented } \\
(n=21)\end{array}$} & $\begin{array}{l}\text { Segmented in } \\
\text { meaningful segments } \\
(n=22)\end{array}$ & $\begin{array}{l}\text { Segmented in random } \\
\text { segments } \\
(n=22)\end{array}$ & \\
& $M$ & $S D$ & $M$ & $S D$ & $M$ & $S D$ \\
\cline { 2 - 7 } & & & & & & \\
\hline $\begin{array}{l}\text { Pretest } \\
\quad \text { Scores (0-8) }\end{array}$ & 0.05 & 0.22 & 0.41 & 1.33 & 0.09 & 0.43 \\
$\quad$ Mental effort (1-9) & 5.13 & 1.50 & 5.30 & 1.81 & 4.39 & 1.70 \\
$\quad$ Studying & & & & & & \\
$\quad$ Mental effort (1-9) & 3.70 & 1.20 & 2.68 & 1.11 & 2.85 & 1.64 \\
$\quad$ Near transfer test & & & & & & \\
$\quad$ Scores (0-8) & 2.81 & 2.60 & 3.73 & 2.49 & 3.86 & 2.64 \\
$\quad$ Mental effort (1-9) & 3.96 & 1.44 & 3.48 & 1.64 & 2.65 & 1.64 \\
\hline
\end{tabular}

ANOVAs with a significance level of .05 were used to analyze whether the three conditions differed from each other. Significant results in the analyses of variance were further investigated by means of contrast tests. The effect sizes are reported as partial eta square $\left(n_{p}{ }^{2}\right)$ for the omnibus ANOVAs and as Cohen's $d$ for the contrast tests. Partial eta squared values of $.01, .06$ and .13 and Cohen's $d$ values of $.20, .50$ and .80 represent small, moderate, and large effect sizes, respectively.

\section{Pretest scores}

As one would expect given random assignment of participants to conditions, the pretest scores of the three conditions did not differ significantly, $F(2,62)=1.25, M S E=$ $0.68, p=.29, n_{p}^{2}=.04$. 


\section{Posttest scores}

No significant differences between the three conditions were found for the posttest scores, $F(2,62)=1.05, M S E=6.65, p=.35, n_{p}{ }^{2}=.03$. So, similar learning outcomes were achieved by learners in all three conditions.

\section{Mental effort}

However, these similar levels of performance were reached with significantly different levels of mental effort investment in studying the animations, $F(2,62)=3.58, M S E=1.79$, $p=.03, n_{p}{ }^{2}=.10$, and in completing the posttest, $F(2,62)=3.84, M S E=2.49, p=.03, n_{p}{ }^{2}=$ .11. In line with what could be expected if either the time-to-process explanation, or a combination of the time-to-process and temporal cueing explanation applied, participants in the meaningfully segmented condition had to invest less mental effort in studying the animations than participants in the non-segmented condition, $t(62)=-2.50, p=.02, d=$ 0.91 , but there was no significant difference on the effort invested in the posttest between those conditions, $t(62)=-1.01, p=.32, d=0.32$. Additionally, in line with what could be expected if only the time-to-process explanation applied, participants in the randomly segmented condition had to invest less mental effort than participants in the non-segmented condition during studying the animations, $t(62)=-2.09, p=.04, d=0.61$, as well as in completing the posttest, $t(62)=-2.74, p=.01, d=0.87$.

\section{Discussion}

This study investigated what the most likely explanation is for the beneficial effects of segmentation of animations on cognitive load and/or learning that have been found in a number of studies (e.g., Hasler et al., 2007; Mayer \& Chandler, 2001; Moreno, 2007; Spanjers, Van Gog, Wouters, \& Van Merriënboer, 2012; Spanjers, Wouters et al., 2011). These findings could be explained by the time-to-process explanation in itself, that is, the additional time provided by the pause reduces cognitive load by providing learners with additional time to share attention between processing and maintaining information. Or they could be explained by a combination of the time-to-process and temporal cueing explanation, that is, not only the additional time plays a role, but the segmentation into meaningful pieces helps learners perceive the underlying problem structure, aiding them to learn the solution procedure with less effort (cf. Spanjers, Van Gog, \& Van Merriënboer, in press).

To address this question a condition with random segments was used in addition to a meaningfully segmented condition. The findings show that not only the meaningfully segmented but also the randomly segmented condition reduced cognitive load (i.e., lower investment of mental effort) compared to a non-segmented condition. Moreover, in the random condition, there was a beneficial effect not only on effort invested in studying the animations but also in effort invested in completing the posttest. This is an indication that in this condition, learning was not only more efficient in terms of the learning process, but also in terms of the learning outcomes (Van Gog \& Paas, 2008). These results seem to provide some evidence that the beneficial effects of segmentation on efficiency of learning 
are mainly due to the time to process information, rather than to cues regarding the structure of the process or procedure shown.

As far as we know this study is the first study to compare the effects of different ways of segmenting on learning from instructional animations. Different ways of segmenting these animations had both positive effects on learning efficiency (i.e., equal learning outcomes were achieved with the investment of less mental effort). Future research should examine whether the results from the present study can be generalized to other kinds of instructional animations or instructional video-based materials.

To conclude, it was found that segmentation supports the learning process in terms of equal learning outcomes attained with less investment of effort, both when animations are divided into meaningful and into random segments. These results seem to be in line with the time-to-process explanation for the beneficial effects of segmentation, but not with the combination of the time-to-process and temporal cueing explanation.

\section{References}

Adobe (2008). Flash CS4 ${ }^{\mathrm{TM}}$ [Computer software]. San Jose, CA: Adobe.

Ayres, P., Marcus, N, Chan, C., \& Qian, N. (2009). Learning hand manipulative tasks: When instructional animations are superior to equivalent static representations. Computers in Human Behavior, 25 ,348-353.

Ayres, P., \& Paas, F. (2007a). Making instructional animations more effective: A cognitive load approach. Applied Cognitive Psychology, 21, 695-700.

Ayres, P., \& Paas, F. (2007b). Can the cognitive load approach make instructional animations more effective? Applied Cognitive Psychology, 21, 811-820.

Barrouillet, P., \& Camos, V. (2007). The time-based resource-sharing model of working memory. In N. Osaka, R. H. Logie, \& M. D'Esposito (Eds.), The cognitive neuroscience of working memory (pp. 59-80). Oxford, England: Oxford University Press.

Boltz, M. (1992). Temporal accent structure and the remembering of filmed narratives. Journal of Experimental Psychology: Human Perception and Performance, 18, 90-105.

Carroll, J. M., \& Bever, T. G. (1976). Segmentation in cinema perception. Science, 191, $1053-$ 1055.

Catrambone, R. (1995). Aiding subgoal learning: Effects on transfer. Journal of Educational Psychology, 87, 5-17.

Florax, M., \& Ploetzner, R. (2010). What contributes to the split-attention effect? The role of text segmentation, picture labeling, and spatial proximity. Learning and Instruction, 20, 216224.

Hasler, B. S., Kersten, B., \& Sweller, J. (2007). Learner control, cognitive load and instructional animation. Applied Cognitive Psychology, 21, 713-729.

Hegarty, M., Kriz, S., \& Cate, C. (2003). The roles of mental animations and external animations in understanding mechanical systems. Cognition and Instruction, 21, 209 - 249.

Höffler, T. N., \& Leutner, D. (2007). Instructional animation versus static pictures: A metaanalysis. Learning and Instruction, 17, 722-738.

Lowe, R. K. (1999). Extracting information from an animation during complex visual learning. European Journal of Psychology of Education, 14, 225-244. 
Mayer, R. E. (2005). Principles for managing essential processing in multimedia learning: Segmenting, pretraining, and modality principles. In R. E. Mayer (Ed.), The Cambridge handbook of multimedia learning (pp. 169-182). New York: Cambridge University Press.

Mayer, R. E. (2009). Multimedia learning (2nd ed.). New York: Cambridge University Press.

Mayer, R. E., \& Chandler, P. (2001). When learning is just a click away: Does simple user interaction foster deeper understanding of multimedia messages? Journal of Educational Psychology, 93, 390-397.

Mayer, R. E., Hegarty, M., Mayer, S., \& Campbell, J. (2005). When static media promote active learning: Annotated illustrations versus narrated animations in multimedia instruction. Journal of Experimental Psychology: Applied, 11, 256-265.

Moreno, R. (2007). Optimising learning from animations by minimising cognitive load: Cognitive and affective consequences of signalling and segmentation methods. Applied Cognitive Psychology, 21, 765-781.

Moreno, R. \& Mayer, R. E. (2007). Interactive multimodal learning environments. Educational Psychology Review, 19, 309-326.

Paas, F. (1992). Training strategies for attaining transfer of problem-solving skill in statistics: A cognitive-load approach. Journal of Educational Psychology, 84, 429-434.

Spanjers, I. A. E., Van Gog, T., \& Van Merriënboer, J. J. G. (2010). A theoretical analysis of how segmentation of dynamic visualizations optimizes students' learning. Educational Psychology Review, 22, 411-423.

Spanjers, I. A. E., Van Gog, T., \& Van Merriënboer, J. J. G. (in press). Segmentation of worked examples: Effects on cognitive load and learning. Applied Cognitive Psychology.

Spanjers, I. A. E., Van Gog, T., Wouters, P., \& Van Merriënboer, J. J. G. (2012). Explaining the segmentation effect in learning from animations: The role of pausing and temporal cueing. Computers \& Education, 59, 274-280.

Spanjers, I. A. E., Wouters, P., van Gog, T., \& Van Merriënboer, J. J. G. (2011). An expertise reversal effect of segmentation in learning from animated worked-out examples. Computers in Human Behavior, 27, 46-52.

Tversky, B., Morrison, J. B., \& Betrancourt, M. (2002). Animation: Can it facilitate? International Journal of Human-Computer Studies, 57, 247-262.

Van Gog, T. \& Paas, F. (2008). Instructional efficiency: Revisiting the original construct in educational research. Educational Psychologist, 43, 16-26.

Van Gog, T., Paas, F., Marcus, N., Ayres, P., \& Sweller, J. (2009). The mirror neuron system and observational learning: Implications for the effectiveness of dynamic visualizations. Educational Psychology Review, 21, 21-30.

Wong, A., Marcus, N., Ayres, P., Smith, L., Cooper, G. A., Paas, F., \& Sweller, J. (2009). Instructional animations can be superior to statics when learning human motor skills. Computers in Human Behavior, 25, 339-347. 



\section{Chapter 7}

\section{General discussion}

The increasing use of animations in education, combined with research raising concerns about their effectiveness, inspired a search for guidelines for animation design that would help to optimize learning processes and learning outcomes. One of the design guidelines proposed to be effective based on prior research is segmentation (e.g., Ayres \& Paas, 2007; Mayer, 2005, 2009). The literature study and four empirical studies described in this dissertation took a closer look at why segmentation of animations is effective. In this final chapter, first the main findings from the studies are presented. Subsequently, some limitations are described. And finally, theoretical and practical implications and directions for future research are discussed.

\section{Main findings}

Based on prior research, it was found that two alternative, but not mutually exclusive, processes may be proposed to underlie the positive effects of segmentation of animations (Chapter 2). The time-to-process (or pausing) explanation states that segmentation has positive effects because in almost all prior studies pauses were inserted between the segments, which would be expected to support students in dealing with the transience of animations by providing them with additional time to perform necessary cognitive processes on smaller units of information without having to attend to and process new incoming information (e.g., Mayer \& Moreno, 2003). The temporal cueing explanation states that segmentation has positive effects because it divides animations in meaningful pieces, and therefore, supports students in the process of mentally dividing the illustrated or demonstrated information (Schnotz \& Lowe, 2008), and in perceiving the structure underlying this information (Boltz, 1992).

It was hypothesized that these explanations would apply only to novices' learning, as students with more prior knowledge would not need the additional time or cues to understand the structure of the materials. Learners with more prior knowledge have cognitive schemas helping them to deal with the transience of the animation and/or supporting them in perceiving the structure underlying the information shown. Hence, in contrast to learners with lower levels of prior knowledge, more advanced students may not benefit from pauses and/or temporal cues provided by the segmentation of animations, that is, an 'expertise reversal' effect might occur (e.g., Kalyuga, Ayres, Chandler, \& Sweller, 2003). The findings reported in Chapter 3 indeed suggest that an expertise reversal effect occurs with the effects of segmentation of animations. A positive trend of segmentation of animations on the learning process was found (i.e., lower investment of mental effort required during learning with segmented animations than with non-segmented animations) for students with lower levels of prior knowledge, but not for students with higher levels of prior knowledge. 
Hence, the subsequent studies focused on $3^{\text {rd }}$ year secondary education students with lower levels of prior knowledge in examining the plausibility of the two explanations (time-to-process and temporal cueing) for the effects of segmentation (Chapters 4, 5, and 6). The study on segmentation of text-based probability calculation examples (Chapter 4) showed that students tended to invest less mental effort in studying segmented text-based worked examples on probability calculation than in studying non-segmented ones. Because these text-based examples were not transient, the learners could pause when they wanted during example study. Therefore, it is unlikely that the time-to-process explanation explains this trend completely, which implies that this finding provides some indication that a temporal cueing explanation might be in effect with these materials, although it should be kept in mind that written text and animation differ in terms of cognitive processes during learning.

To directly compare the explanations with animations, the separate and combined effects of (meaningfully) segmenting animations by pauses and by temporal cueing (i.e., temporarily darkening the screen slightly) on mental effort investment and learning outcomes were studied (Chapter 5). A positive main effect of temporarily darkening the screen at segment boundaries was found on mental effort invested in animation study. This reduction in mental effort seems to provide some support for the temporal cueing explanation as well. Additionally, it was found that pauses had a positive main effect on learning outcomes, which provides support for the time-to-process explanation. However, the pauses were inserted at meaningful places in this study. Therefore, it cannot be ruled out that they not only provided learners with additional time for necessary cognitive processes, but also with cues indicating how to mentally divide the animation. Thus, according to this finding, it was unclear whether it is the time to process, or a combination of time to process and cues regarding segment boundaries that makes segmentation effective. To further explore this question, the effects on mental effort investment and learning outcomes of segmenting animations by pauses into either meaningful or random segments was investigated (Chapter 6). This study seemed to provide evidence that time to process is most important in explaining beneficial effects, rather than a combination of the temporal cueing and the time-to-process explanation: Students had to invest less mental effort during animation study not only in the meaningfully segmented condition, but also in the randomly segmented condition, than in the non-segmented condition. Besides, the students who learned from the randomly segmented animations had to invest less mental effort in completing the posttest than the students who learned from non-segmented animations, indicating they had acquired richer cognitive schemata for more efficiently solving the type of problems demonstrated in the animations.

In sum, our studies suggest that pauses play an important role in reaching the positive effects of segmentation for novices. The time-to-process explanation thus seems to be a plausible explanation for the positive effects of segmentation. Besides, in two (of the three) studies the findings also provide preliminary support for the temporal cueing explanation. 


\section{Limitations}

The studies presented in this dissertation have some limitations. All studies used the same animations, demonstrating and explaining how to solve probability calculation problems. Therefore, it is unclear whether the findings can be generalized to other types of animations (e.g., demonstrating mechanical or natural systems) from which learners have to acquire other types of knowledge than procedural problem-solving skills. However, it is likely that future studies with other animations would find similar results, given that the beneficial effect of segmenting has been found with a variety of materials (e.g., Catrambone, 1995; Florax \& Ploetzner, 2010; Hasler, Kersten, \& Sweller, 2007; Mayer \& Chandler, 2001; Moreno, 2007). Furthermore, the studies only compared different types of animations with each other to investigate why segmentation has positive effects on the learning process or on learning outcomes. It was not investigated whether segmentation improves the learning efficiency of animations to such a large extent that they are more efficient than equivalent non-transient material.

Regarding the data collected, a limitation is that only immediate posttests were used, and as such, it is unclear whether the effects would remain over time or whether different conditions would have different effects over time. Additionally, no data were collected on the time students took to complete the test items and to read the text-based worked examples. Accordingly, it was not possible to examine potential differences in the time needed to complete the posttest between students from the different conditions, which could be another indicator of efficiency: When students in a particular condition complete the test in less time but achieve similar test results, this would imply that their learning is more efficient in terms of learning outcomes. In the text-based examples study, differences in how long the students learning from the segmented and non-segmented text-based worked examples paused at the segment boundaries could not be examined. Accordingly, while the data of this study seem to favor the cueing explanation, it cannot be excluded that students in the condition with segmented written worked examples paused longer at the boundaries between the segments than the students in the non-segmented condition. If they indeed paused longer at those boundaries, this would indicate that the time-to-process explanation applies as well. Therefore, it would be helpful in future studies to collect data on time-on-task during the tests and time-on-task, reading rate, and pausing behavior while studying segmented text-based examples.

Finally, the effect sizes were sometimes small. Therefore, the results should be interpreted with caution. Potentially, the small effects are partly due to the conduction of the studies in schools rather than in laboratory situations. In schools it is more difficult to control and monitor factors such as short disturbances due to noise or student off-task behavior. On the other hand, testing the effects in school situations makes the results more ecologically valid, because this is the place where instructional animations are eventually to be used. Despite these limitations, the studies presented in this dissertation have some interesting theoretical and practical implications. 


\section{Theoretical and practical implications}

As for theoretical implications, one contribution this dissertation has made is an attempt to combine cognitive load theory with theories and research evidence from cognitive (neuro)science on working memory functions: Insights from the time-based resourcesharing model of working memory (Barrouillet \& Camos, 2007) were added. According to this model, learners are only able to pay attention to one cognitive activity at one moment in time. So when attention is captured by processing for a large proportion of the available time, attention can be given to maintaining only for a small proportion of the time, with the consequence that information may be forgotten. Cognitive load is in this model, therefore, dependent on the proportion of the time that attention needs to be given to processing, and is, as a consequence, unavailable for maintaining. This implies that the cognitive load imposed is higher when a higher or an equal number of elements needs to be processed and maintained in the same or a smaller amount of time. In the newest update of cognitive load theory (Sweller, 2010), both intrinsic and extraneous cognitive load are dependent on element interactivity, that is, on the number of information elements that have to be processed and maintained simultaneously. These information elements could be inherent to the learning material (i.e. intrinsic cognitive load) or due to non-optimal ways of presenting the material (i.e., extraneous cognitive load). This fits very well with the conceptualization of cognitive load in the time-based resource-sharing model, which does not distinguish between the nature of the elements to be processed, but does add the aspect of time to the aspect of element interactivity. Especially for instructional formats in which time plays an important role, as in transient animations, combining this model with cognitive load theory might allow for a better explanation of the difficulties learners experience; for instance, when studying animations it explains in more detail why transience is so difficult to deal with, and why pauses may prevent these difficulties. The time-based resource-sharing model is, therefore, a useful addition to cognitive load theory.

Besides the cognitive load theory and the time-based resource-sharing model, the event segmentation theory was used in this dissertation to explain the positive effects of segmentation. The event segmentation theory states that people mentally divide what they perceive in pieces with begin and end points in time, and describes the processes underlying this mentally dividing of information in pieces (e.g., Zacks, Speer, Swallow, Braver, \& Reynolds, 2007). The way people mentally divide the information affects their storage of the information in long-term memory (e.g., Kurby \& Zacks, 2008; Zacks et al., 2007). Therefore, based on event segmentation theory, segmentation could be beneficial, because people are supported in mentally dividing what they see (cf., Kurby \& Zacks, 2008; Zacks et al., 2007; see also Boltz, 1992; Schwan, Garsoffky, \& Hesse, 2000). Cognitive load theory explains the positive effects of segmentation as due to better use of limited working memory resources for the cognitive processes necessary for learning (e.g., Sweller, 2010), but does not explicate the processes executed during studying dynamic visualizations in great detail. So, by using the event segmentation theory, more insights could be gained in processes people execute when studying dynamic visualizations, and why segmentation may support them in executing these processes. 
As for the practical implications, segmentation by temporarily darkening the screen slightly and by inserting pauses were both found to have positive effects on the learning process or on the learning outcomes. Across studies the evidence for the time-to-process explanation seemed to be more consistent than the evidence for the temporal cueing explanation. So, for designers of instructional material with animations, segmenting the animations by pauses may be the best option. However, the finding of an expertise reversal effect with regard to the effects of segmentation on the learning process suggest that animations should be segmented in instructional material intended for learners with lower prior knowledge, but not in instructional material for learners with more prior knowledge.

A tendency was found that studying segmented text-based worked examples required less mental effort than studying non-segmented ones. This tendency was in line with the findings on segmentation of worked examples by Catrambone (1995) and of segmenting a text by Florax and Ploetzner (2010). These findings suggest that segmentation may be beneficial when included in textual instructional material as well, although the dynamics in the underlying processes may be different given that learners can pause at any time when studying texts. Possibly, the temporal cueing effect is more important for written text based materials while the time-to-process explanation is more pertinent to transient materials.

Instructing learners to actively divide or segment text-based worked examples in pieces appeared to introduce a form of interactivity which hinders the learning process of novice learners. Learners who were instructed to actively segment during studying textbased worked examples were found to invest more mental effort in this studying than learners who were presented segmented or non-segmented text-based worked examples (Chapter 4). Additionally, they invested more mental effort in completing the posttest than the students who were presented with segmented worked examples. This investment of more mental effort did not lead to larger learning gains, however. Designers of instructional material should, therefore, not ask novice learners to actively segment textbased worked examples and keep in mind that interactivity does not always support the learning process.

\section{Future research and conclusion}

Based on the studies presented in this dissertation some interesting questions for future research can be raised. For instance, the results showed that segmentation is only effective for novice learners (Chapter 3). This implies that the design of animations should be adapted when learners' knowledge increases. Given that learners also acquire knowledge when studying a longer series of animations on the same topic, future studies should examine whether gradually changing animations from segmented to non-segmented ones would foster learning. This could be done, for instance, by studying whether decreasing the number of pauses and increasing the length of the segments is a useful way to adapt the animations when the learners gain more prior knowledge.

Secondly, two particular ways of segmentation were examined, by means of pauses of 2 seconds and by temporarily darkening the screen, and both had positive, but different, effects. However, other ways of segmenting (e.g., longer pauses, other temporal cues) or 
combinations of different ways of segmenting might potentially have even stronger effects. Hence, future studies might examine the effect of pauses with a shorter or longer duration, investigate effects of temporal cues consisting of labels (e.g., Moreno, 2007) or key frames in combination with the animation (e.g., Arguel \& Jamet, 2009) and investigate effects of combining different ways to segment animations, such as a combination of pauses and labels (e.g., Moreno, 2007).

Thirdly, the finding that learners benefit from segmentation in random segments, just as they benefit from segmentation in meaningful segments, is quite counterintuitive and warrants further investigation. Based on event segmentation theory positive effects can be expected from segmentation in meaningful segments, but not from segmentation in nonmeaningful segments (cf., Zacks et al., 2007). Boltz (1992) found indeed that insertion of commercials in episodes of a miniseries at event boundaries had positive effects on recalling shown information, while insertion of commercials at points between event boundaries had negative effects on this performance. So, her findings suggest that memory for the material is affected by the placement of additional features in line with or not in line with the underlying structure in the information. Although our study differ in several respects from the study of Boltz (pauses rather than commercials, animations rather than video, etc.) our results do not seem to be in line with her findings and event segmentation theory, but more in line with the finding of Carroll and Bever (1976). They found that recognizing stimuli taken from shown film clips took longer after the occurrence of a change in the action, but not after the occurrence of a change in camera distance or camera angle. And although this study again differs on a number of aspects, like the type of dynamic visualizations used, the means used to segment the dynamic visualizations and the outcome measures, from our study, this study suggests, just as our study, that participants can sometimes neglect segmentation in a non-meaningful way. Or, in other words, that under some circumstances additional features which are not in line with the underlying structure in the information do not increase the time needed to recognize the stimuli or hinder learning. That other studies comparing dynamic visualizations with additional features segmenting dynamic visualizations either in line or not in line with the underlying structure of the presented information differ from our study on several aspects is not surprising, since the event segmentation theory is not often used in studies with regard to learning from instructional animations (for exceptions, see Arguel \& Jamet, 2009; Lowe \& Boucheix, 2008; Meyer, Rasch, \& Meyer, 2009; Schnotz \& Lowe, 2008; Wong et al, 2009). Due to these differences, it is difficult to draw conclusions on why the results from our study seem to differ from the findings by Boltz (1992) and seem to be more in line with the finding by Carroll and Bever (1976). Therefore, future studies should attempt to replicate our findings with other instructional animations and other outcome measures in order to draw a conclusion on the effects of segmentation in random segments with more certainty. Additionally, future studies should try to uncover the circumstances under which segmenting in meaningful and non-meaningful segments both have positive effects, as is found in this study, and under which circumstances their effects differ, as is found by Boltz (1992) and predicted by event segmentation theory (Zacks et al., 2007).

Fourthly, to gain more insight in the processes underlying positive effects of segmentation, it would be interesting in future studies to collect data about fluctuations in 
cognitive load and cognitive processes taking place during animation study. After each animation students rated their mental effort on a subjective rating scale. It is possible with this measure to investigate differences between conditions in the overall load invested, but not to investigate how the amount of mental effort invested fluctuates during animation study. Such fluctuations can be investigated with on-line measures, such as secondary tasks (Brünken, Plass, \& Leutner, 2003), EEG (Antonenko, Paas, Grabner, \& Van Gog, 2010), or eye tracking (Van Gerven, Paas, Van Merriënboer, \& Schmidt, 2004; Van Gog, Kester, Nievelstein, Giesbers, \& Paas, 2009). Especially given the more specific predictions that can be made based on the time-based resource-sharing model of working memory and the event segmentation theory, it would be interesting to examine fluctuations in the amount of mental effort invested during animation study in future studies, and the effects of segmenting in different units (i.e., meaningful and random) and with different means (i.e., pauses and temporarily darkening) on those fluctuations.

Besides examining fluctuations in mental effort during animation study, future studies may focus on uncovering on-line cognitive processes taking place during studying animations segmented in different units and by different means. A useful method for uncovering cognitive processes taking place during narrative animations is cued retrospective reporting, that is, asking participants to report the thoughts they had during studying the animations, while viewing a replay of the animations with their eye movements superimposed on it (Van Gog, Paas, Van Merriënboer, \& Witte, 2005). Additionally, examining how people actively divide or segment animations in pieces may also uncover cognitive processes taking place during learning from animations. Because of the role mentally dividing plays in interpretation and storage of information in long term memory, the way learners mentally divide instructional material can be expected to influence their learning (Zacks et al., 2007; Zacks \& Swallow, 2007; see also Koopman \& Newtson, 1981). This is also suggested by studies investigating the relation between how people actively segment dynamic visualizations and their memory for the information shown (Hanson \& Hirst, 1989; Schwan et al., 2000; see also Zacks, Speer, Vettel, \& Jacoby, 2006; Zalla, Pradat-Diehl, \& Sirigu, 2003). Therefore, it would be interesting to examine this relation with instructional dynamic visualizations in future studies. A related issue for future research is comparing the segmentation behaviour of participants viewing animations segmented in random segments, segmented in meaningful segments, or nonsegmented. Furthermore, these future studies could also combine actively segmenting with retrospective reporting by having participants actively segment the material during a first view and asking them afterwards what they were attending to at the points where they segmented the material (Christoffersen, Woods, \& Blike, 2007; Van den Bogert, Van Bruggen, \& Jochems, 2011).

In conclusion, this dissertation suggests that pauses in animations are important for reaching the positive effects of segmentation on the learning process and/or learning outcomes of novice students, but that temporal cueing of the boundaries between segments may have some positive effects on the learning process as well. These positive effects on the learning process disappear as learners gain more knowledge. 


\section{References}

Antonenko, P., Paas, F., Grabner, R., \& Van Gog, T. (2010). Using electroencephalography to measure cognitive load. Educational Psychology Review, 22, 425-438.

Arguel, A., \& Jamet, E. (2009). Using video and static pictures to improve learning of procedural contents. Computers in Human Behavior, 25, 354-359.

Ayres, P., \& Paas, F. (2007). Can the cognitive load approach make instructional animations more effective? Applied Cognitive Psychology, 21, 811-820.

Barrouillet, P., \& Camos, V. (2007). The time-based resource-sharing model of working memory. In N. Osaka, R. H. Logie, \& M. D'Esposito (Eds.), The cognitive neuroscience of working memory (pp. 59-80). Oxford, England: Oxford University Press.

Boltz, M. (1992). Temporal accent structure and the remembering of filmed narratives. Journal of Experimental Psychology: Human Perception and Performance, 18, 90-105.

Catrambone, R. (1995). Aiding subgoal learning: Effects on transfer. Journal of Educational Psychology, 87, 5-17.

Brünken, R., Plass, J. L., \& Leutner, D. (2003). Direct measurement of cognitive load in multimedia learning. Educational Psychologist, 38, 53-61

Carroll, J. M., \& Bever, T. G. (1976). Segmentation in cinema perception. Science, 191, 10531055.

Catrambone, R. (1995). Aiding subgoal learning: Effects on transfer. Journal of Educational Psychology, 87, 5-17.

Christoffersen, K., Woods, D. D., \& Blike, G. T. (2007). Discovering the events expert practitioners extract from dynamic data streams: The modified unit marking technique. Cognition, Technology, \& Work, 9, 81-89.

Florax, M., \& Ploetzner, R. (2010). What contributes to the split-attention effect? The role of text segmentation, picture labeling, and spatial proximity. Learning and Instruction, 20, 216224.

Hanson, C., \& Hirst, W. (1989). On the representation of events: A study of orientation, recall, and recognition. Journal of Experimental Psychology: General, 118, 136-147.

Hasler, B. S., Kersten, B., \& Sweller, J. (2007). Learner control, cognitive load and instructional animation. Applied Cognitive Psychology, 21, 713-729.

Kalyuga, S., Ayres, P., Chandler, P., \& Sweller, J. (2003). The expertise reversal effect. Educational Psychologist, 38, 23-31.

Koopman, C., \& Newtson, D. (1981). Level of analysis in the perception of ongoing instruction: An exploratory study. Journal of Educational Psychology, 73, 212-223.

Kurby, C. A., \& Zacks, J. M. (2008). Segmentation in the perception and memory of events. Trends in Cognitive Sciences, 12, 72-79.

Lowe, R., \& Boucheix, J.-M. (2008). Learning from animated diagrams: How are mental models build? In G. Stapleton, J. Howse, \& J. Lee (Eds.), Diagrammatic Representation and Inference (pp. 266-281). Berlin: Springer.

Mayer, R. E. (2005). Principles for managing essential processing in multimedia learning: Segmenting, pretraining, and modality principles. In R. E. Mayer (Ed.), The Cambridge handbook of multimedia learning (pp. 169-182). New York: Cambridge University Press.

Mayer, R. E. (2009). Multimedia learning (2nd ed.). New York: Cambridge University Press.

Mayer, R. E., \& Chandler, P. (2001). When learning is just a click away: Does simple user interaction foster deeper understanding of multimedia messages? Journal of Educational Psychology, 93, 390-397. 
Mayer, R. E., \& Moreno, R. (2003). Nine ways to reduce cognitive load in multimedia learning. Educational Psychologist, 38, 43 - 52.

Meyer, K., Rasch, T., \& Schnotz, W. (2010). Effects of animation's speed of presentation on perceptual processing and learning. Learning and Instruction, 20. 136-145.

Moreno, R. (2007). Optimising learning from animations by minimising cognitive load: Cognitive and affective consequences of signalling and segmentation methods. Applied Cognitive Psychology, 21, 765-781.

Schnotz, W., \& Lowe, R. (2008). A unified view of learning from animated and static graphics. In R. Lowe \& W. Schnotz (Eds.), Learning with animations: Research implications for design (pp. 304-356). New York: Cambridge University Press.

Schwan, S., Garsoffky, B., \& Hesse, F. W. (2000). Do film cuts facilitate the perceptual and cognitive organization of activity sequences? Memory \& Cognition, 28, 214-223.

Sweller, J. (2010). Element interactivity and intrinsic, extraneous and germane cognitive load. Educational Psychology Review, 22, 123-138.

Van den Bogert, N., Van Bruggen, J., \& Jochems, W. (2011). Differences in visual perception between novice teachers and experienced teachers when observing recorded classroom situations. Submitted for publication.

Van Gerven, P. W. M., Paas, F., Van Merriënboer, J. J. G., \& Schmidt, H. G. (2004). Memory load and the cognitive pupillary response in aging. Psychophysiology, 41, 167-174.

Van Gog, T., Kester, L., Nievelstein, F., Giesbers, B., \& Paas, F. (2009). Uncovering cognitive processes: Different techniques that can contribute to cognitive load research and instruction. Computers in Human Behavior, 25 , 325-331.

Van Gog, T., Paas, F., Van Merriënboer, J. J. G., \& Witte, P. (2005). Uncovering the problemsolving process: Cued retrospective reporting versus concurrent and retrospective reporting. Journal of Experimental Psychology: Applied, 11, 237-244.

Wong, A., Marcus, N., Ayres, P., Smith, L., Cooper, G. A., Paas, F., \& Sweller, J. (2009). Instructional animations can be superior to statics when learning human motor skills. Computers in Human Behavior, 25, 339-347.

Zacks, J. M., Speer, N. K., Swallow, K. M., Braver, T. S., \& Reynolds, J. R. (2007). Event perception: A mind-brain perspective. Psychological Bulletin, 133, 273-293.

Zacks, J. M., Speer, N. K., Vettel, J. M., \& Jacoby, L. L. (2006). Event understanding and memory in healthy aging and dementia of the alzheimer type. Psychology and Aging, 21, 466-482.

Zacks, J. M., \& Swallow, K. M. (2007). Event segmentation. Current Directions in Psychological Science, 16, 80-84.

Zalla, T., Pradat-Diehl, P., \& Sirigu, A. (2003). Perception of action boundaries in patients with frontal lobe damage. Neuropsychologia, 41, 1619-1627. 



\section{Summary}

This dissertation focuses on the design of instructional animations, more specifically, on segmenting as a means to improve the effectiveness of animations for novices' learning. Animations that visualize processes or procedures over time are attractive and appealing, and are included more and more often in instructional materials. However, research has shown that animations are not always more effective for learning than series of static pictures, which are less expensive to develop. This finding inspired research on ways to improve animations and optimize their effectiveness for learning. A number of design guidelines aimed at improving the effectiveness of animations have been proposed. One of those is segmentation, that is, presenting animations in pieces rather than as a continuous stream of information. In this dissertation, it is examined more closely why segmentation of instructional animations positively affects the learning process (in terms of mental effort invested during study, which is a measure of experienced cognitive load) and learning outcomes. This is examined in a literature study and four empirical studies.

In Chapter 2 a review is presented of studies that investigated the effects of segmentation of dynamic visualizations. Several studies found positive effects of segmentation of dynamic visualizations on learning outcomes, mental effort invested in study, or both. Additionally, two alternative but not mutually exclusive explanations for the segmentation effect are discussed in this Chapter. The time-to-process explanation (or pausing explanation) is based on the assumption of Cognitive Load Theory (e.g., Sweller, 2010) that limitations of working memory should be taken into account when designing effective instructional materials. According to the Time-Based Resource-Sharing Model of Barrouillet and Camos (2007) working memory resources are divided between different cognitive processing and maintaining activities by switching attention rapidly back and forth. When processing takes up a large amount of the available time, little time remains to give attention to maintaining information in working memory, and, as a consequence, information may be forgotten. Pauses which are inserted between segments give learners additional time to perform necessary cognitive processes on smaller units of information and in that way support students in learning from the animations. The other explanation is the temporal cueing explanation based on the Event Segmentation Theory (Zacks, Speer, Swallow, Braver \& Reynolds, 2007). According to this theory people mentally segment events they perceive in sub events. Segmentation may cue event boundaries, and in that way support people in this process of mentally segmenting the information and help them perceive the structure underlying a process or procedure.

The study presented in Chapter 3 aimed to examine whether an expertise reversal effect occurs with the effects of segmentation of animations. It is likely that segmentation, regardless of whether it is due mainly to pausing, cueing event boundaries, or a combination of both, is only effective for novice students, who have little if any prior knowledge of the topic of the animation. Prior knowledge might enable students to deal with animations' transience (i.e., information disappears continuously to make place for new information presented in the next moment) and to see the structure of the presented 
information, and hence, students with prior knowledge might no longer benefit from segmentation. Previous research has shown that instructional design guidelines which are effective for novices' learning process or outcomes are often not effective for more advanced students (i.e., the 'expertise reversal effect'; see Kalyuga, Ayres, Chandler, \& Sweller, 2003). In this experiment, secondary education students with different amounts of prior knowledge studied either eight segmented or eight non-segmented animations on probability calculation. The segmented animations were divided into meaningful pieces by the insertion of pauses of 2 seconds. The animations continued automatically after those 2 seconds. An interaction effect was found on invested mental effort, indicating that learners with lower levels of prior knowledge tended to benefit from segmentation (i.e., tended to invest less mental effort in learning from the segmented animations than from the nonsegmented animations) while there was no benefit for learners with more prior knowledge. No such interaction was found for learning outcomes on the near and far transfer test. It can be concluded that learning from segmented animations was more efficient (i.e., same level of learning outcomes reached with less investment of effort) than learning from nonsegmented animations for students with low prior knowledge, but not for students with more prior knowledge. In other words, this study seems to provide some evidence that an expertise reversal effect occurs with segmentation of animations.

In the next three chapters, the plausibility of the two explanations for the positive effects of segmentation for novice students, which were provided in Chapter 2, was examined. In the study presented in Chapter 4, third-year secondary education students with little prior knowledge learned from four text-based worked examples on probability calculation in one of three conditions: a) studying worked examples in a segmented format (i.e., in pieces separated by blank lines), b) being instructed to actively segment the examples during study by indicating what they consider the boundaries between segments, or c) studying the examples in a non-segmented format. It was found that presenting the worked examples in a segmented format tended to reduce mental effort invested in understanding the worked examples without decreasing learning gains. The instruction to actively segment, on the other hand, increased the mental effort required for understanding the worked examples without increasing learning gains compared to the other two conditions. Additionally, students who were instructed to segment actively had to put more mental effort in completing the posttest than learners who studied segmented worked examples (but they did not obtain larger learning gains). Because the worked examples consisted of written text, they were not transient and learners could pause during example study whenever they wanted. Therefore, it is unlikely that the time-to-process (or pausing) explanation explains the found trend that segmentation leads to a reduction in mental effort invested during learning, and this finding seems to provide support for the temporal cueing explanation, which states that the segmentation supported the students in grouping information elements together. In addition, this study shows that instructing students to interact with learning material, which is often assumed to lead to deeper processing, indeed leads them to invest more effort, but does not necessarily result in better learning outcomes. For these novices, actively segmenting may have been a secondary task, distracting them from the primary task of learning the content of the examples. 
Because the text-based worked examples used in Chapter 4 were not transient, it was not possible to examine the role that pauses play in the segmentation effect in animations. This was addressed in the study described in Chapter 5. Third-year secondary education students studied four condition-specific animations on probability calculation, either animations that were: a) non-segmented, b) segmented by pauses, c) segmented by temporarily darkening the screen slightly, and d) segmented by a combination of pauses and temporarily darkening the screen. In the two conditions in which the animations were segmented by pauses, the animations stopped at the end of each segment and continued automatically after two seconds. In the two conditions in which the animations were segmented by temporarily darkening the screen, a grey, transparent frame was placed on top of the animations, either for half a second (in the condition without pausing) or for the duration of the pauses (in the combined condition). The results revealed a main effect of insertion of pauses, with pausing leading to higher learning outcomes. This supports the time-to-process explanation. Additionally, however, there was a main effect of darkening the screen: students in these conditions invested less mental effort in studying the animations than students in the other two conditions, which supports the temporal cueing explanation. The interaction effects were not significant. It can be concluded that both pausing and temporal cueing seem to play a role in the positive effects of segmentation on learning outcomes and mental effort.

In Chapter 5, the pauses, even without the temporarily darkening of the screen, would also provide signals regarding the structure of the material. As such, the positive effects of pausing could not solely be attributed to the time-to-process explanation. Therefore, the study presented in Chapter 6 investigated the effects of pausing at meaningful vs. random places in the animations. Both the time-to-process explanation and the combination of the time-to-process and the temporal cueing explanation predict positive effects on learning outcomes and/or invested mental effort of meaningfully segmented animations. However, for random segments, the time-to-process explanation predicts positive results but the combination of the time-to-process and temporal cueing explanation does not, because segmenting in random pieces would be expected to hinder learning by providing wrong temporal cues. Third year secondary education students studied four animations on probability calculation, either a) non-segmented, b) segmented by pauses into meaningful pieces, or c) segmented by pauses into random pieces. Again, pauses lasted 2 seconds, and the animations continued automatically after the pauses. There were no significant differences between conditions in performance on the posttest. However, there were differences in mental effort invested in studying the animations and completing the posttest. Studying meaningfully segmented animations required less mental effort than studying non-segmented animations. Furthermore, studying randomly segmented animations also required less mental effort than studying non-segmented animations, and also reduced effort invested in completing the posttest. In other words, random segmenting seemed to enhance efficiency in terms of both the learning process (equal test performance reached with less effort during study) and learning outcomes (equal test performance reached with less effort invested in the test). These findings are in line with the predictions of the time-to-process explanation, but run contrary to the predictions of the combined time-to-process and temporal cueing explanation. Hence, it 
seems that we may conclude that the beneficial effects of segmentation of animations are mainly due to additional time to process.

In the General Discussion in Chapter 7, the results from the empirical studies are discussed, along with their limitations, theoretical and practical implications, and ideas for future research. Taken together, the studies reveal that pauses are important for the positive effects of segmentation in animations, but that temporal cues may also play a role in these positive effects of segmentation. Furthermore, it was found that segmentation is only effective for novice students.

\section{References}

Barrouillet, P., \& Camos, V. (2007). The time-based resource-sharing model of working memory. In N. Osaka, R. H. Logie, \& M. D’Esposito (Eds.), The cognitive neuroscience of working memory (pp. 59-80). Oxford, England: Oxford University Press.

Kalyuga, S., Ayres, P., Chandler, P., \& Sweller, J. (2003). The expertise reversal effect. Educational Psychologist, 38, 23-31.

Sweller, J. (2010). Element interactivity and intrinsic, extraneous, and germane cognitive load. Educational Psychology Review, 22, 123-138.

Zacks, J. M., Speer, N. K., Swallow, K. M., Braver, T. S., \& Reynolds, J. R. (2007). Event perception: A mind-brain perspective. Psychological Bulletin, 133, 273-293. 


\section{Samenvatting}

Dit proefschrift gaat over het ontwerpen van instructieve animaties, of meer specifiek over segmentatie als een manier om de effectiviteit van animaties voor het leren van novieten (i.e., lerenden die nog geen specifieke voorkennis hebben over een leertaak) te verbeteren. Animaties die het verloop van processen of procedures door de tijd heen laten zien zijn aantrekkelijk en worden daarom steeds vaker gebruikt in instructiemateriaal. Maar onderzoek heeft laten zien dat animaties niet altijd effectiever zijn voor het leren dan een reeks statische plaatjes, terwijl die veel minder duur zijn om te ontwikkelen. Deze bevinding heeft aanleiding gegeven onderzoek te doen naar manieren om animaties te verbeteren en hun effectiviteit voor het leren te optimaliseren. Dat onderzoek heeft reeds geleid tot een aantal ontwerprichtlijnen om de effectiviteit van animaties te verbeteren. Een daarvan is segmentatie, dat wil zeggen het presenteren van animaties in stukjes in plaats van als een continue stroom van informatie. Het doel van de studies in dit proefschrift was om meer specifiek te onderzoeken waarom segmentatie van instructieve animaties het leerproces (in termen van de hoeveelheid moeite die is geïnvesteerd in het bestuderen als maat voor de ervaren hoeveelheid cognitieve belasting) en leeruitkomsten positief beïnvloedt. Dit is onderzocht in een literatuurstudie en vier empirische studies.

In Hoofdstuk 2 wordt een overzicht gegeven van studies die het effect van segmentatie van dynamische visualisaties onderzocht hebben. Verschillende studies vonden een positief effect van segmentatie op leeruitkomsten, moeite geïnvesteerd in het bestuderen, of beide. Daarnaast worden twee verschillende, maar elkaar niet uitsluitende, verklaringen voor het effect van segmentatie besproken in dit Hoofdstuk. De verwerkingstijdverklaring (of pauzeverklaring) is gebaseerd op de aanname van de cognitieve belastingstheorie (e.g., Sweller, 2010) dat beperkingen van het werkgeheugen in acht genomen moeten worden bij het ontwerpen van effectief instructiemateriaal. Volgens het 'time-based resource-sharing model' van Barrouillet and Camos (2007) wordt de werkgeheugencapaciteit verdeeld tussen verschillende cognitieve verwerkings- en onthoudactiviteiten door de aandacht snel te wisselen tussen de activiteiten. Wanneer een groot deel van de beschikbare tijd nodig is voor het verwerken van informatie, blijft weinig tijd over om aandacht te geven aan het onthouden van informatie, met als gevolg dat informatie mogelijk wordt vergeten. Pauzes tussen de segmenten geven lerenden extra tijd om de nodige cognitieve verwerkingsactiviteiten uit te voeren op kleinere stukjes informatie en ondersteunen hen op die manier bij het leren van de animaties. De andere verklaring is de temporele-cueingverklaring gebaseerd op de 'event segmentation' theorie (Zacks, Speer, Swallow, Braver \& Reynolds, 2007). Volgens deze theorie delen mensen de gebeurtenissen die ze waarnemen mentaal op in subgebeurtenissen. Segmentatie geeft de grenzen tussen subgebeurtenissen aan, en op die manier zou het lerenden kunnen ondersteunen bij het in betekenisvolle stukjes opdelen van de informatie en helpen bij het zien van de onderliggende structuur van een proces of procedure.

De studie die in Hoofdstuk 3 wordt beschreven, onderzoekt het optreden van een interactie tussen voorkennis en de effecten van segmentatie van animaties. Het is 
waarschijnlijk dat segmentatie, ongeacht of het voornamelijk te wijten is aan pauzes, het cueing van grenzen tussen subgebeurtenissen of een combinatie van beide, alleen effectief is voor beginnende lerenden, die weinig tot geen voorkennis hebben over het onderwerp van de animatie. Voorkennis kan lerenden in staat stellen om met de vluchtigheid van informatie in animaties (d.w.z. informatie verdwijnt continu om plaats te maken voor nieuwe informatie) om te gaan en om de structuur in de gepresenteerde informatie te zien. Daarom profiteren lerenden met voorkennis mogelijk niet meer van segmentatie. Eerder onderzoek heeft laten zien dat ontwerprichtlijnen die effectief zijn voor het leerproces of de leeruitkomsten van beginnende lerenden vaak niet effectief zijn voor meer gevorderde lerenden (dit is het zogenaamde 'expertise reversal effect' zie Kalyuga, Ayres, Chandler, \& Sweller, 2003). In dit experiment bestudeerden middelbare scholieren met verschillende mate van voorkennis acht gesegmenteerde of acht niet-gesegmenteerde animaties over kansberekening. De gesegmenteerde animaties waren door pauzes van 2 seconden in betekenisvolle stukjes opgedeeld. De animaties gingen vanzelf na deze 2 seconden verder. Een interactie-effect werd gevonden voor geïnvesteerde moeite. Dit effect gaf een trend aan waarbij lerenden met weinig voorkennis profiteerden van de segmentatie (d.w.z. dat ze minder moeite hoefden te investeren in het leren van de gesegmenteerde animaties dan van niet-gesegmenteerde), terwijl lerenden met meer voorkennis niet van de segmentatie profiteerden. Voor scores op de nabije en verre transfer test werden dergelijke interactieeffecten niet gevonden. Het kan worden geconcludeerd dat het leren van gesegmenteerde animaties efficiënter was (d.w.z. gelijke leeruitkomsten werden bereikt met minder moeite) dan leren van niet-gesegmenteerde animaties voor lerenden met weinig voorkennis, maar niet voor lerenden met meer voorkennis. Met andere woorden, deze studie lijkt enige ondersteuning te vinden voor het optreden van een 'expertise reversal effect' voor segmentatie van animaties.

In de volgende drie hoofdstukken werd de waarschijnlijkheid onderzocht van de twee verklaringen voor de positieve effecten van segmentatie voor beginnende lerenden: de verwerkingstijdverklaring en de temporele-cueingverklaring. In de studie die wordt beschreven in Hoofdstuk 4 leerden derdejaars middelbare scholieren met weinig voorkennis over kansberekening, door middel van het bestuderen van vier uitgewerkte voorbeelden onder één van drie condities: a) het bestuderen van uitgewerkte voorbeelden in een gesegmenteerde lay-out (d.w.z. in stukjes verdeeld door witregels), b) het bestuderen van uitgewerkte voorbeelden met de instructie om ze zelf in stukjes op te delen, of c) het bestuderen van uitgewerkte voorbeelden in een niet-gesegmenteerde lay-out. Er werd een trend gevonden dat het leren van uitgewerkte voorbeelden in een gesegmenteerde lay-out minder moeite kostte dan leren van de voorbeelden in een niet-gesegmenteerde layout, terwijl de leerwinsten even goed waren. De instructie om de voorbeelden in stukjes op te delen leidde echter tot het investeren van meer moeite in het bestuderen van de uitgewerkte voorbeelden zonder dat dit tot meer leren leidde dan in de andere twee condities. Daarnaast investeerden de lerenden die de instructie hadden gekregen om de voorbeelden in stukjes op te delen meer moeite in het maken van de eindtest dan de lerenden die de voorbeelden in een gesegmenteerde lay-out aangeboden kregen (maar zonder grotere leerwinsten). Omdat de voorbeelden uit geschreven tekst bestonden, was de informatie niet vluchtig, en konden de lerenden dus pauzeren tijdens het bestuderen van de 
voorbeelden wanneer ze dat wilden. De verwerkingstijdverklaring (of pauzeverklaring) is daarom geen waarschijnlijke verklaring voor de gevonden trend dat segmentatie leidde tot vermindering van de hoeveelheid geïnvesteerde moeite tijdens het leren. Deze bevinding lijkt dus ondersteuning te leveren aan de temporele-cueingverklaring, die stelt dat segmentatie lerenden ondersteunt in het groeperen van informatie-elementen. Daarnaast liet deze studie zien dat instructie geven om te interacteren met het instructiemateriaal, wat vaak wordt gezien als een manier om dieper leren te stimuleren, inderdaad de hoeveelheid geïnvesteerde moeite verhoogde, maar niet leidde tot betere leeruitkomsten. Voor deze beginnende lerenden zou het zelf in stukjes opdelen kunnen worden gezien als een additionele taak die hen afleidt van de primaire taak, namelijk het leren van de voorbeelden.

Omdat de tekstuele informatie in de uitgewerkte voorbeelden die in de studie in Hoofdstuk 4 werden gebruikt niet vluchtig was, was het niet mogelijk om de rol die pauzes spelen in het effect van segmentatie bij animaties te onderzoeken. Dit werd onderzocht in de studie beschreven in Hoofdstuk 5. Derdejaars middelbare scholieren bestudeerden vier animaties over kansberekening in één van vier condities: a) niet gesegmenteerd, b) gesegmenteerd door pauzes, c) gesegmenteerd door tijdelijk donkerder worden van het scherm en d) gesegmenteerd door een combinatie van pauzes en tijdelijk donkerder worden van het scherm. In de twee condities waarin de animaties werden gesegmenteerd door pauzes stopten de animaties aan het eind van ieder segment om na 2 seconden vanzelf weer verder te gaan. In de twee condities waarin de animaties werden gesegmenteerd door het tijdelijk donkerder worden van het scherm, werd een grijze, transparante laag over de animaties geplaatst voor een halve seconde (in de conditie zonder pauzes) of gedurende de pauzes (in de gecombineerde conditie). De resultaten lieten een hoofdeffect van de factor 'pauzes' op leeruitkomsten zien: Segmentatie door pauzes leidde tot betere leeruitkomsten, wat ondersteuning levert aan de verwerkingstijdverklaring. Daarnaast werd echter een hoofdeffect van de factor 'tijdelijk donkerder worden van het scherm' gevonden op moeite: het bestuderen van de animaties kostte de lerenden in deze condities minder moeite dan de lerenden in de andere twee condities, wat ondersteuning levert aan de temporelecueingverklaring. De interactie-effecten waren niet significant. Er kan dus worden geconcludeerd dat zowel pauzes als temporele cues een rol lijken te spelen in de positieve effecten van segmentatie op leeruitkomsten en geïnvesteerde moeite.

In de studie beschreven in Hoofdstuk 5 zouden de pauzes, zelfs zonder het tijdelijk donkerder worden van het scherm, signalen met betrekking tot de structuur van de animaties kunnen hebben gegeven. De positieve effecten van de pauzes kunnen dus niet met zekerheid aan de verwerkingstijdverklaring worden toegeschreven. Daarom wordt in de studie die wordt beschreven in Hoofdstuk 6 onderzocht wat de effecten zijn van pauzeren op betekenisvolle momenten versus op random momenten in de animaties. Zowel op basis van de verwerkingstijdverklaring als op basis van de combinatie van de verwerkingstijdverklaring en de temporele-cueingverklaring kunnen positieve effecten op leeruitkomsten en/of geïnvesteerde moeite verwacht worden van segmentatie in betekenisvolle segmenten. Maar, terwijl op basis van de verwerkingstijdverklaring positieve effecten te verwachten zijn van segmentatie in random segmenten, zou volgens de combinatie van de verwerkingstijdverklaring en de temporele-cueingverklaring 
segmentatie in random segmenten het leren juist hinderen, aangezien een dergelijke segmentatie verkeerde temporele cues geeft. Derdejaars middelbare scholieren bestudeerden vier animaties over kansberekening in één van drie condities: a) niet gesegmenteerd, b) gesegmenteerd in betekenisvolle segmenten door pauzes of c) gesegmenteerd in random segmenten door pauzes. De pauzes duurden weer 2 seconden en de animaties gingen vanzelf verder na deze pauzes. Er werden geen significante verschillen gevonden in de prestaties op de posttest. Maar wel verschillen in de hoeveelheid moeite die geïnvesteerd werd in het bestuderen van de animaties en het maken van de posttest. Het bestuderen van animaties die in betekenisvolle segmenten waren opgedeeld kostte minder moeite dan het bestuderen van niet-gesegmenteerde animaties. Verder kostte het bestuderen van animaties die in random segmenten waren opgedeeld minder moeite dan het bestuderen van niet-gesegmenteerde animaties, en kostte het maken van de posttest minder moeite na het bestuderen van animaties die in random segmenten waren opgedeeld dan na het bestuderen van niet-gesegmenteerde animaties. In andere woorden, segmentatie in random segmenten leidde niet alleen tot een grotere efficientie van het leerproces (zelfde prestaties op de test met minder geïnvesteerde moeite tijdens het bestuderen), maar ook van leeruitkomsten (zelfde prestaties met minder geïnvesteerde moeite tijdens het maken van de test). Deze bevindingen zijn in lijn met de voorspellingen op basis van de verwerkingstijdverklaring, maar niet met die op basis van de combinatie van de verwerkingstijdverklaring en de temporele-cueingverklaring. Daarom lijkt de conclusie te zijn dat de positieve effecten van segmentatie van animaties voornamelijk te wijten zijn aan extra verwerkingstijd.

In de Algemene Discussie in Hoofdstuk 7 worden de voornaamste bevindingen van het proefschrift gepresenteerd, gevolgd door een kritische discussie van de beperkingen van de empirische studies, de theoretische en praktische implicaties van dit onderzoek en ideeën voor vervolgonderzoek. Gezamenlijk laten de studies zien dat pauzes belangrijk zijn voor de positieve effecten van segmentatie van animaties maar dat temporele cues mogelijk ook een rol spelen in deze positieve effecten van segmentatie. Verder werd gevonden dat segmentatie van animaties alleen voor novieten gunstig is.

\section{Referenties}

Barrouillet, P., \& Camos, V. (2007). The time-based resource-sharing model of working memory. In N. Osaka, R. H. Logie, \& M. D'Esposito (Eds.), The cognitive neuroscience of working memory (pp. 59-80). Oxford, England: Oxford University Press.

Kalyuga, S., Ayres, P., Chandler, P., \& Sweller, J. (2003). The expertise reversal effect. Educational Psychologist, 38, 23-31.

Sweller, J. (2010). Element interactivity and intrinsic, extraneous, and germane cognitive load. Educational Psychology Review, 22, 123-138.

Zacks, J. M., Speer, N. K., Swallow, K. M., Braver, T. S., \& Reynolds, J. R. (2007). Event perception: A mind-brain perspective. Psychological Bulletin, 133, 273-293. 


\section{Dankwoord}

Begin 2008 solliciteerde ik zowel bij het OnderwijsTechnologisch Expertise Centrum (nu Centre for Learning Sciences and Technologies) bij de Open Universiteit als bij Onderzoek van Onderwijs bij de faculteit van Health Medicine and Life science (FHML) bij de Universiteit Maastricht op heel interessante vacatures op het gebied van de onderwijspsychologie. Net voor het sollicatiegesprek bij de Universiteit Maastricht, was ik al aangenomen bij de Open Universiteit; nu is het dan ook bijzonder om uiteindelijk toch in Maastricht te promoveren. Ik zou graag een aantal mensen van beide groepen specifiek willen bedanken.

Als eerste wil ik mijn promotor Jeroen en mijn dagelijks begeleidster Tamara bedanken. Ik weet niet hoe ik mijn dank in woorden uit moet drukken. Het schrijven van een dankwoord is toch anders dan van een artikel. Zonder jullie hulp, adviezen en vertrouwen, en jullie snelle en heel gedetailleerd feedback op vragen en opgestuurde stukken had ik dit project niet kunnen doen, en al zeker niet in 4 jaar. Deze goede en snelle reacties op vragen en stukken die per e-mail gestuurd werden, maakte het mogelijk om een prettige samenwerking te hebben toen ik nog in Heerlen bij de Open Universiteit werkte en Jeroen al naar de Universiteit Maastricht was verhuisd, en later om bij de Universiteit Maastricht te werken toen Tamara naar de Erasmus Universiteit Rotterdam was verhuisd. Het was immers niet mogelijk om even van Heerlen naar Maastricht of van Maastricht naar Rotterdam te lopen om een korte vraag te stellen, of te informeren hoe het met het bekijken van een stuk stond. En eigenlijk werkt het ook gewoon prettiger, wanneer je weet dat er snel gekeken wordt naar wat je stuurt. Ik heb veel kunnen leren van jullie adviezen, ideeen en feedback. Tamara, ook bedankt voor je belangstelling voor zaken die niet direct met het project te maken hadden.

Pieter Wouters, bedankt dat ik je animaties en andere materialen mocht gebruiken en aanpassen voor mijn project. Ook bedankt voor je hulp bij het aanpassen van de animaties en je hulp bij het schrijven van enkele artikelen. Ook wil ik Huib Tabbers en Bjorn de Koning bedanken dat ik een animatie van hen mocht gebruiken.

Natuurlijk wil ik ook de leerlingen, studenten, docenten en andere medewerkers (systeembeheerders, schoolleiders, teamleiders) van de scholen die deelgenomen hebben aan de onderzoeken en pilots behorende bij mijn promotieproject (Fontys Hogescholen in Tilburg, Augustinianum in Eindhoven, Bisschoppelijk College in Weert, Christiaan Huygens College in Eindhoven, Eckartcollege in Eindhoven, Heerbeeck College in Best, Krimpenerwaard College in Krimpen aan den IJssel, Rythovius College in Eersel, SG Were Di in Valkenswaard, Sintermeertencollege in Heerlen, Sint-Maartenscollege in Maastricht en Sondervick College in Veldhoven), heel hartelijk bedanken voor hun deelname en hulp. Zonder jullie medewerking waren deze onderzoeken niet mogelijk geweest. Voor het regelen van ruimtes, technische zaken en uitleg over werken met de eye tracker en de bijbehorende software bij de pilotstudies waarvoor de leerlingen naar de Open Universiteit kwamen dank ik Mat Heijnen, Mieke Haemers, Danny Kostons en Halszka Jarodzka. 
Mijn mede-promovendi van de Open Universiteit en Universiteit Maastricht wil ik bedanken voor hun collegialiteit, gezelligheid en hulp, bijvoorbeeld in de vorm van feedback op artikelen. Ik ga jullie niet allemaal bij naam noemen, want stel je voor dat ik dan iemand vergeet. Enkele mede-promovendi wil ik wel bij naam noemen. Jimmie, bedankt dat je een proefschriftreview met mij wilde publiceren in Pedagogische Studiën en voor al je hulp en goede uitleg bij statistische vragen. Mijn kamergenootjes Bettine, Jonne, Juliëtte en Mariëtte wil ik bedanken voor hun gezelligheid, steun en luisterend oor. En binnenkort zijn ze weg: het rijtje verhuisdozen met het blauwe dekentje, mijn stapels met artikelen die ik opruimde door ze op in plaats van in een kast te leggen; en de plaatjes die ik maar ophing aan planken, kasten en randen, want ik vond het zo zonde om ze weg te gooien.

Mariëtte en Juliëtte, ik vind het leuk dat jullie mijn paranimfen willen zijn. Mariëtte, omdat wij op onze kamer beiden full time onderzoek deden en beiden experimenteel onderzoek op scholen deden, heb jij waarschijnlijk het meest mijn leuke en frustrerende ervaringen bij de onderzoeken aangehoord. Dankjewel voor alle gesprekjes tussen het werk en voor je optimisme. Juliëtte, dankjewel voor je belangstelling en je gezelligheid. Het was een leuke verrassing wanneer je, in een maand dat ik dacht je niet te zien vanwege je co-schappen, nog net voor ik naar Eindhoven vertrok vlug binnenkwam vallen om te kijken hoe het ging, of wanneer je in je pauze vlug even langs gelopen kwam om 5 minuten te werken, te eten en te vragen hoe het ging. Als je er full time was, was dat natuurlijk ook leuk en gezellig. Maar soms valt het onverwachte meer op.

Ook alle andere collega's bij de Open Universiteit en de Universiteit Maastricht wil ik bedanken voor hun collegaliteit, belangstelling en hulp. Een speciaal woord van dank voor Jean voor het programmeren van een stukje code dat onmisbaar was voor de verzameling en opslag van de data in één van mijn experimenten. Floris, bedankt voor de Flash action script code om een timer bij een stukje tekst te zetten.

Für die schöne Zeit und die schönen Möglichkeiten während meines Auslandaufenthaltes, danke ich der Arbeitsgruppe von Herrn Leutner (Prof. Dr. Leutner, Dr. Maria Opfermann, Dr. Annett Schmeck, Florian, Theresa, Jens, Christian, Sabrina, Emine, Luisa und Katleen (hoffentlich auch bald Dr. Ich wünsche dir viel Erfolg mit den letzten Sachen in deinem Project)).

Furthermore, I want to thank Aimen Khacharem for giving me the opportunity to work together on two articles.

Ten slotte wil ik mijn ouders bedanken voor hun steun en belangstelling. Ook wil ik mijn man Michael, bedanken voor zijn steun en liefde. Het was altijd fijn om weer thuis te komen (en al helemaal om niet te hoeven koken, maar te weten dat het eten al op tafel staat wanneer ik mijn fiets de tuin in rij). Ook bedankt voor je hulp bij mijn eerste stapjes en latere problemen in het herprogrammeren van mijn animaties. Multimedia is niet jouw afstudeerrichting; Toch kon ik niet zonder jouw hulp hierin. Ik hou van je!

Ingrid Spanjers,

Essen, maart 2012 


\section{Curriculum vitae}

Ingrid Spanjers was born on November 19th, 1982 in Eindhoven, the Netherlands. She did pre-university at the Pleincollege Eckart in Eindhoven. After graduating from high school in 2001, she completed the first three years of the study Pedagogical and Educational Sciences at the Radboud University in Nijmegen, the Netherlands. Subsequently, she did a Research Master in Behavioural Sciences with a special focus on Educational Sciences at the Radboud University. In 2007 she graduated Cum Laude for this master. After completing her master, she worked for two research projects at the Radboud University. In May 2008, she started her PhD project at the OnderwijsTechnologisch Expertise Centrum (yet Centre for Learning Sciences and Technologies) at the Open Universiteit Nederland. She worked at the Open University also as a teacher in one of the course of the distance master program Educational Sciences. Since November 2009 she continued her PhD project at Department of Educational Development and Research at Maastricht University. At Maastricht University, she was also teacher in one of the course of the distance master program Medical Health Professions Education. In 2011, she married Michael Galeazzi, after a relation of eleven years.

Ingrid Spanjers werd geboren op 19 November 1982 in Eindhoven. Ze volgde het VWO op het Pleincollege Eckart in Eindhoven. $\mathrm{Na}$ de middelbare school afgerond te hebben in 2001, heeft ze de eerste drie jaar van de studie Pedagogische Wetenschappen en Onderwijskunde gevolgd aan de Radboud Universiteit in Nijmegen. Daarna heeft ze een Engelstalige Onderzoeksmaster Behavioural Sciences (Gedragswetenschappen) met als afstudeerrichting Educational Sciences (Pedagogische en Onderwijswetenschappen) gevolgd aan de Radboud Universiteit. In 2007 heeft ze deze master cum laude afgerond. $\mathrm{Na}$ het afronden van haar master heeft ze voor twee onderzoeksprojecten aan de Radboud Universiteit gewerkt. In mei 2008 is ze met haar promotieproject begonnen bij het OnderwijsTechnologisch Expertise Centrum (nu Centre for Learning Sciences and Technologies) aan de Open Universiteit Nederland. Ze heeft bij de Open Universiteit ook als docent gewerkt in één van de cursussen van de afstandsmaster Onderwijswetenschappen. Vanaf november 2009 is ze verder gegaan met haar project bij Onderwijsontwikkeling en -onderzoek aan de Universiteit Maastricht. Aan de Universiteit Maastricht was ze ook docent in één van de cursussen van de afstandsmaster Medical Health Professions Education. In 2011 is ze getrouwd met Michael Galeazzi, na een relatie van 11 jaar. 



\section{SHE Dissertation Series}

In the SHE Dissertation Series dissertations are published of $\mathrm{PhD}$ candidates from the School of Health Professions Education (SHE) who defended their PhD thesis at Maastricht University. The most recent ones are listed below. For more information go to: www.maastrichtuniversity.nl/she.

Persoon, M.C. (19-01-2012) Learning in Urology; The influence of simulators and human factors

Pawlikowska, T.R.B. (21-12-2011) Patient Enablement; A Living Dialogue

Sok Ying Liaw, (14-12-2011) Rescuing A Patient In Deteriorating Situations (RAPIDS): A programmatic approach in developing and evaluating a simulation-based educational program

Singaram, V.S. (7-12-2011) Exploring the Impact of Diversity Factors on Problem-Based Collaborative Learning

Balslev, T. (24-11-2011) Learning to diagnose using patient video cases in paediatrics: Perceptive and cognitive processes

Widyandana, D. (19-10-2011) Integrating Pre-clinical skills training in skills laboratory and primary health care centers to prepare medical students for their clerkships

Durning, S.J. (09-09-2011) Exploring the Influence of Contextual Factors of the Clinical Encounter on Clinical Reasoning Success (Unraveling context specificity)

Govaerts, M.J.B. (08-09-2011) Climbing the Pyramid;Towards Understanding Performance Assessment

Stalmeijer, R. E. (07-07-2011) Evaluating Clinical Teaching through Cognitive Apprenticeship.

Malling, B.V.G. (01-07-2011) Managing word-based postgraduate medical education in clinical departments

Veldhuijzen, J.W. (17-06-2011) Challenging the patient-centred paradigm: designing feasible guidelines for doctor patient communication.

Van Blankenstein, F. (18-05-2011) Elaboration during problem-based, small group discussion: A new approach to study collaborative learning.

Van Mook, W. (13-05-2011) Teaching and assessment of professional behavior: Rhetoric and reality.

De Leng, B. (8-12-2009). Wired for learning. How computers can support interaction in small group learning in higher education. 
Maiorova, T. (29-05-2009). The role of gender in medical specialty choice and general practice preferences.

Bokken, L. (04-03-2009). Innovative use of simulated patients for educational purposes.

Wagenaar, A. (18-09-2008). Learning in internships. What and how students learn from experience.

Driessen, E. (25-06-2008). Educating the self-critical doctor. Using portfolio to stimulate and assess medical students' reflection.

Derkx, H. (18-06-2008). For your ears only. Quality of telephone triage at out-of-hours centres in the Netherlands.

Niessen, Th. (30-11-2007). Emerging epistemologies: making sense of teaching practice.

Budé, L. (05-10-2007). On the improvement of students' conceptual understanding in statistics education.

Niemantsverdriet, S. (26-07-2007). Learning from international internships: A reconstruction in the medical domain.

Marambe, K. (20-06-2007). Patterns of student learning in medical education - A Sri Lankan study in traditional curriculum.

Pleijers, A. (19-01-2007). Tutorial group discussion in problem-based learning.

Sargeant, J. (21-09-2006). Multi-source feedback for physician learning and change.

Dornan, T. (12-06-2006). Experience-based learning.

Wass, V. (12-05-2006). The assessment of clinical competence in high stakes examinations.

Prince, K. (21-04-2006). Problem-based learning as a preparation for professional practice. 


\section{ICO Dissertation Series}

\section{ico}

In the ICO Dissertation Series dissertations are published of graduate students from faculties and institutes on educational research within the following universities: Eindhoven University of Technology, Leiden University, Maastricht University, Open University of the Netherlands, University of Amsterdam, University of Groningen, University of Twente, Utrecht University, VU University Amsterdam, and Wageningen University (and formerly Radboud University Nijmegen and Tilburg University).

184. Honingh, M.E. (17-04-2008). Beroepsonderwijs tussen publiek en privaat: Een studie naar opvattingen en gedrag van docenten en middenmanagers in bekostigde en niet-bekostigde onderwijsinstellingen in het middelbaar beroepsonderwijs. Amsterdam: University of Amsterdam.

185. Baartman, L.K.J. (24-04-2008). Assessing the assessment: Development and use of quality criteria for competence assessment programmes. Utrecht: Utrecht University.

186. Corbalan Perez, G. (25-04-2008). Shared control over task selection: Helping students to select their own learning tasks. Heerlen: Open University of theNetherlands.

187. Hendrikse, H.P. (22-05-2008). Wiskundig actief: Het ondersteunen van onderzoekend leren in het wiskunde onderwijs. Enschede: University of Twente.

188. Moonen, M.L.I. (26-09-2008). Testing the multi-feature hypothesis: Tasks, mental actions and second language acquisition. Utrecht: Utrecht University.

189. Hooreman, R.W. (18-11-2008). Synchronous coaching of the trainee teacher: An experimental approach. Eindhoven: Eindhoven University of Technology.

190. Bakker, M.E.J. (02-12-2008). Design and evaluation of video portfolios:

Reliability, generalizability, and validity of an authentic performance assessment for teachers. Leiden: Leiden University.

191. Kicken, W. (12-12-2008). Portfolio use in vocational education: Helping students to direct their learning. Heerlen: Open University of the Netherlands.

192. Kollöffel, B.J. (18-12-2008). Getting the picture: The role of external representations in simulation-based inquiry learning. Enschede: University of Twente.

193. Walraven, A. (19-12-2008). Becoming a critical websearcher: Effects of instruction to foster transfer. Heerlen: Open University of the Netherlands.

194. Radstake, H. (14-05-2009). Teaching in diversity: Teachers and pupils about tense situations in ethnically heterogeneous classes. Amsterdam: University of Amsterdam.

195. Du Chatenier, E. (09-09-2009). Open innovation competence: Towards a competence profile for inter-organizational collaboration in innovation teams.

Wageningen: Wageningen University.

196. Van Borkulo, S.P. (26-06-2009). The assessment of learning outcomes of computer modelling in secondary science education. Enschede: University of Twente.

197. Handelzalts, A. (17-09-2009). Collaborative curriculum development in teacher design teams. Enschede: University of Twente.

198. Nievelstein, F.E.R.M. (18-09-2009). Learning law: Expertise differences and the effect of instructional support. Heerlen: Open University of the Netherlands.

199. Visser-Wijnveen, G.J. (23-09-2009). The research-teaching nexus in the humanities: Variations among academics. Leiden: Leiden University.

200. Van der Rijst, R.M. (23-09-2009). The research-teaching nexus in the sciences: Scientific research dispositions and teaching practice. Leiden: Leiden University. 
201. Mainhard, M.T. (25-09-2009). Time consistency in teacher-class relationships. Utrecht: Utrecht University.

202. Van Ewijk, R. (20-10-2009). Empirical essays on education and health. Amsterdam: University of Amsterdam.

203. Seezink, A. (18-11-2009). Continuing teacher development for competence-based teaching. Tilburg: Tilburg University.

204. Rohaan, E.J. (09-12-2009). Testing teacher knowledge for technology teaching in primary schools. Eindhoven: Eindhoven University of Technology.

205. Kirschner, F.C. (11-12-2009). United brains for complex learning. Heerlen: Open University of the Netherlands.

206. Wetzels, S.A.J. (18-12-2009). Individualized strategies for prior knowledge activation. Heerlen: Open University of the Netherlands.

207. Zitter, I.I. (04-02-2010). Designing for learning: Studying learning environments in higher professional education from a design perspective. Utrecht: Utrecht University.

208. Koopman, M. (11-02-2010). Students' goal orientations, information processing strategies and knowledge development in competence-based pre-vocational secondary education. Eindhoven: Eindhoven University of Technology.

209. Platteel, T. (11-02-2010). Knowledge development of secondary school L1 teachers on concept-context rich education in an action-research setting. Leiden: Leiden University.

210. Mittendorff, K. M. (12-03-2010). Career conversations in senior secondary vocational education. Eindhoven: Eindhoven University of Technology.

211. Moolenaar, N.M.(01-06-2010). Ties with potential: Nature, antecedents, and consequences of social networks in school teams. Amsterdam: University of Amsterdam.

212. Duijnhouwer, H. (04-06-2010). Feedback effects on students' writing motivation, process, and performance. Utrecht: Utrecht University.

213. Kessels, C.C. (30-06-2010). The influence of induction programs on beginning teachers' well-being and professional development. Leiden: Leiden University.

214. Endedijk, M.D. (02-07-2010). Student teachers' self-regulated learning. Utrecht: Utrecht University.

215. De Bakker, G.M. (08-09-2010). Allocated online reciprocal peer support as a candidate for decreasing the tutoring load of teachers. Eindhoven: Eindhoven University of Technology.

216. Groenier, M. (10-09-2010). The decisive moment: Making diagnostic decisions and designing treatments. Enschede: University of Twente.

217. Bonestroo, W.J. (24-09-2010). Planning with graphical overview: Effects of support tools on self-regulated learning. Enschede: University of Twente.

218. Vos, M.A.J. (30-09-2010). Interaction between teachers and teaching materials: On the implementation of context-based chemistry education. Eindhoven: Eindhoven University of Technology.

219. Kostons, D.D.N.M. (05-11-2010). On the role of self-assessment and task-selection skills in self-regulated learning. Heerlen: Open University of the Netherlands.

220. Bruin-Muurling, G. (21-12-2010). The development of proficiency in the fraction domain: Affordances and constraints in the curriculum. Eindhoven: Eindhoven University of Technology. 